Metals and Ceramics Division

CRADA Final Report

For CRADA Number ORNL02-0630

\title{
Development of a New Class of Fe-3Cr-W(V) Ferritic Steels for Industrial Process Applications ${ }^{*}$
}

\author{
V. K. Sikka \\ Oak Ridge National Laboratory \\ M. H. Jawad \\ Nooter Corporation \\ Date Published - June 2005 \\ Prepared by the \\ OAK RIDGE NATIONAL LABORATORY \\ Oak Ridge, Tennessee 37831 \\ Managed by \\ UT-BATTELLE, LLC \\ For the \\ U.S. Department of Energy \\ Under Contract DE-AC05-00OR22725 \\ APPROVED FOR PUBLIC RELEASE \\ UNLIMITED DISTRIBUTION
}

\footnotetext{
* This work was supported through a CRADA with Nooter Corporation, sponsored by the U.S. Department of Energy, Office of Energy Efficiency and Renewable Energy, Industrial Technologies Program, under contract DE-AC05-00OR22725 with UT-Battelle, LLC.
} 


\section{Abstract}

The project, "Development of a New Class of Fe-3Cr-W(V) Ferritic Steels for Industrial Process Applications," was a Cooperative Research and Development Agreement (CRADA) between Oak Ridge National Laboratory (ORNL) and Nooter Corporation. This project dealt with improving the materials performance and fabrication for the hydrotreating reactor vessels, heat recovery systems, and other components for the petroleum and chemical industries. The petroleum and chemical industries use reactor vessels that can approach the ship weights of approximately 300 tons with vessel wall thicknesses of 3 to 8 in. These vessels are typically fabricated from $\mathrm{Fe}-\mathrm{Cr}$-Mo steels with chromium ranging from 1.25 to $12 \%$ and molybdenum from 1 to $2 \%$. Steels in this composition have great advantages of high thermal conductivity, low thermal expansion, low cost, and properties obtainable by heat treatment. With all of the advantages of $\mathrm{Fe}-\mathrm{Cr}$-Mo steels, several issues are faced in design and fabrication of vessels and related components. These issues include the following:

1. Low strength properties of current alloys require thicker sections.

2. Increased thickness causes heat-treatment issues related to nonuniformity across the thickness and thus not achieving the optimum properties.

3. Fracture toughness (ductile-to-brittle transition) is a critical safety issue for these vessels, and it is affected in thick sections due to nonuniformity of microstructure.

4. PWHT needed after welding and makes fabrication more time-consuming with increased cost.

5. PWHT needed after welding also limits any modifications of the large vessels in service.

The goal of this project was to reduce the weight of large-pressure vessel components (ranging from 100 to 300 tons) by approximately $25 \%$ and reduce fabrication cost and improve in-service modification feasibility through development of $\mathrm{Fe}-3 \mathrm{Cr}-\mathrm{W}(\mathrm{V})$ steels with combination of nearly a 50\% higher strength, a lower DBTT and a higher upper-shelf energy, ease of heat treating, and a strong potential for not requiring PWHT.

\section{Statement of Objectives}

The objective of this project was to develop a new class of $\mathrm{Fe}_{3} \mathrm{Cr}-\mathrm{W}(\mathrm{V})$ ferritic steels for chemical process applications based on a patented ORNL steel, industrial heat recovery boilers, and hoods for basic open-hearth (BOH) and electric-arc furnace (EAF) for steel making. The project goal was to reduce the weight of large pressure vessel and associated components by approximately $25 \%$ and eliminate the need for postweld heat treatment (PWHT) with estimated energy savings of 21 trillion BTU/year and cost savings of approximately $\$ 237$ million for chemical vessel and related components used in the United States.

\section{Benefits to the Funding DOE Office's Mission}

Significant progress towards commercialization of the new steels developed in this project was made through the following steps:

1. Approval of specifications in ASTM was obtained for both Grades A and B. 
2. Got closer to obtaining ASME Pressure Vessel and Boiler Code approved design allowable stresses for Grade A by submitting its comprehensive mechanical properties data package to the code committees.

3. Retaining Dr. Maan Jawad as a consultant to the project for participating at the ASME Code Committee Review meetings to answer any questions that might arise during deliberations.

Further commercialization will occur through visits by Dr. Maan Jawad to various companies and making their system design engineers familiar with the advantages of using the new steels

\section{Technical Discussion of Work Performed by All Parties}

The project, "Development of a New Class of Fe-3Cr-W(V) Ferritic Steels for Industrial Process Applications," was a Cooperative Research and Development Agreement (CRADA) between Oak Ridge National Laboratory (ORNL) and Nooter Corporation. The ORNL participant was Dr. Vinod K. Sikka. Others involved in this project were chemical and petrochemical industries (ExxonMobil Chemical Company, BP Amoco, and DuPont), materials producers (ISG Plate, Ellwood Materials Technologies Company, Plymouth Tube Company, and Ellwood National Forge), component fabricator and welding process developer (Nooter Fabrication Services Inc.), weld wire producer and process developer (Stoody Company), and a heat recovery unit construction company (Nooter-Eriksen). Industry participated by: (1) identifying reactor vessels and other components that can take advantage of the new steel, (2) component testing, (3) assisting in producing production-size heats of the new steel, (4) assisting in component fabrication and process development, and (5) welding process development. Welding wire suppliers produced small batches for trials by Nooter Fabrication Services Inc. and ORNL. Industry representatives also provided guidance and direction to the project through active participation in identifying and monitoring project deliverables and technical progress reports.

This project dealt with improving the materials performance and fabrication for the hydrotreating reactor vessels, heat recovery systems, and other components for the petroleum and chemical industries. The petroleum and chemical industries use reactor vessels that can approach the ship weights of approximately 300 tons with vessel wall thicknesses of 3 to 8 in. These vessels are typically fabricated from $\mathrm{Fe}-\mathrm{Cr}$-Mo steels with chromium ranging from 1.25 to $12 \%$ and molybdenum from 1 to $2 \%$. Steels in this composition have great advantages of high thermal conductivity, low thermal expansion, low cost, and properties obtainable by heat treatment. With all of the advantages of Fe-Cr-Mo steels, several issues were faced in design and fabrication of vessels and related components. These issues included the following:

1. Low-strength properties of current alloys require thicker sections.

2. Increased thickness causes heat-treatment issues related to nonuniformity across the thickness and thus not achieving the optimum properties.

3. Fracture toughness (ductile-to-brittle transition) is a critical safety issue for these vessels, and it is affected in thick sections due to nonuniformity of microstructure.

4. PWHT needed after welding and makes fabrication more time-consuming with increased cost.

5. PWHT needed after welding also limits any modifications of the large vessels in service. 
Quite a number of chemical processing equipment is currently fabricated from $\mathrm{Fe}-2.25 \mathrm{Cr}-1 \mathrm{Mo}$ steel, commonly known as Grade 22. Some of the equipment fabricated from this steel has to use section thickness up to $10 \mathrm{in}$. and can weigh as much as 100 to 300 tons. Most of this equipment is built to ASME Code rules and, thus, if PWHT is required, once erected, no equipment modifications are possible. The $50 \%$ higher tensile strength of the newly developed steel will reduce the section sizes to nearly half and thereby reducing the equipment weight size from 100 to 300 tons down to 50 to 150 tons. Furthermore, since some welds are made by the gas tungsten arc (GTA) process, they require no PWHT and once the equipment is erected, it can be modified by using the GTA welding process.

\subsection{Potential Applications and Impacts Target Industries and Magnitude of Potential Energy Savings}

The newly developed steel was targeted for chemical process reactors such as hydrocrackers, hydrotreaters, and industrial heat recovery systems. For the chemical process reactors, alloy is needed as forgings and plate and for heat recovery systems; it is needed as tubing.

The target industries for this project include: chemical and petrochemical companies, energy companies, steel producers and product manufacturer, component fabricators, and welding consumable producers. One or more industry representatives were part of this project for each industry.

The development of the advanced steel that meets the project goal will result in energy savings from a combination of several factors including: (1) elimination of energy needed to produce 25 to $50 \%$ less steel for fabricating components, (2) significant reduction in energy needed to weld 25 to $50 \%$ thinner steel sections, and (3) reduction in energy by eliminating PWHT for certain weld practices such as GTA.

The energy savings are also anticipated through the following:

1. Improvement in chemical process efficiencies by operating at higher temperature through the use of the new alloy; the chemical process such as hydrotreater could increase by $1.5 \%$

2. For the heat recovery units, the thinner tubes will result in higher heat transfer and, thus, higher heat recovery; this improvement is estimated at $1 \%$.

It is estimated that by 2020 , full-scale implementation of the advanced alloy developed in this project will result in an energy savings of 21 trillion Btu/year.

\subsection{Commercialization Status and Plans}

A plan that identified steps needed for commercialization of the new steels was developed. Identified steps included: (1) getting specifications of the new steels approved in ASTM, (2) getting ASME Pressure Vessel and Boiler Code approved allowable design stresses for the new steels, (3) getting designer of systems to become familiar with the properties of the new 
steels so that they can be specified as material of choice, and (4) providing test material and welding filler for fabricators to become familiar in the use of new steels.

The progress made towards the commercialization included:

1. Both Grades A and B were approved for inclusion in American Standards for Testing Materials (ASTM) specifications: This has already been accomplished. The new alloys are listed in Specification A1041-04.

2. Design allowable stresses for the alloy have to be set by American Society of Mechanical Engineers (ASME) Boiler and Pressure Vessel Code committees. Setting of the design allowables by ASME requires the submission of detailed mechanical property data package for review and analysis by the Code committees. The data package for the advanced alloy developed in this study was submitted in August 2004. It typically takes 12 to 24 months for Code bodies to review all of the information and perform analysis to set the design allowable stresses. In order to expediate the ASME Code approval process, we have subcontracted Dr. Maan Jawad of Global Engineering (previously with Nooter Corporation) to actively pursue the process by participating in ASME Code Committee meetings on a regular basis and respond to any questions that may be asked.

3. New Alloys needs to be specified by equipment designers. In addition to approvals by ASTM and ASME Code, a parallel activity is needed to educate the equipment designers about the benefits of the new alloy. This activity was partially accomplished by:

(a) presenting papers at technical conferences, and (b) sharing information on this alloy by the industrial partners of this project within their companies (for the users) and with their customer (for the alloy producers). Although both of these activities are making the users aware of the new alloy, we are relying on our consultant, Dr. Maan Jawad, to further this cause by making visits to individual companies and making presentations about this alloy. Because of his design background gained at Nooter Corporation and familiarity with both chemical and heat recovery systems, it is anticipated that his involvement will further reduce the time for commercial use of the new alloy.

4. Commercial suppliers of alloy, welding consumables, and component fabrication experience: In addition to approvals by ASTM and ASME and designer specifying the new alloy as material of choice, it has to be commercially available at a competitive price in various product forms (forgings, plate, tubing, and piping). Furthermore, the welding consumables such as filler wire, flux, and electrodes need to be available commercially. The team members of this project are capable of meeting both of these requirements as they arise.

The component fabricators have been contacting ORNL to receive the plate samples from the newly developed alloy so that they can develop their own procedures for bending, forming, and welding. The plate samples are currently being offered at no cost to U.S.-based companies for their use. Based on these trials, these companies will be ready to build equipment when the need arises. 
In summary, all elements essential for commercialization of the new alloy are in place and further technology transfer is necessary.

\subsection{Domestic Technology Status Including Emerging Technologies}

Ferritic steels of 1-3Cr-Mo have a variety of uses at temperatures of 450 to $550^{\circ} \mathrm{C}$ and below, due to their combination of better oxidation/corrosion resistance and elevated temperature strength relative to carbon steels with less chromium. These applications include (but are not limited to) piping, heat exchangers, superheater tubing and pressure vessels in oil refineries, chemical processing plants, and fossil-fired electrical power generating plants. The most common steel in this class is the 2.25Cr-1Mo steel, designated Grade 22 (ASME code), which was first used in the U.S. in the 1940s. The improved heat resistance combined with the low thermal expansion and excellent thermal conductivity inherent to such ferritic steels and alloys drive its use in many applications. It has good weldability, can be fabricated by various wrought methods, and can be used in the bainitic or tempered-martensitic conditions. It has good impact toughness and a DBTT below room temperature. There are a number of domestic producers.

The Cr-Mo-V steels were developed in the late 1940s and early 1950s for improved creep strength above $480^{\circ} \mathrm{C}$ in steam turbine bolting and rotor applications. They are also used for steam turbine casing applications. $1 \mathrm{Cr}-1 \mathrm{Mo}-0.25 \mathrm{~V}$ is a typical composition, with many different minor variants. Bainitic structures (upper bainite) produce the best combination of creepresistance, ductility and toughness. Several research efforts in the mid-1980s (including work at ORNL) produced vanadium-modified bainitic steels related to Grade 22 but with improved creep strength, including $2.25 \mathrm{Cr}-1 \mathrm{Mo}-\mathrm{VTiB}$ and $3 \mathrm{Cr}-1 \mathrm{MoV}$, for coal-gasification and other advanced coal conversion technologies. However, these steels are not produced in the U.S., and the development efforts were essentially Japanese (see next section).

In the U.S., new 2.25Cr-2WV and 3Cr-3WV bainitic steels were developed in 1985 to 1990 as part of an effort of the U.S. Fusion Reactor Materials Program to develop new steels with faster radioactivity decay for fusion reactor applications that began in the mid-1980s. These new steels, which are the subject of this proposal, were radically different than standard Grade 22, both in terms of their as-processed microstructures and mechanical properties. These new steels are much stronger than Grade 22 at 550 to $600^{\circ} \mathrm{C}$, and have good toughness properties (see section 1.1B) after normal tempering. They were also found to have good toughness in the untempered condition (DBTT of $-35^{\circ} \mathrm{C}$ and upper-shelf impact energy of $100 \mathrm{ft}-\mathrm{lb}$ ), that is not found in the Grade 22. Normal tempered Grade 22 contains coarse and finer dispersions of chromium-rich $\mathrm{M}_{23} \mathrm{C}_{6}$, whereas the $3 \mathrm{Cr}-3 \mathrm{WV}$ contain some coarse iron-rich $\mathrm{M}_{3} \mathrm{C}$, chromium-rich $\mathrm{M}_{23} \mathrm{C}_{6}$, and uniform dispersions of very fine vanadium- and tungsten-rich $\mathrm{MC}$ (which has not been observed previously). Martensitic 9-12Cr steels cannot be used at all without optimum tempering, and their use necessitates pre- and PWHTs for welding such steels in most engineering applications. The behavior of the $3 \mathrm{Cr}-3 \mathrm{WV}$ steels in the untempered condition strongly suggests that these new steels may be useful after welding without the pre- and PWHTs. These new steels also have not yet been fully optimized with regard to the minor or micro additions of titanium, tantalum, boron, and nitrogen being used in such advanced bainitic steels by the Japanese today. 
While there have been significant world-wide efforts to continuously improve the 9-12Cr-Mo martensitic steels with the additions of tungsten, cobalt, vanadium, niobium, carbon, boron and nitrogen following the significant improvements achieved in modified $9 \mathrm{Cr}-1 \mathrm{Mo}$ in the late $1970 \mathrm{~s}$ and early 1980s, there have only been Japanese efforts since the mid-1990s to similarly improve Grade 22. The most advanced of these is the new $2.25 \mathrm{Cr}-1.6 \mathrm{~W}-\mathrm{V}-\mathrm{Nb}$ (T23) steel developed jointly by Mitsubishi Heavy Industries, Ltd. and Sumitomo Metal Industries, Ltd. And 2.5Cr-1Mo-V-Ti (T24) steel developed by Japan Steel Works in Japan in 1994. These new steels have almost twice the creep strength of Grade 22 at $600^{\circ} \mathrm{C}$, and have good weldability (it is claimed they can be welded without pre- or PWHTs). The steels were approved in Section 1 of the ASME Boiler and Pressure Vessel Code Committee for construction use as T23 and T24 in 1995. Testing of T23 and T24 continues large-diameter and thicker wall piping and pressure vessel applications, with examination of components after service, and the effects of different component fabrication methods. More advanced properties testing include aging and creepfatigue interactions.

\subsection{Results and Discussion}

The research objective of this project was to develop a new class of $\mathrm{Fe} 3 \mathrm{Cr}-\mathrm{W}(\mathrm{V})$ ferritic steels for chemical process applications based on a patented ORNL steel. The project goal was to reduce the weight of large pressure-vessel and associated components by approximately $25 \%$ and eliminate the need for PWHTs with estimated energy savings of 21 trillion BTU/year and cost savings of approximately $\$ 237$ million for chemical vessel and related components used in the United States.

\subsubsection{Project Approach}

The objectives of the proposal were achieved through the successful application of the following concepts:

1. Understanding the Role of Replacing Molybdenum by Tungsten in Currently Used Fe2.25Cr-1Mo Alloys

It is recognized from work reported in literature and the background preliminary work on ORNL alloy compositions that $\mathrm{Fe}-\mathrm{Cr}-\mathrm{W}$ alloys with partial or complete replacement of molybdenum with tungsten have superior strength properties at room temperature and retain those properties at high temperature. A systematic prediction of phase formation during heat treatment of $\mathrm{Fe}-\mathrm{Cr}-\mathrm{W}$ alloys was carried out and compared with the similar predictions on $\mathrm{Fe}-\mathrm{Cr}-\mathrm{Mo}$ and $\mathrm{Fe}-\mathrm{Cr}-\mathrm{Mo}(\mathrm{W})$ alloys. Phase prediction and their stability were conducted by using ThermoCalc ${ }^{\mathrm{TM}}$ and kinetic modeling. Predicted results were verified with experimental data and once verified were used to optimize alloy compositions with desired levels of strength and thermal stability. In addition to developing nominal compositions, ThermoCalc ${ }^{\mathrm{TM}}$ was also used to set limits on residual elements such as manganese, silicon, phosphorus, etc. Predicted results on residual elements were verified by producing and testing experimental size heats. 
2. Development of Time-Temperature-Transformation (TTT) Curves for Conducting Heat Treatment for Selected Properties

The ferritic steels derive their strength, toughness, and thermal stability based on the microstructure that develops during heat treatment. A TTT diagram was developed for each of the identified compositions through the use of Gleeble equipment available at ORNL. The TTT diagrams provide information on critical phase transformation temperatures and the cooling steps (continuous versus step cooling) required for generating a desired microstructure. This information is needed for selecting cooling parameters for a range of component section thicknesses.

3. Melting and Processing of Fe-Cr-W Alloy Compositions

In this concept, experimental size heats of the alloy compositions identified in concept 1 above were melted and processed into plate product. Both hot forging and rolling processes were carried out. The results of experimental heats become the input for selecting composition and processing of large production-size heats and component fabrication.

4. Mechanical Properties Characterization

The most important aspect of this project was to develop an alloy(s) that will reduce the component weight by approximately $25 \%$. Such weight reductions will result from nearly $50 \%$ higher strength than currently used Fe-Cr-Mo alloys. This concept required determining the mechanical properties such as tensile, toughness, and creep for both the experimental- and commercial-size heats.

5. Welding Process Development and Weldment Properties

For the Fe-Cr-W steels to be useful for fabrication of large components, their welding process development is essential. In this concept, emphasis was on several items including: (a) validation of applicability of currently used processes for $\mathrm{Fe}$-Cr-Mo steels,

(b) identification of weld wire compositions, and (c) determination of the need for any PWHT. For the sake of comparison with base metal and currently used Fe-Cr-Mo steels, mechanical properties of the weldments such as hardness, tensile, creep, and toughness were carried out.

6. Microstructural Thermal Stability

Ferritic steels derive their properties from the microstructural features that result from phase transformations during heat treatment and precipitation. It is the thermal stability of these structural features that determine the life of the component in service. In this concept, both base and weldments were subjected to thermal exposures at ranges of temperatures and times. The changes from thermal exposures will be measured by mechanical property tests such as tensile, creep, toughness, and hardness. Thermal stability results carried out in the laboratory will be modeled using kinetic model and verified. Results of this analysis will be used to predict the end-of-life of components in service.

7. Manufacturing and Testing of Prototype Components This concept will deal with fabrication of prototype components of selected $\mathrm{Fe}-\mathrm{Cr}-\mathrm{W}$ alloy composition and its performance evaluation by installing in a chemical plant environment and other potential applications in BOF hoods and recovery boilers. The prototype component testing will provide additional data about corrosion performance of the alloy under actual operating conditions.

8. Preparation of Data Packages for ASTM and ASME Code Approvals

The chemical pressure vessels are designed and constructed to ASME Code design stress values. For Fe-Cr-W alloys to find applications in pressure vessels and other components for 
chemical industry, alloy composition and properties data along with welding process and component testing results were assembled into a data package for approvals from the appropriate ASTM and ASME Code bodies.

Significant results were obtained during this project for each of the proposed concepts. Most relevant and important results are described below. Details are presented in appendices to this report.

\subsubsection{Alloy Phase Stability Analysis}

One focus during this project was to develop an alloy that was superior to the currently available commercial or near-commercial alloys in the composition range of $\mathrm{Fe}-3$ to $9 \mathrm{Cr}-\mathrm{Mo}(\mathrm{W})$ and containing refractory carbide formers such as $\mathrm{Nb}, \mathrm{V}$, etc. These alloys included a well known base alloy $\mathrm{Fe}-2.25 \mathrm{Cr}-1 \mathrm{Mo}$, designated as Grade 22, two recent high-strength versions of the alloy from Japan, designated as T23 and T24, and a high-strength Fe-9Cr-1Mo grade developed nearly 22 years ago at ORNL, designated as T91. Detailed chemical compositions of these alloys are presented in Table 1. In addition to the commercial alloys, R. L. Klueh at ORNL had developed patented alloys of nominal $\mathrm{Fe}-3 \mathrm{Cr}-3 \mathrm{~W}$ compositions.

Detailed chemical analysis of two $\mathrm{Fe}-3 \mathrm{Cr}-3 \mathrm{~W}$ compositions that were scaled up to $400-\mathrm{lb}$ heats is shown in Table 2. Although the proposed project was based on Fe-3Cr-3W alloys, early in the project the industrial team recommended that those alloys be replaced with new compositions so that new U.S. and international patents could be obtained. The new alloys developed during this project replaced part of the W in Klueh's alloys by Mo. Nominal compositions of the new alloys are also included in Table 2. Both U.S. and international patents were filed for the new compositions.

A detailed phase analysis was carried out using ThermoCalc ${ }^{\mathrm{TM}}$ modeling for alloy compositions listed in Tables 1 and 2. Results presented in Fig. 1 show that after a $700^{\circ} \mathrm{C}$ temper, the base Fe$2.25 \mathrm{Cr}-1 \mathrm{Mo}$ alloy contains only $\mathrm{M}_{23} \mathrm{C}_{6}$ phase. In comparison, alloy $\mathrm{T} 23$ contains $\mathrm{V}(\mathrm{C}, \mathrm{N}), \mathrm{M}_{6} \mathrm{C}$, $\mathrm{M}_{23} \mathrm{C}_{6}$, and $\mathrm{M}_{2} \mathrm{~B}$. Alloy T24 contains the same phase as T23 with the exception of the absence of $\mathrm{M}_{6} \mathrm{C}$ phase. In comparison, the ORNL alloys (Klueh's base patents) of $\mathrm{Fe}-3 \mathrm{Cr}-3 \mathrm{~W}$ base (ORNL) and that containing $0.1 \mathrm{wt} \% \mathrm{Ta}\left(\mathrm{ORNL}-\mathrm{VT}\right.$ ), only showed $\mathrm{V}(\mathrm{C}, \mathrm{N}) \mathrm{M}_{6} \mathrm{C}$, and $\mathrm{M}_{7} \mathrm{C}_{3}$ phases. The $\mathrm{M}_{23} \mathrm{C}_{6}$ phase was absent in both alloys. It was recognized that the absence of $\mathrm{M}_{23} \mathrm{C}_{6}$ in the $\mathrm{Fe}-3 \mathrm{Cr}-3 \mathrm{~W}$ alloys was the one important reason for their unique mechanical properties of high-temperature strength and toughness.

Figure 2 shows the comparative phase analysis for the base line $\mathrm{Fe}-3 \mathrm{Cr}-3 \mathrm{~W}$ alloy (ORNL) and the newly developed composition based on Fe-3Cr-W(Mo), A79741. The compositions of both of these alloys are given in Table 2. Results in Fig. 2 are for tempering temperatures of 700 and $730^{\circ} \mathrm{C}$ and show that the partial replacement of $\mathrm{W}$ with $\mathrm{W}+$ Mo changes the phase stability. The Fe-3Cr-3W alloys contained $\mathrm{V}(\mathrm{C}, \mathrm{N}), \mathrm{M}_{6} \mathrm{C}$, and $\mathrm{M}_{7} \mathrm{C}_{3}$, and the new alloys contain $\mathrm{V}(\mathrm{C}, \mathrm{N}), \mathrm{M}_{6} \mathrm{C}$, and $\mathrm{M}_{23} \mathrm{C}_{6}$. 
Table 1. Chemical analysis of commercial or near-commercial alloys used or proposed for the petrochemical industry

\begin{tabular}{|c|c|c|c|c|}
\hline \multirow{3}{*}{ Element } & \multicolumn{4}{|c|}{ Alloy (wt \%) } \\
\hline & \multicolumn{4}{|c|}{ Commercial / Near Commercial } \\
\hline & ${\mathrm{T} 22^{2}}^{2}$ & $T 23^{a, c}$ & $T 24^{a, d}$ & $T 91^{a, e}$ \\
\hline C & $0.15 \max$ & $0.04-0.10$ & $0.05-0.10$ & $0.08-0.12$ \\
\hline Si & $0.25-1.00$ & $0.50 \max$ & $0.15-0.45$ & $0.20-0.50$ \\
\hline $\mathrm{Mn}$ & $0.30-0.60$ & $0.10-0.60$ & $0.30-0.70$ & $0.30-0.60$ \\
\hline$P$ & $0.030 \max$ & 0.030 max & $0.020 \max$ & $0.020 \max$ \\
\hline $\mathrm{S}$ & 0.030 max & 0.010 max & $0.010 \max$ & $0.010 \max$ \\
\hline $\mathrm{Cr}$ & $1.9-2.6$ & $1.9-2.6$ & $2.2-2.6$ & $8.0-9.5$ \\
\hline Mo & $0.87-1.13$ & $0.05-0.30$ & $0.90-1.10$ & $0.85-1.05$ \\
\hline $\mathrm{N}$ & $b$ & 0.030 max & $0.12 \max$ & $0.030-0.070$ \\
\hline $\bar{W}$ & $b$ & $1.45-1.75$ & $b$ & $b$ \\
\hline $\mathrm{V}$ & $b$ & $0.20-0.30$ & $0.20-0.30$ & $0.18-0.25$ \\
\hline $\mathrm{Nb}$ & $b$ & $0.02-0.08$ & $b$ & $0.06-0.10$ \\
\hline $\mathrm{Ta}$ & $b$ & b & $b$ & $b$ \\
\hline$B$ & $b$ & $0.0005-0.0060$ & $0.0015-0.0070$ & $b$ \\
\hline $\mathrm{Ti}$ & $b$ & $b$ & $0.05-0.10$ & $\frac{a}{b}$ \\
\hline $\mathrm{Ni}$ & $b$ & $b$ & $b$ & $0.40 \max$ \\
\hline Al & $b$ & $0.030 \max$ & $0.020 \max$ & $0.040 \max$ \\
\hline & & 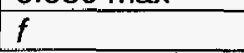 & s & \\
\hline
\end{tabular}

Table 2. Chemical composition of Fe-3Cr-3W (heats 10293 and 10294) and $\mathrm{Fe}-3 \mathrm{Cr}-3 \mathrm{~W}(\mathrm{Mo})$ (heat 79741) alloys

\begin{tabular}{|c|c|c|c|}
\hline \multirow{2}{*}{ Element } & \multicolumn{3}{|c|}{ Heat (wt \%) } \\
\cline { 2 - 4 } & $\mathbf{1 0 2 9 3}$ & $\mathbf{1 0 2 9 4}$ & $\mathbf{A 7 9 7 4 1}$ \\
\hline $\mathrm{C}$ & 0.10 & 0.1 & 0.099 \\
\hline $\mathrm{Mn}$ & 0.39 & 0.41 & 0.34 \\
\hline $\mathrm{P}$ & 0.01 & 0.011 & 0.009 \\
\hline $\mathrm{S}$ & 0.004 & 0.005 & 0.003 \\
\hline $\mathrm{Si}$ & 0.16 & 0.16 & 0.21 \\
\hline $\mathrm{Ni}$ & 0.01 & $<0.01$ & 0.15 \\
\hline $\mathrm{Cr}$ & 3.04 & 3.02 & 2.97 \\
\hline $\mathrm{Mo}$ & 0.01 & 0.01 & 0.73 \\
\hline $\mathrm{V}$ & 0.21 & 0.21 & 0.22 \\
\hline $\mathrm{Cb}$ & 0.003 & 0.004 & 0.002 \\
\hline $\mathrm{Ti}$ & 0.001 & 0.001 & 0.003 \\
\hline $\mathrm{Co}$ & 0.005 & 0.006 & 0.014 \\
\hline $\mathrm{Cu}$ & 0.01 & 0.01 & 0.11 \\
\hline $\mathrm{Al}$ & 0.003 & 0.003 & 0.008 \\
\hline $\mathrm{B}$ & 0.001 & 0.001 & $<0.001$ \\
\hline $\mathrm{W}$ & 3.05 & 3.07 & 1.68 \\
\hline $\mathrm{As}$ & 0.001 & 0.001 & 0.005 \\
\hline $\mathrm{Sn}$ & 0.003 & 0.004 & 0.008 \\
\hline $\mathrm{Zr}$ & $<0.001$ & $<0.001$ & $<0.001$ \\
\hline $\mathrm{N}$ & 0.004 & 0.003 & 0.009 \\
\hline $\mathrm{O}$ & 0.005 & 0.004 & 0.004 \\
\hline $\mathrm{Ta}$ & $<0.01$ & 0.09 & --- \\
\hline & & \multicolumn{2}{c|}{} \\
\hline
\end{tabular}




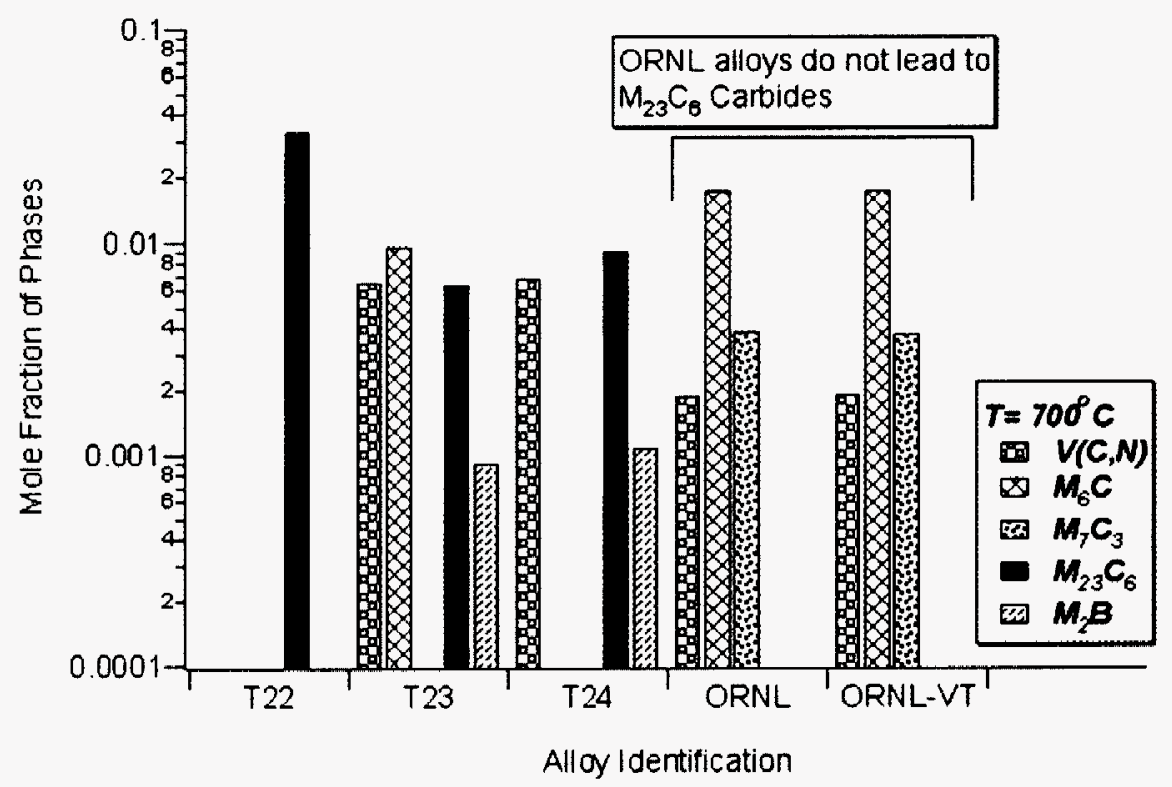

Figure 1. Comparison of stable phases predicted in various commercial and near-commercial alloys and Oak Ridge National Laboratory (alloys ( $\mathrm{Fe}-3 \mathrm{Cr}-3 \mathrm{~W}$ based). All calculations are for a tempering temperature of $700^{\circ} \mathrm{C}$.

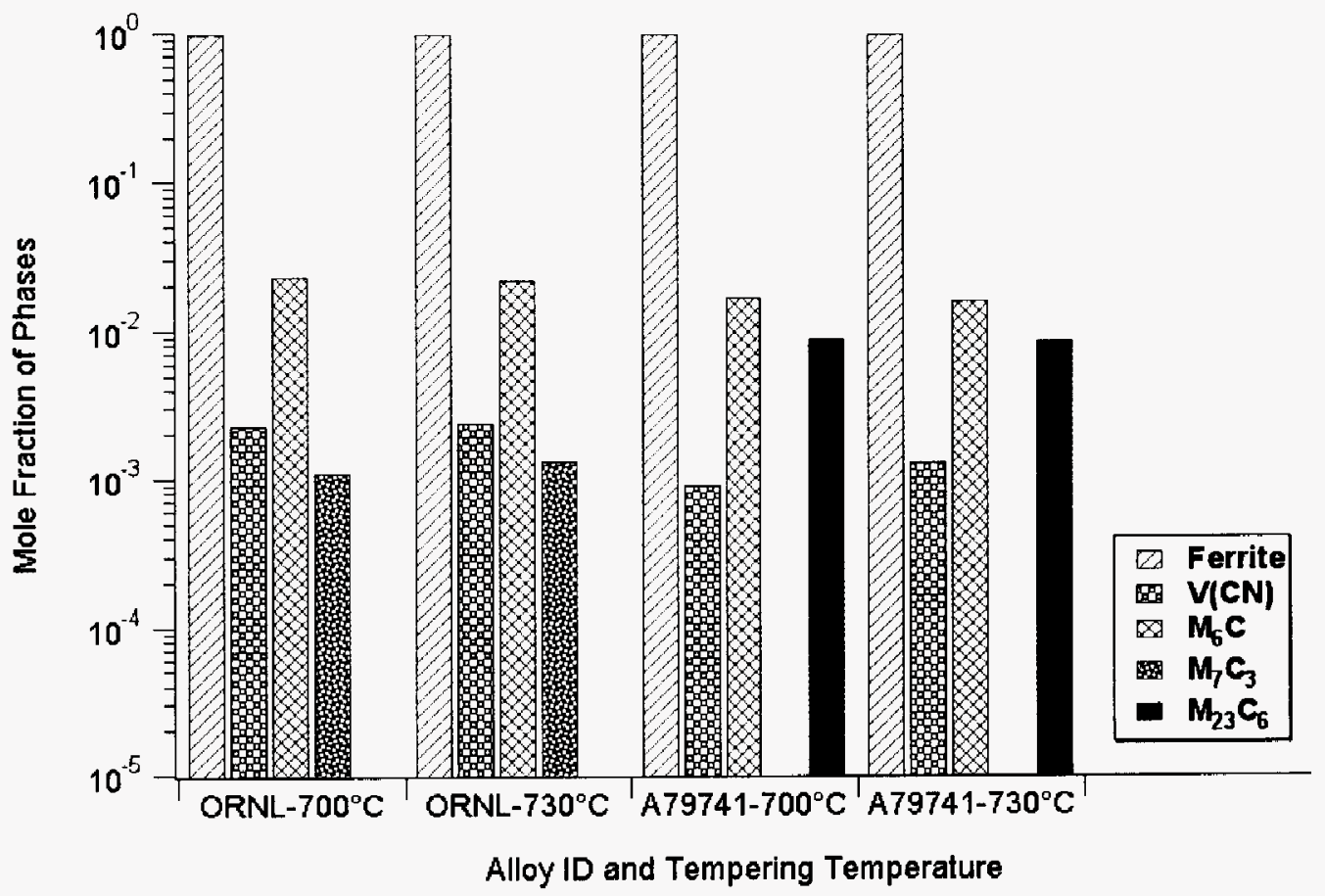

Figure 2. Comparison of stable phases predicted in Oak Ridge National Laboratory (ORNL) alloys containing ORNL $\mathrm{Fe}-3 \mathrm{Cr}-3 \mathrm{~W}$ versus heat $79741 \mathrm{Fe}-3 \mathrm{Cr}-\mathrm{W}(\mathrm{Mo})$. Calculations were for tempering temperatures of 700 and $730^{\circ} \mathrm{C}$. 
A summary of the predicted phases present in various alloys is given in Table 3. This table shows: (1) the lowest strength alloy contains a simple $\mathrm{M}_{23} \mathrm{C}_{6}$ phase. All of the higher strength alloys contain three or four phases. Furthermore, the ORNL Fe-3Cr-3W and $\mathrm{Fe} 3 \mathrm{Cr}-3 \mathrm{~W}$ alloys with $0.1 \mathrm{wt} \% \mathrm{Ta}\left(\mathrm{ORNL}-\mathrm{VT}\right.$ ) were unique in that they did not contain any $\mathrm{M}_{23} \mathrm{C}_{6}$. However, when part of the $\mathrm{W}$ was replaced in the new alloy (A79741) with $\mathrm{W}+\mathrm{Mo}$, the $\mathrm{M}_{23} \mathrm{C}_{6}$ phase stabilized instead of the $\mathrm{M}_{7} \mathrm{C}_{3}$ phase. Effects of this change in phase stability will be discussed in later sections of this report.

Table 3. Comparison of predicted phases present in various alloys after tempering temperatures of 700 or $730^{\circ} \mathrm{C}$

\begin{tabular}{|c|c|c|c|c|c|c|}
\hline \multirow[b]{2}{*}{ Phase } & \multicolumn{6}{|c|}{ Alloys } \\
\hline & $T 22^{\mathrm{a}}$ & $T_{23}{ }^{\mathrm{a}}$ & $T 24^{\mathrm{a}}$ & ORNL $^{\mathbf{a}, c, a}$ & ORNL-VT ${ }^{\mathrm{a}, \mathrm{e}}$ & A79741 $1^{\mathrm{a}, \mathrm{b}, \mathrm{C}}$ \\
\hline $\mathrm{V}(\mathrm{C}, \mathrm{N})$ & No & Yes & Yes & Yes & Yes & Yes \\
\hline $\mathrm{M}_{6} \mathrm{C}$ & No & Yes & No & Yes & Yes & Yes \\
\hline $\mathrm{M}_{7} \mathrm{C}_{3}$ & No & No & No & Yes & Yes & No \\
\hline $\mathrm{M}_{23} \mathrm{C}_{6}$ & Yes & Yes & Yes & No & No & Yes \\
\hline $\mathrm{M}_{2} \mathrm{~B}$ & No & Yes & Yes & No & No & No \\
\hline
\end{tabular}

${ }^{a}$ Analysis carried out for tempering temperature of $700^{\circ} \mathrm{C}$.

${ }^{b}$ Newly developed alloy from this project. It is also known as Grade A and alloy 315 in the report text and figures.

${ }^{c}$ Analysis also carried out for tempering temperature of $730^{\circ} \mathrm{C}$.

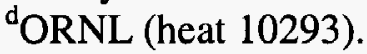

${ }^{\circ}$ ORNL-VT (heat 10294).

Transmission electron micrographs of $2.25 \mathrm{Cr}-1 \mathrm{Mo}$ and $2.25 \mathrm{Cr}-2 \mathrm{WV}$ are compared in Fig. 3. These micrographs show the presence of $\mathrm{M}_{23} \mathrm{C}_{6}$ in $2.25 \mathrm{Cr}-1 \mathrm{Mo}$ (T22) as predicted and its absence in the Mo-free $2.25 \mathrm{Cr}-2 \mathrm{WV}$ alloy, which matches the predicted phases. The $2.25 \mathrm{Cr}$ $2 \mathrm{WV}$ also showed the presence of fine $\mathrm{MC}$ carbides, which is consistent with the prediction of $\mathrm{V}(\mathrm{C}, \mathrm{N})$ and the presence of $\mathrm{M}_{3} \mathrm{C}+\mathrm{M}_{7} \mathrm{C}_{3}$, which is qualitatively consistent with the prediction of $\mathrm{M}_{6} \mathrm{C}+\mathrm{M}_{7} \mathrm{C}_{3}$.

\subsubsection{Alloy Development and Commercial Heat Melting and Processing}

The alloys were developed based on heats weighing $500 \mathrm{~g}(1 \mathrm{lb})$ that were initially melted using nonconsumable-arc melting and casting into water-cooled copper molds. Alloys with acceptable microstructure, impact, and strength properties were vacuum-induction melted (VIM) in $7.5-\mathrm{kg}$ (15-lb) heats. The next incremental steps were 150- and 500-kg (300- and 1000-lb) heats, which were both done at commercial vendors. Based on data for these heats, both Grades A and B $[(\mathrm{Fe}-3 \mathrm{Cr}-3(\mathrm{~W}+\mathrm{Mo})]$ alloys were melted in 50-ton heats at Ellwood Quality Steel (EQS), New Castle, PA. The heats were melted by an electric-arc furnace, vacuum degassed, and cast into three round ingots and two slab ingots for each heat. The two round ingots from each grade were remelted by electroslag remelting (ESR) and vacuum-arc remelting (VAR) processes and recast in round ingots. 

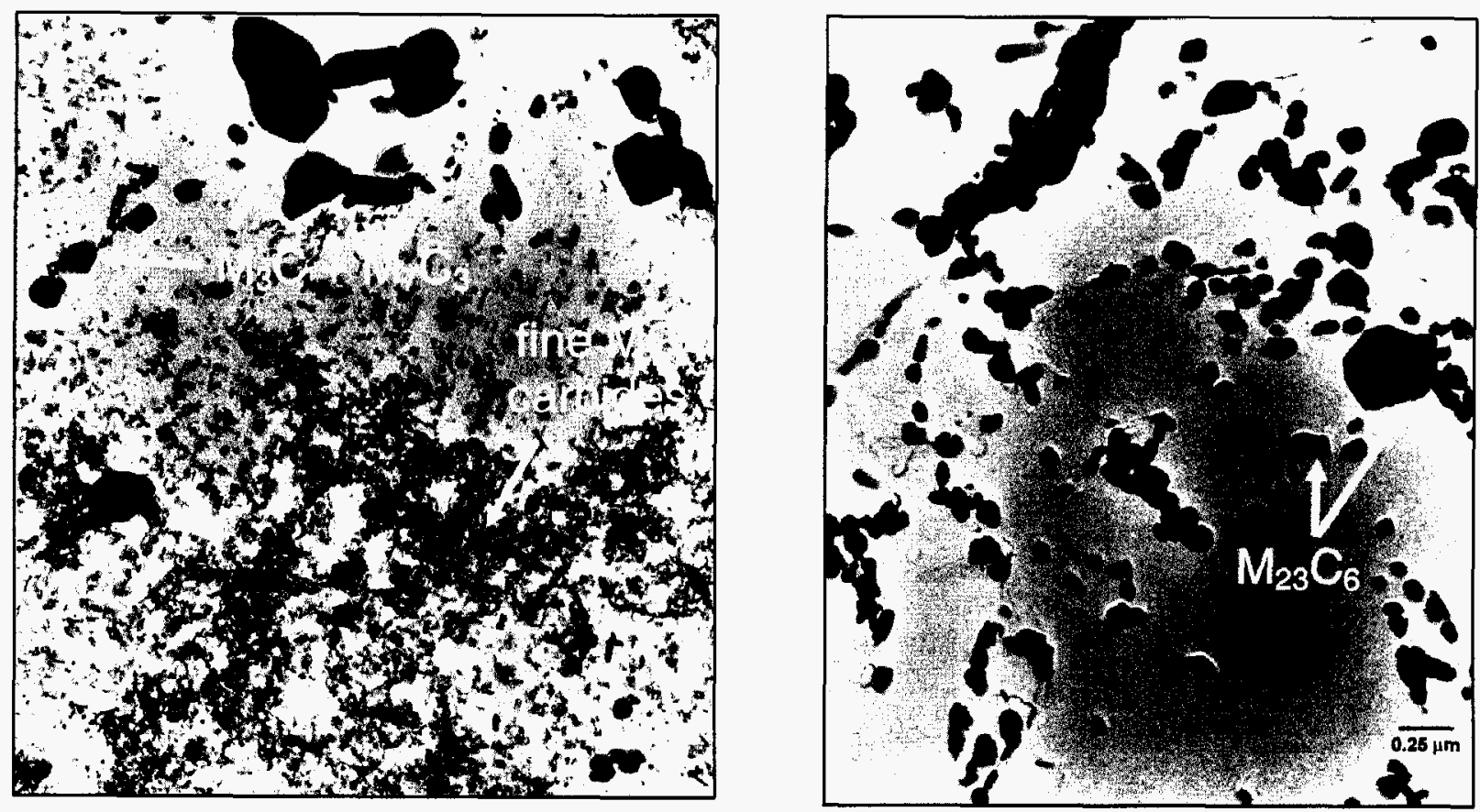

AEM/XEDS Analysis of carbides on extraction replicas

Figure 3. Comparison of phase observed in $2.25 \mathrm{Cr}-1 \mathrm{Mo}$ and $2.25 \mathrm{Cr}-2 \mathrm{WV}$ alloys after normalizing and tempering treatment.

The round ingots from the electric furnace, ESR, and VAR heats were hot-forged to $305-\mathrm{mm}$ (12-in.) rounds and 152-mm (6-in.) round corner square billets at Ellwood City Forge, Ellwood City, PA. The slab ingots were hot-rolled to 1.5 - by 3 -in.-thick plate product at ISG, Coatsville, PA. Part of the 152-mm (6-in.), round corner forgings were hot-rolled to 95-mm (3.75-in.) round bars for processing into seamless tubing at Plymouth Tube Co., Winamac, IN. Two different sizes of tubes were produced by the piercing process. No problems were encountered in the processing of slab and round ingots into hot-rolled plate, forgings, or bars and tubing from either Grades A or B. The melting of 50-ton heats, their pouring into various molds, and processed product forms such as forged billets, rolled plates, and seamless tubing are shown in Fig. 4.

\subsubsection{Alloy Compositions}

The chemical composition of 50-ton heats of electric-furnace-melted heats of Grades A and B are shown in Table 4. Target compositions are included for comparison. This table shows that all elements of the electric furnace-melted 50-ton heats met the specified elements in the aim chemistry.

Chemical analysis of the electric furnace-melted heats changed when remelted by VAR and ESR processes. Comparison of the chemical analysis of Grades A and B in electric furnace, VAR, and ESR are shown in Tables 5 and 6. 
The following are the significant changes observed in the chemistry of Grades A and B after remelting processes:

1. Electroslag remelting reduces the content of $\mathrm{Si}$ in both Grades $\mathrm{A}$ and $\mathrm{B}$. It also lowers the $\mathrm{Ta}$ content for Grade B.

2. VAR reduces the content of $\mathrm{Mn}$ in both grades. It also reduces the $\mathrm{O}$ content for both alloys.

Both grades still meet the specified chemistry range for these alloys.
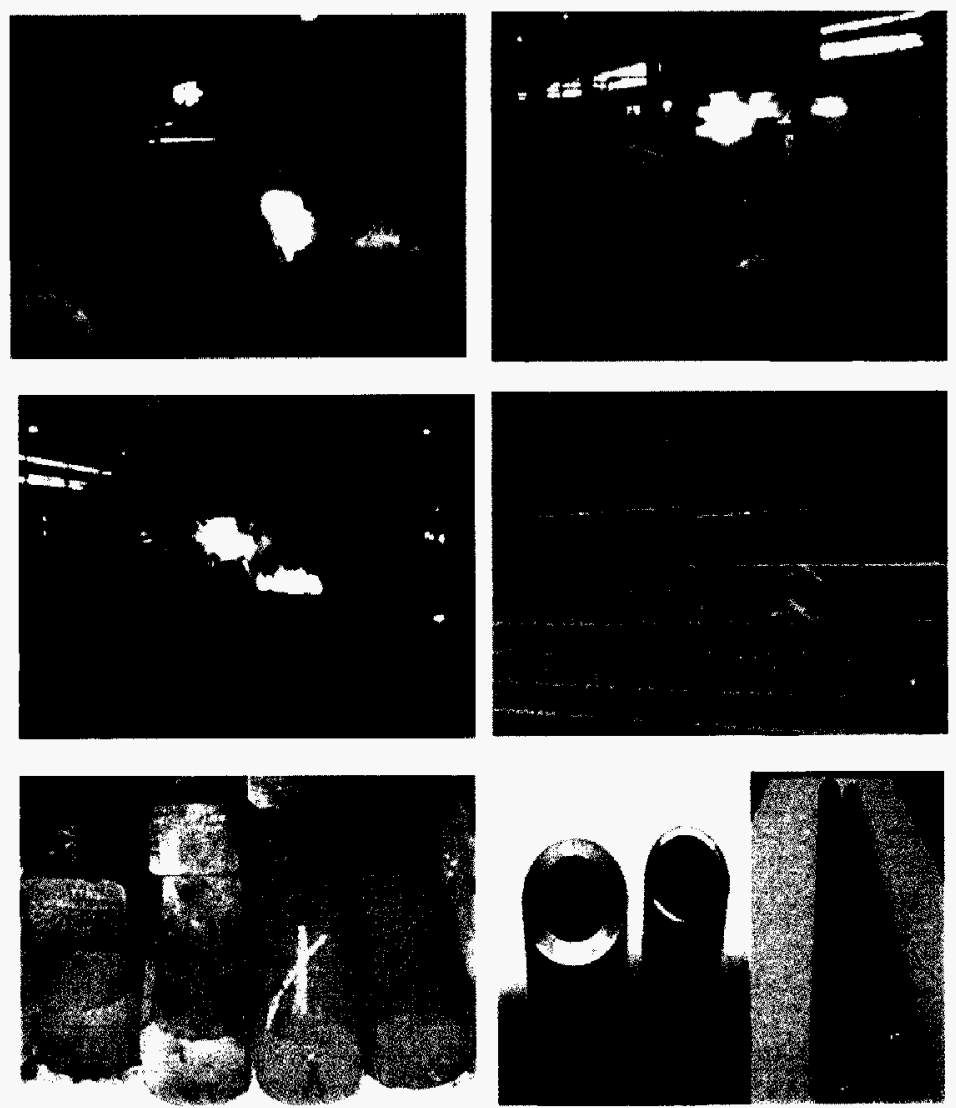

Figure 4. Electric furnace melting of 50-ton commercial heats and their casting into ingots and processing into hot-forged ingots, hot-rolled plate, and tubing.

\subsubsection{Heat Treatment}

Alloys developed in this project obtain their strength through generating a bainitic microstructure. Desired structure requires the knowledge of temperature for converting the ferrite into austenite and identification of cooling rates that produce desired bainitic structure. The continuous cooling transformation (CCT) diagram that yields such information were developed for both Grades A and B. The CCT curves for Grades A and B are shown in Figs. 5 and 6. These figures show that there is only a very minor difference in the transformation behavior of the two grades. Figure 7 shows the CCT curve for Grade B. A cooling curve showing a cooling rate of $20^{\circ} \mathrm{C} / \mathrm{min}$ is shown on this graph. Based on this figure, it is estimated that a cooling rate of $20^{\circ} \mathrm{C} / \mathrm{min}$ is 
required to avoid the ferrite formation in these steels. Although the cooling rate curve is shown for Grade B, it is valid for Grade A also.

Table 4. Vendor and check analysis of two 50-ton heats of Fe-3Cr-W alloy

\begin{tabular}{|c|c|c|c|c|c|c|c|c|}
\hline \multirow{4}{*}{ Element } & \multicolumn{8}{|c|}{ Weight percent } \\
\hline & \multicolumn{4}{|c|}{ Grade A, Heat L7974 } & \multicolumn{4}{|c|}{ Grade B, Heat L8644 } \\
\hline & \multicolumn{3}{|c|}{ 27-In. Round } & \multirow{2}{*}{$\begin{array}{c}\text { 12-in. Slab } \\
\text { Vendor }\end{array}$} & \multicolumn{3}{|c|}{ 27-in. Round } & \multirow{2}{*}{$\frac{\text { 12-in. Slab }}{\text { Vendor }}$} \\
\hline & AIM & Vendor & Check & & AIM & Vendor & Check & \\
\hline Carbon & 0.10 & 0.11 & 0.099 & 0.11 & 0.10 & 0.11 & 0.11 & 0.11 \\
\hline Manganese & 0.35 & 0.36 & 0.34 & 0.36 & 0.35 & 0.36 & 0.35 & 0.36 \\
\hline Phosphorus & $0.01^{a}$ & 0.007 & 0.009 & 0.007 & $0.01^{\circ}$ & 0.008 & 0.009 & 0.008 \\
\hline Sulfur & $0.01^{a}$ & 0.002 & 0.003 & 0.002 & $0.01^{\circ}$ & 0.002 & 0.002 & 0.002 \\
\hline Silicon & 0.2 & 0.21 & 0.21 & 0.21 & 0.2 & 0.2 & 0.2 & 0.2 \\
\hline Nickel & $0.02^{a}$ & 0.15 & 0.15 & 0.15 & $0.02^{a}$ & 0.12 & 0.12 & 0.12 \\
\hline Chromium & 3.00 & 2.99 & 2.97 & 2.99 & 3.00 & 3.01 & 3.02 & 3.01 \\
\hline Molybdenum & 0.75 & 0.76 & 0.73 & 0.76 & 0.75 & 0.74 & 0.73 & 0.74 \\
\hline Vanadium & 0.25 & 0.249 & 0.22 & 0.249 & 0.25 & 0.236 & 0.21 & 0.236 \\
\hline Columbium & $\cdots$ & $\ldots$ & 0.002 & $\cdots$ & $\cdots$ & --- & 0.002 & ---- \\
\hline Titanium & $-\cdots$ & $\ldots$ & 0.003 & $\ldots$ & $\ldots$ & ---- & 0.004 & ---- \\
\hline Cobalt & ---- & $\cdots$ & 0.014 & $\cdots$ & $-\cdots$ & $\ldots$ & 0.016 & ---- \\
\hline Copper & $-\cdots$ & 0.11 & 0.11 & 0.11 & +--- & 0.17 & 0.17 & 0.17 \\
\hline Aluminum & $\ldots$ & 0.013 & 0.008 & 0.013 & $\cdots$ & 0.011 & 0.006 & 0.011 \\
\hline Boron & $0.01^{a}$ & 0.0002 & $<0.001$ & 0.0002 & $0.01^{a}$ & 0.0001 & $<0.001$ & 0.0001 \\
\hline Tungsten & 1.5 & 1.55 & 1.68 & 1.55 & 1.5 & 1.48 & 1.62 & 1.48 \\
\hline Arsenic & $\ldots$ & ---- & 0.005 & $\cdots$ & ---- & $\ldots$ & 0.006 & $\cdots$ \\
\hline Tin & $\cdots$ & $\ldots$ & 0.008 & $\cdots$ & ---- & $\cdots$ & 0.009 & $-\cdots--$ \\
\hline Zirconium & ---- & $\cdots$ & $<0.001$ & $\cdots$ & $\ldots$ & $\ldots$ & $<0.001$ & $-\cdots$ \\
\hline Nitrogen & --- & $\cdots$ & 0.009 & $\cdots$ & $\ldots$ & ---- & 0.011 & $\ldots$ \\
\hline Oxygen & $-\cdots$ & $\ldots$ & 0.004 & $\cdots$ & $\cdots$ & $-\cdots$ & 0.001 & $\ldots$ \\
\hline Hydrogen & $\ldots$ & $1.6^{5}$ & $\cdots$ & $2.2^{b}$ & $\ldots$ & $1.3^{b}$ & --- & $2.3^{b}$ \\
\hline Tantalum & $\ldots$ & ---- & 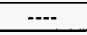 & $-\cdots$ & 0.10 & 0.107 & 0.1 & 0.107 \\
\hline
\end{tabular}

Table 5. Chemical analysis of the electric-furnace-melted 50-ton heat 79741 of Grade A after electroslag remelting heat 79742 and vacuum-arc remelting heat 79743

\begin{tabular}{|c|c|c|c|c|}
\hline \multirow{2}{*}{ Element } & \multirow{2}{*}{ Range } & \multicolumn{3}{|c|}{ Weight percent } \\
\hline & & $79741^{a}$ & $79742^{b}$ & $79743^{c}$ \\
\hline$\overline{\bar{C}}$ & $0.08-0.12$ & 0.099 & 0.11 & 0.11 \\
\hline $\mathrm{Mn}$ & $0.25-0.45$ & 0.34 & 0.33 & 0.25 \\
\hline $\mathrm{P}$ & $0.01 \mathrm{Max}$ & 0.009 & 0.008 & 0.008 \\
\hline$s$ & $0.01 \mathrm{Max}$ & 0.003 & 0.001 & 0.001 \\
\hline $\mathrm{Si}$ & $0.15-0.4$ & 0.21 & 0.15 & 0.21 \\
\hline $\mathrm{Ni}$ & $0.25 \mathrm{Max}$ & 0.15 & 0.15 & 0.15 \\
\hline $\mathrm{Cr}$ & $2.8-3.2$ & 2.97 & 2.95 & 2.97 \\
\hline Mo & $0.65-0.85$ & 0.73 & 0.74 & 0.74 \\
\hline $\mathrm{V}$ & $0.2-0.3$ & 0.22 & 0.22 & 0.22 \\
\hline $\mathrm{Cb}$ & $\cdots$ & 0.002 & 0.001 & 0.002 \\
\hline$-\mathrm{Ti}^{2}$ & $\cdots$ & 0.003 & 0.003 & 0.003 \\
\hline Co & - & 0.014 & 0.013 & 0.013 \\
\hline $\mathrm{Cu}$ & $\cdots$ & 0.11 & 0.11 & 0.1 \\
\hline Al & $\cdots$ & 0.008 & 0.005 & 0.008 \\
\hline$B$ & $0.001 \mathrm{Max}$ & $<0.001$ & $<0.001$ & $<0.001$ \\
\hline W & $1.35-1.65$ & 1.68 & 1.67 & 1.68 \\
\hline As & - & 0.005 & 0.007 & 0.007 \\
\hline $\mathrm{Sn}$ & 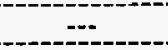 & 0.008 & 0.008 & 0.008 \\
\hline$Z r$ & --. & $<0.001$ & $<0.001$ & $<0.001$ \\
\hline $\mathrm{N}$ & - & 0.009 & 0.013 & 0.004 \\
\hline OO & - & 0.004 & 0.001 & $<0.001$ \\
\hline $\mathrm{Ta}$ & - & $\cdots$ & $<0.001$ & $<0.01$ \\
\hline
\end{tabular}


Table 6. Chemical analysis of the electric-furnace-melted 50-ton heat 86441 of Grade B after electroslag remelting heat 86442 and vacuum-arc remelting heat 86443

\begin{tabular}{|c|c|c|c|c|}
\hline \multirow{2}{*}{ Element } & \multirow{2}{*}{ Range } & \multicolumn{3}{|c|}{ Weight percent } \\
\hline & & $86441^{a}$ & $86442^{b}$ & $86443^{c}$ \\
\hline $\mathrm{C}$ & $0.08-0.12$ & 0.11 & 0.11 & 0.11 \\
\hline $\mathrm{Mn}$ & $0.25-0.45$ & 0.35 & 0.33 & 0.22 \\
\hline $\mathrm{P}$ & $0.01 \mathrm{Max}$ & 0.009 & 0.009 & 0.009 \\
\hline $\bar{S}$ & $0.01 \mathrm{Max}$ & 0.002 & 0.001 & 0.001 \\
\hline Si & $0.15-0.4$ & 0.2 & 0.15 & 0.2 \\
\hline $\mathrm{Ni}$ & $0.25 \mathrm{Max}$ & 0.12 & 0.12 & 0.12 \\
\hline $\mathrm{Cr}$ & $2.8-3.2$ & 3.02 & 3.03 & 3.03 \\
\hline Mo & $0.65-0.85$ & 0.73 & 0.72 & 0.72 \\
\hline $\mathrm{V}$ & $0.2-0.3$ & 0.21 & 0.21 & 0.21 \\
\hline $\mathrm{Cb}$ & -- & 0.002 & 0.002 & 0.002 \\
\hline $\mathrm{Ti}$ & $\cdots$ & 0.004 & 0.003 & 0.003 \\
\hline $\mathrm{Co}$ & 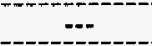 & 0.016 & 0.016 & 0.016 \\
\hline $\mathrm{Cu}$ & - & 0.17 & 0.17 & 0.15 \\
\hline $\mathrm{Al}$ & $\cdots$ & 0.006 & 0.009 & 0.006 \\
\hline$B$ & 0.001 Max & $<0.01$ & $<0.001$ & $<0.01$ \\
\hline $\mathrm{W}$ & $1.35-1.65$ & 1.62 & 1.61 & 1.61 \\
\hline As & -1 & 0.006 & 0.008 & 0.007 \\
\hline $\mathrm{Sn}$ & 品 & 0.009 & 0.01 & 0.01 \\
\hline $\mathrm{Zr}$ & - & $<0.001$ & $<0.001$ & $<0.001$ \\
\hline $\mathrm{N}$ & $\ldots$ & 0.011 & 0.012 & 0.004 \\
\hline 0 & - & 0.001 & 0.001 & $<0.001$ \\
\hline $\mathrm{Ta}$ & $0.07-0.13$ & 0.1 & 0.08 & 0.1 \\
\hline
\end{tabular}

${ }^{a}$ Electric furnace.

${ }^{\mathrm{b}}$ Electroslag remelted.

${ }^{c}$ Vacuum-arc remelted.

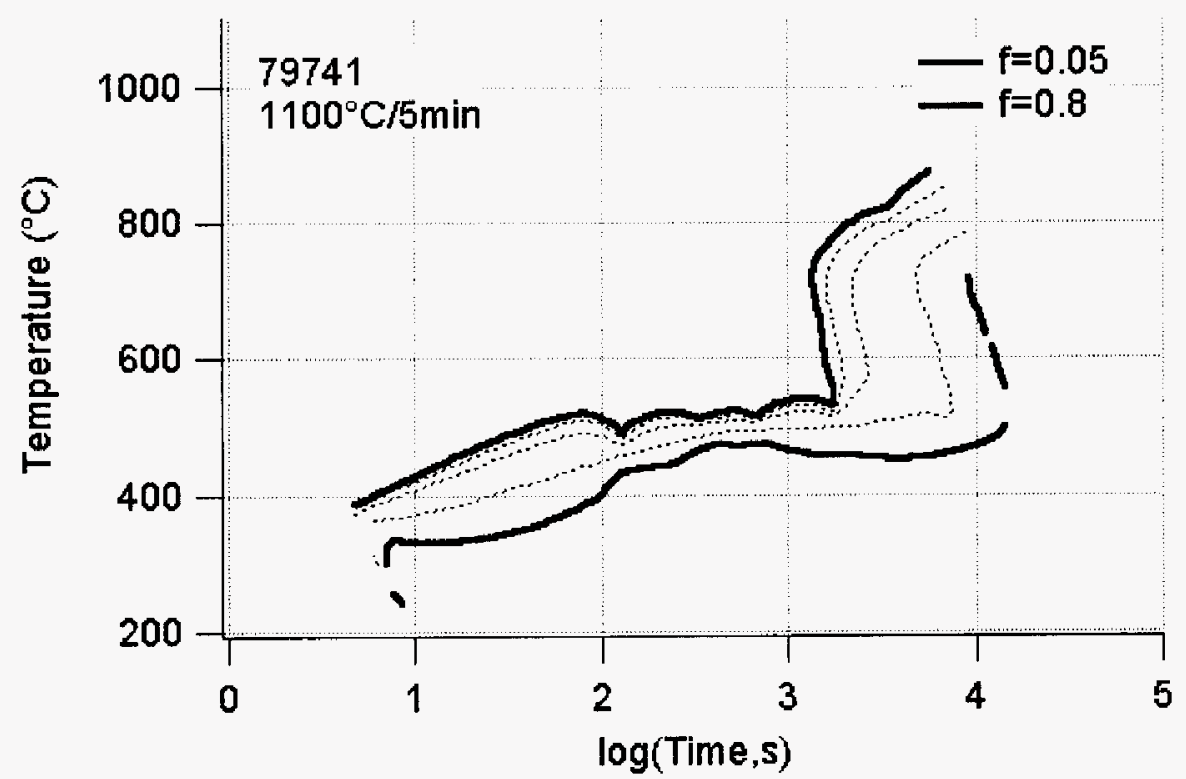

Figure 5. Continuous cooling transformation diagram for Grade A (heat 79741). 


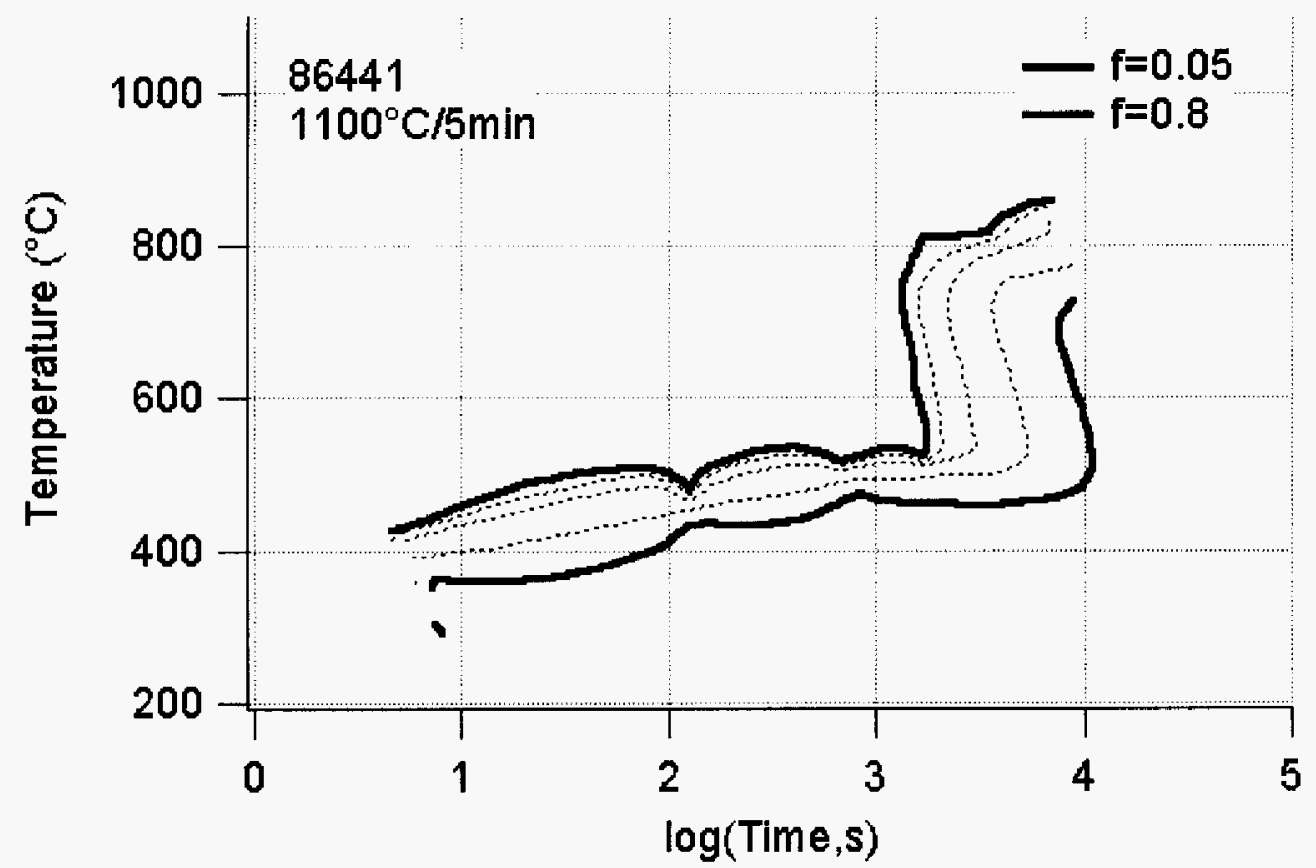

Figure 6. Continuous cooling transformation diagram for Grade B (heat 86441).

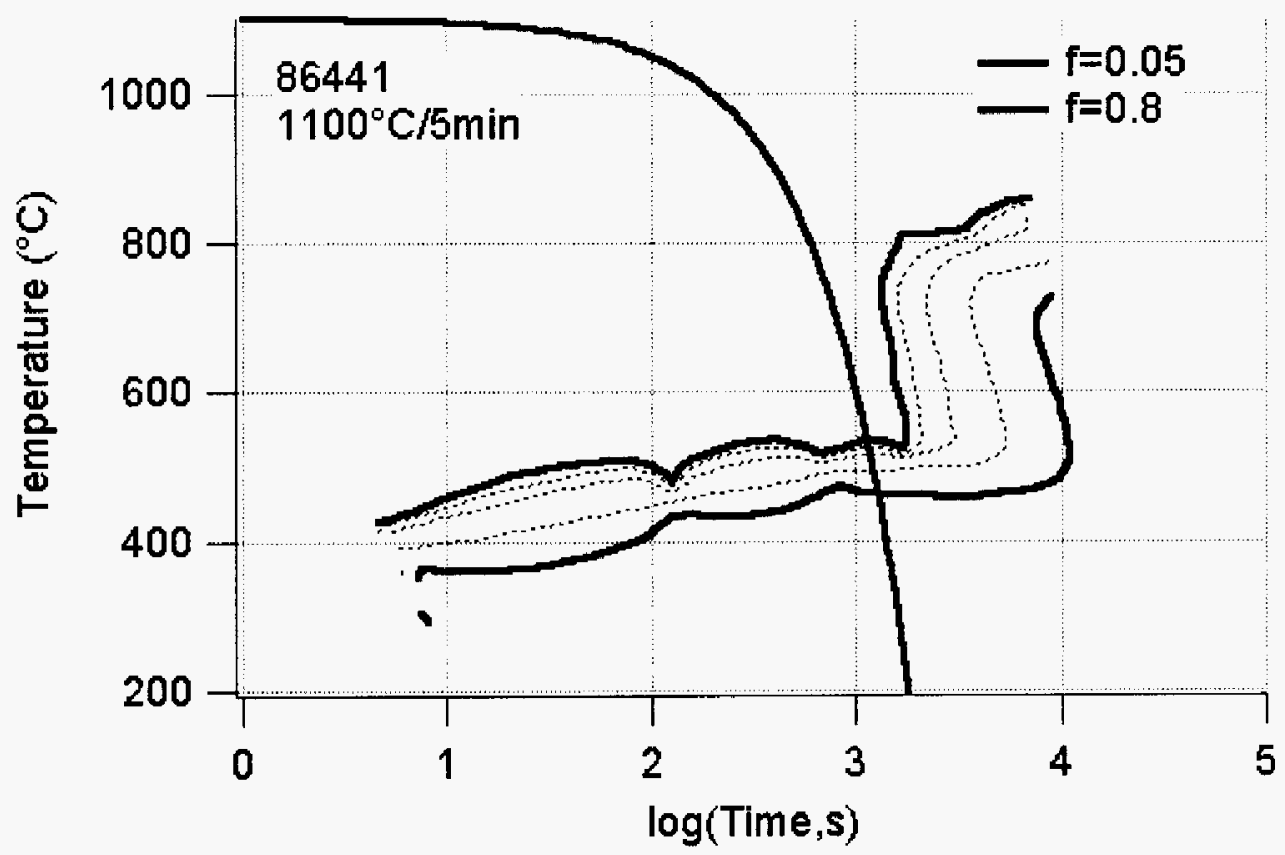

Figure 7 . Curve for cooling rate of $20^{\circ} \mathrm{C} / \mathrm{min}$ is shown on the cooling transformation temperature plot of Grade B (heat 86441). 
The upper use temperature of the ferrite steels is limited by critical transformation temperatures known as $A_{1}$ and $A_{3} . A_{1}$ is the lowest temperature where ferrite transforms to austenite and $A_{3}$ is the highest temperature above which ferrite to austenite transformation is complete. The $A_{1}$ and $\mathrm{A}_{3}$ temperatures for Grades $\mathrm{A}$ and $\mathrm{B}$ are given in Table 7.

Table 7. Critical transformation temperatures for Grades A and B

\begin{tabular}{|c|c|c|}
\hline \multirow{2}{*}{$\begin{array}{c}\text { Critical } \\
\text { Temperature }\end{array}$} & \multicolumn{2}{|c|}{ Grade A (Heat 79741) $^{\circ} \mathrm{Grade} \mathrm{B} \mathrm{(Heat} \mathrm{86441}$} \\
\hline$A_{1}$ & 865 & 858 \\
\hline$A_{3}$ & 967 & 970 \\
\hline
\end{tabular}

Effect of tempering treatment on the tensile properties of plates of both Grades A and B (alloys 315 and $315 T$ ) was studied in a comprehensive manner by Ken Orie of ISG Plate (see Appendix C) for his detailed presentation. He investigated the tensile properties of both the 1.5- and 3-in.thick plates after tempering temperature in the range of 1225 to $1380^{\circ} \mathrm{F}$. Test data was developed on sections of the plates heat-treated in the laboratory heat-treating furnace and on the plates heat treated in mill heat-treating furnace. The yield strength data at room temperature for both Grades $\mathrm{A}$ and $\mathrm{B}$ of 1.5- and 3-in.-thick plates are plotted in Fig. 8. The plates designated as A8141 refer to electric furnace-melted heat 79741 of Grade A without Ta. The plates marked A8142 (Ta) refer to electric furnace-melted heat 86441 of Grade B and contains 0.1 wt $\%$ Ta. Similar plots for ultimate tensile strength and total elongation are shown in Figs. 9 and 10. Data in Figs. 8, 9, and 10 shows the strength values for the 3 -in.-thick plate are generally lower than those for 1.5-in.-thick plate. The mill-annealed plates showed somewhat lower ductility than plates tempered in the laboratory furnace at ISG Plate.

The effect of temperature tempering on the tensile properties of 1.5- and 3-in.-thick plates of Grade A (heat 79741) [data generated by Ken Orie at ISG Plate] are compared with the data generated on 6- by 6-in. forgings at ORNL in Figs. 11 through 13. These figures show that data on forgings are in good agreement with the data on plate product and, thus, forms a good basis for selecting tempering temperature for desired tensile properties.

Effect of tempering temperature on the Charpy-impact properties of 1.5- and 3-in.-thick plates of Grades A and B was also extensively investigated by Ken Orie of ISG Plate. These data are summarized in Table 8 . The Charpy-impact energy at $32^{\circ} \mathrm{F}$ for 1.5 -in.-thick plates of Grades A and $B$ are plotted as a function of Larson-Miller parameter (LMP) in Fig. 14. The LMP for tempering is described as follows:

$$
\mathrm{LMP}=(\mathrm{T}+460)(20+\log \mathrm{t}),
$$

where

$\mathrm{T} \quad=$ tempering temperature in ${ }^{\circ} \mathrm{F}$,

$\mathrm{t}=$ tempering time in hours,

$460=$ used to convert ${ }^{\circ} \mathrm{F}$ to ${ }^{\circ} \mathrm{R}$, and

$20=$ Larson-Miller constant. 


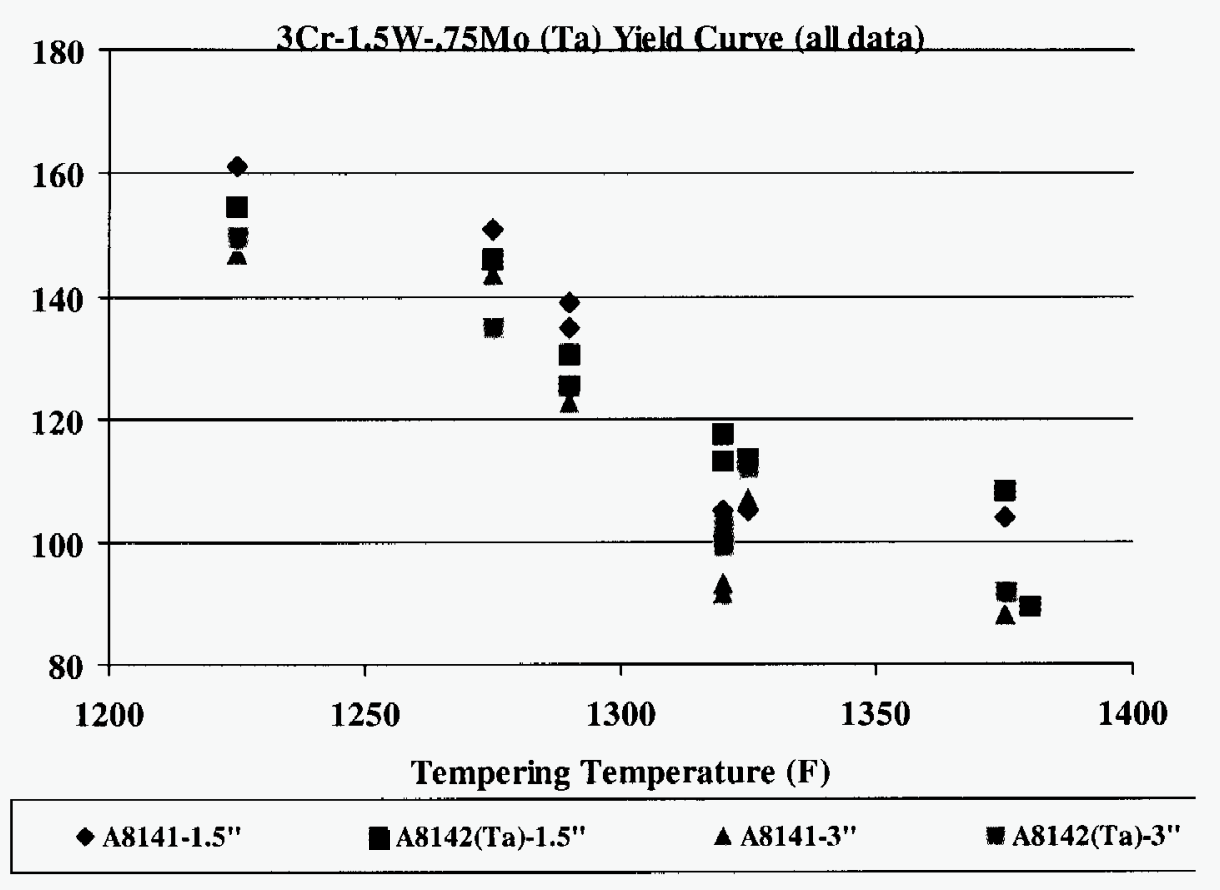

Figure 8. Plot of yield strength at room temperature as a function of tempering temperature for 1.5- and 3-in.-thick plates of Grades A and B [A8141 and A8142(Ta)] (data from Ken Orie at ISG Plate, Coatesville, PA).

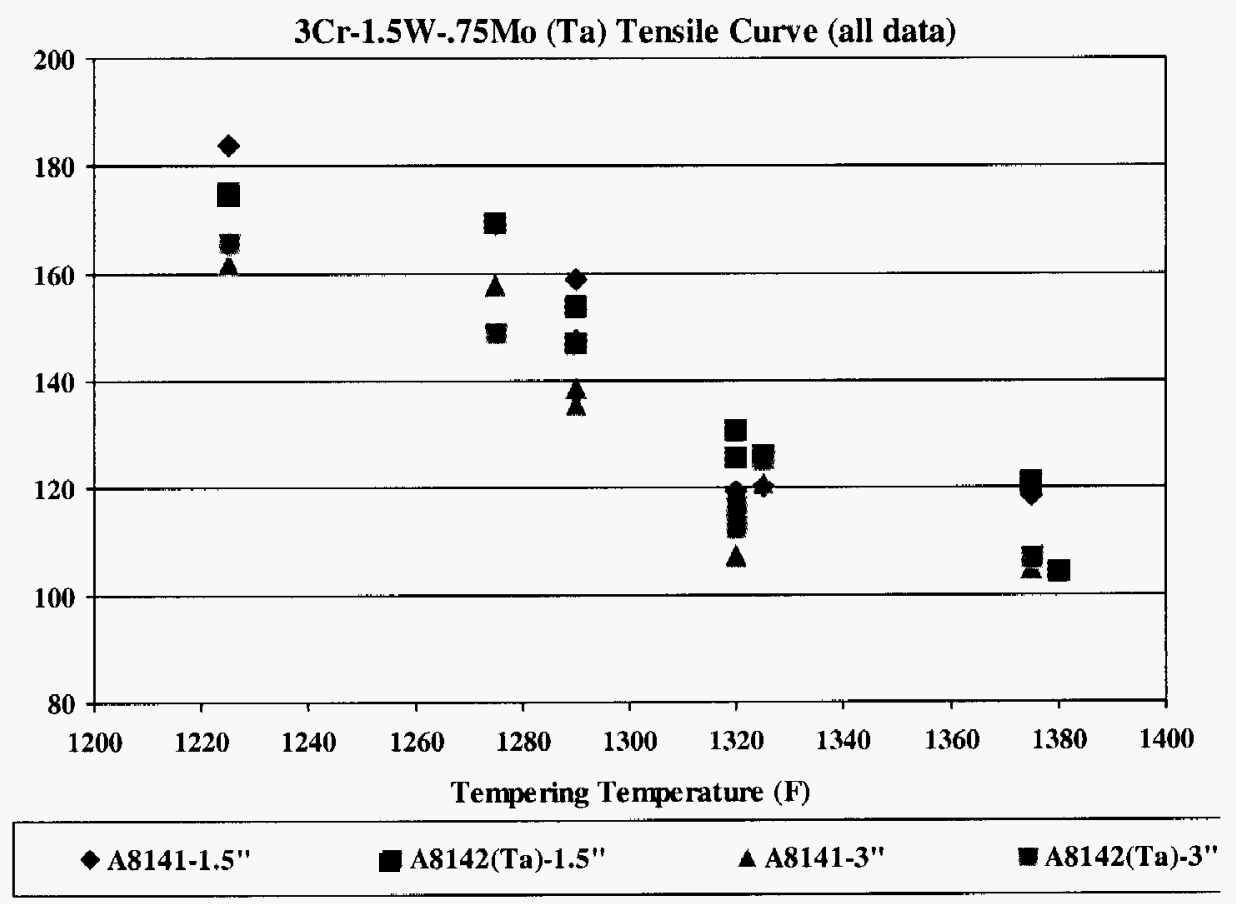

Figure 9. Plot of ultimate tensile strength at room temperature as a function of tempering temperature for 1.5- and 3-in.-thick plates of Grades A and B [A8141 and A8142(Ta)] (data from Ken Orie at ISG Plate, Coatesville, PA). 


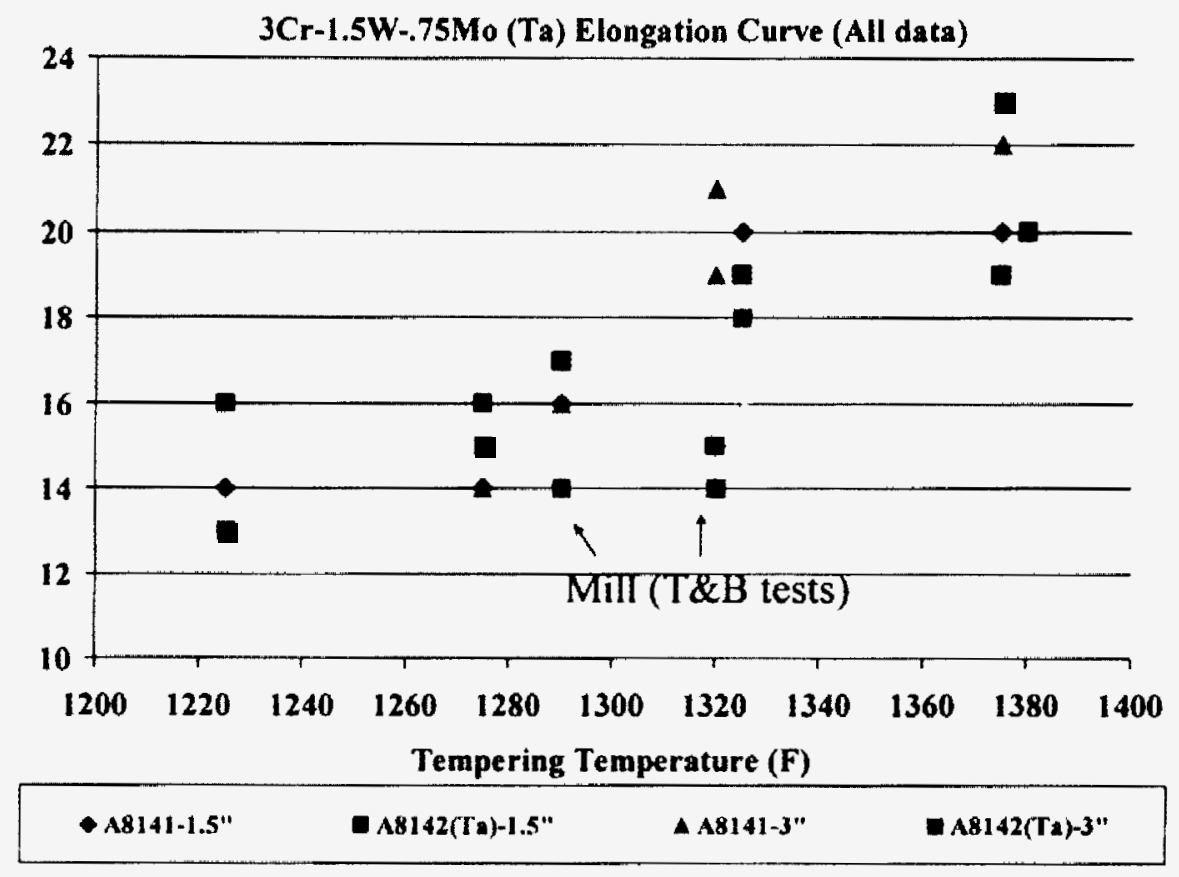

Figure 10. Plot of total elongation at room temperature as a function of tempering temperature for 1.5- and 3-in.-thick plates of Grades A and B [A8141 and A8142(Ta)] (data from Ken Orie at ISG Plate, Coatesville, PA).

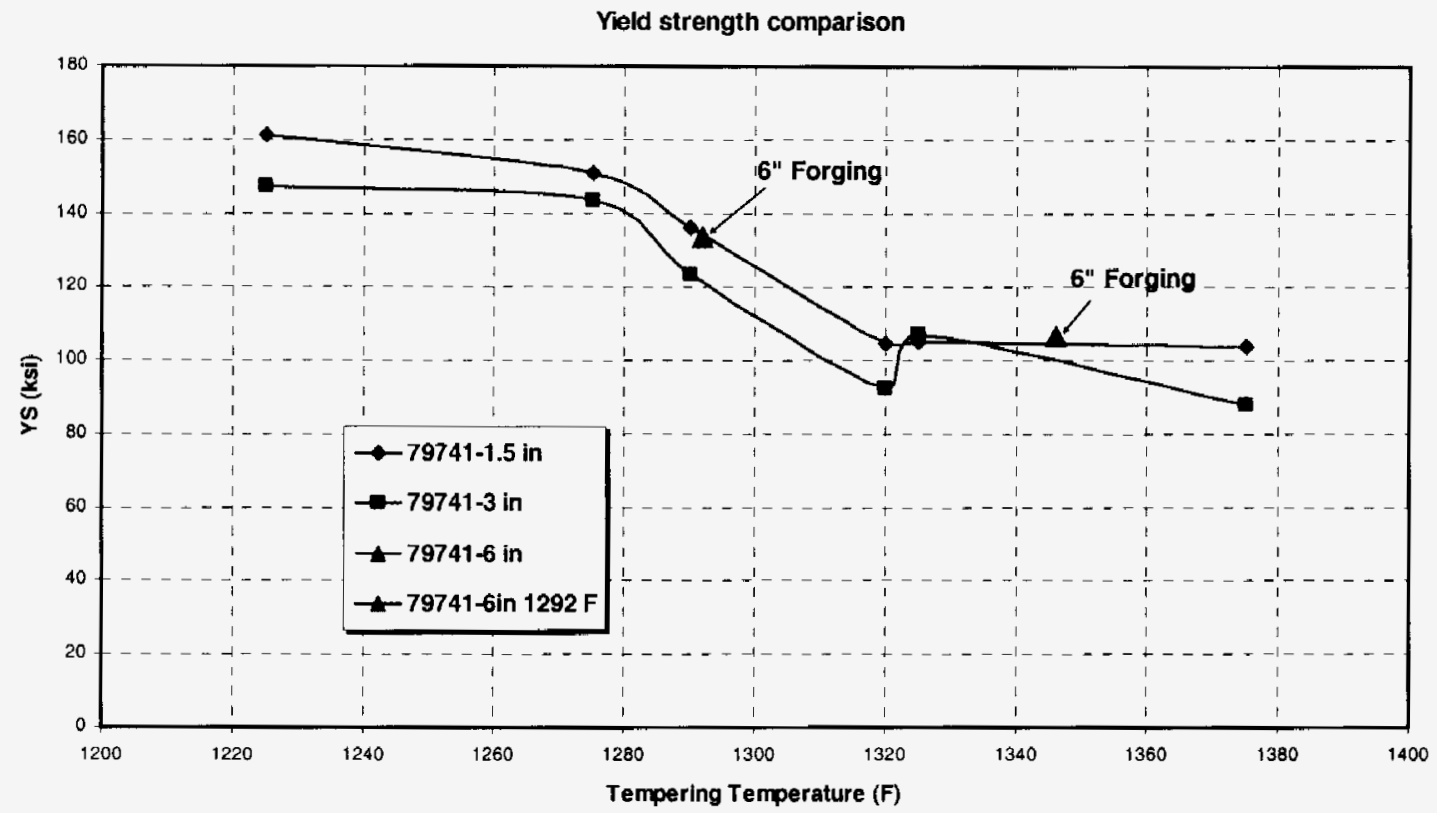

Figure 11. Comparison of tempering response for yield strength at room temperature of 1.5-and 3-in.-thick plates tested at ISG Plate, Coatesville, PA, with 6- by 6-in. forging tested at the Oak Ridge National Laboratory, Oak Ridge, TN, for Grade A (heat 79741). 


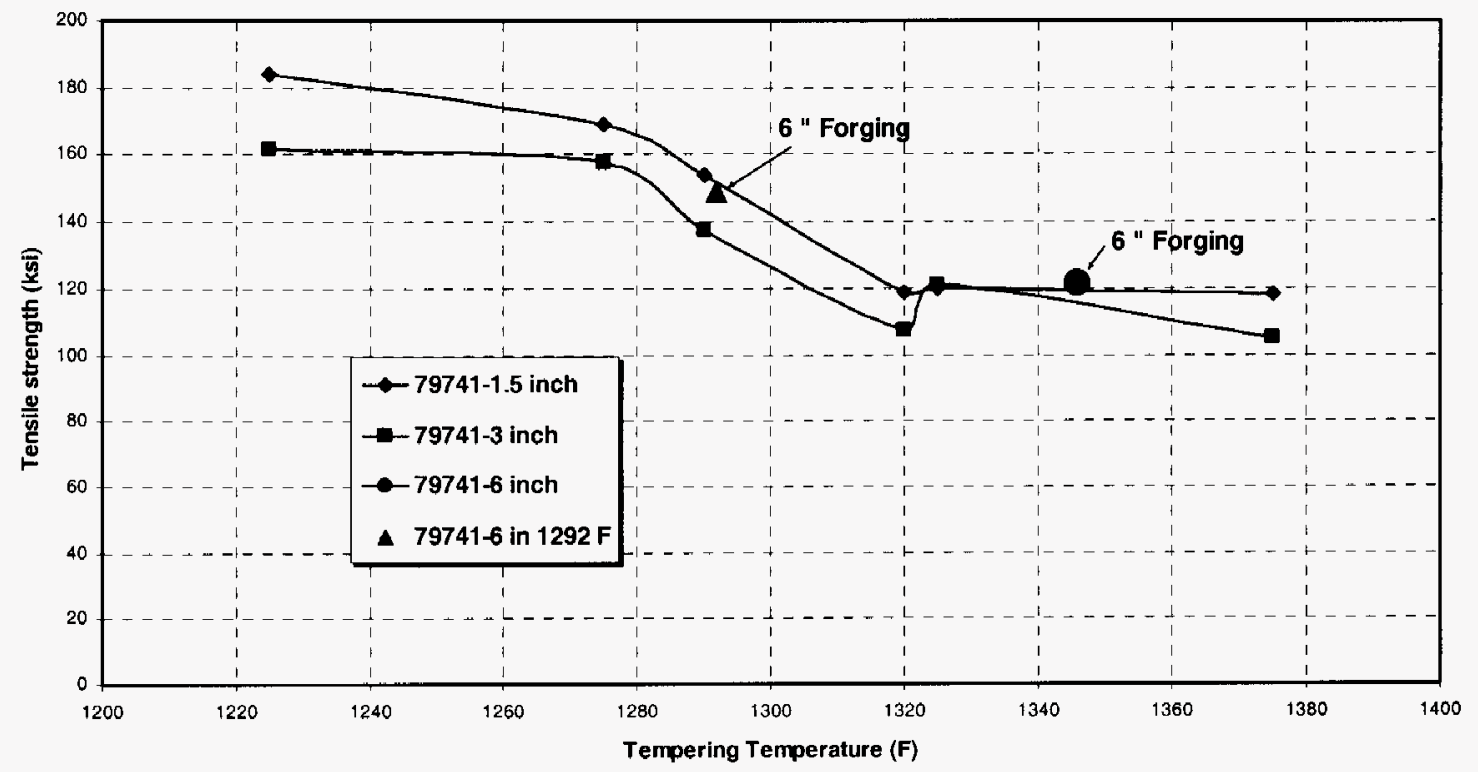

Figure 12. Comparison of tempering response for ultimate tensile strength at room temperature of 1.5- and 3-in.-thick plates tested at ISG Plate, Coatesville, PA, with 6- by 6-in. forgings tested at the Oak Ridge National Laboratory, Oak Ridge, TN, for Grade A (heat 79741).

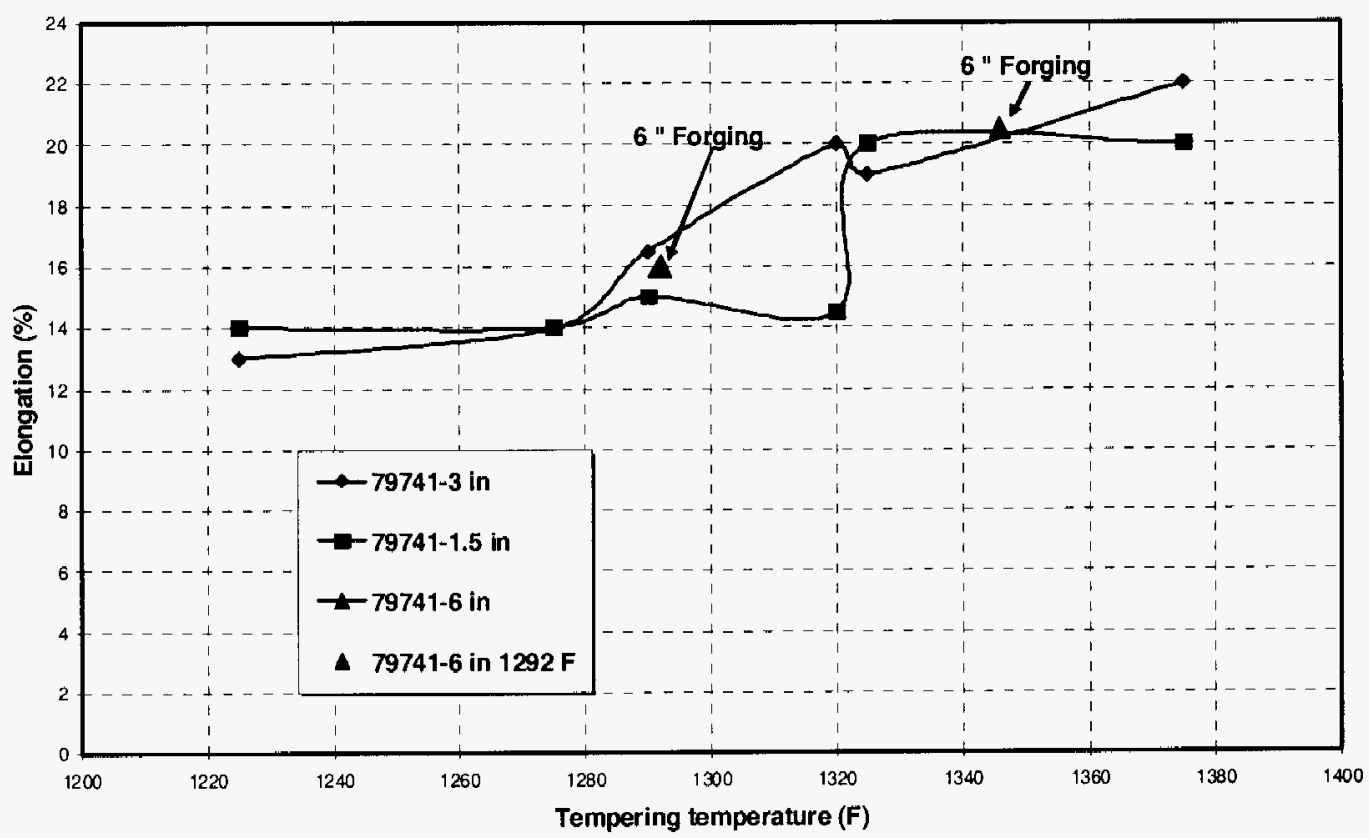

Figure 13. Comparison of tempering response for total elongation at room temperature of 1.5and 3-in.-thick plates tested at ISG Plate with 6- by 6-in. forgings tested at the Oak Ridge National Laboratory for Grade A (heat 79741). 
Table 8. Charpy-impact properties of 1.5- and 3-in.-thick plates of Grade A (79741) and Grade $B(86441)$ as affected by various tempering temperatures

(data from Ken Orie at ISG Plate, Coatesville, PA) Impact Results for $3 \mathrm{Cr}-1.5 \mathrm{~W}-.75 \mathrm{Mo}$ (Ta)

\begin{tabular}{|c|c|c|c|c|c|c|c|c|c|c|c|c|c|c|}
\hline \multirow{2}{*}{$\begin{array}{c}\text { Meit } \\
\text { A8141-1 } \\
(L 7974)\end{array}$} & \multirow{2}{*}{$\begin{array}{c}\text { Ga } \\
1.5^{\prime \prime}\end{array}$} & \multirow{2}{*}{$\begin{array}{c}\text { Temper (F) } \\
1225 \\
1275\end{array}$} & \multicolumn{3}{|c|}{$\begin{array}{l}\text { Energy }(F t-1 \mathrm{bs}) \\
+68 \mathrm{~F}(\mathrm{~L})\end{array}$} & \multicolumn{3}{|c|}{$\begin{array}{c}\text { Energy (Ft-lbs) } \\
+32 F \text { (Long / Trans) }\end{array}$} & \multicolumn{3}{|c|}{ Energy (Ft-1bs) } & \multicolumn{3}{|c|}{ Energy (Ft-lbs) } \\
\hline & & & $\begin{array}{l}8 \\
5\end{array}$ & $\begin{array}{l}8 \\
6\end{array}$ & $\begin{array}{c}9 \\
14\end{array}$ & $\begin{array}{l}5 / 4 \\
8 / 8\end{array}$ & $\begin{array}{c}6 / 4 \\
10 / 10\end{array}$ & $\begin{array}{c}12 / 8 \\
11 / 12\end{array}$ & $\begin{array}{l}5 \\
6\end{array}$ & $\begin{array}{l}11 \\
10\end{array}$ & $\begin{array}{l}11 \\
12\end{array}$ & $\begin{array}{l}3 \\
3\end{array}$ & $\begin{array}{l}5 \\
5\end{array}$ & $\begin{array}{l}7 \\
5\end{array}$ \\
\hline & & $1290(M) B$ & & & & $8 / 11$ & $11 / 14$ & $12 / 14$ & & & & & & \\
\hline & & $1290(M) T$ & & & & $20 / 7$ & $24 / 12$ & $24 / 13$ & & & & & & \\
\hline & & $1320(M) B$ & & & & $105 / 102$ & $107 / 105$ & $108 / 105$ & & & & & & \\
\hline & & $1320(M) T$ & & & & $112 / 111$ & $117 / 111$ & $117 / 116$ & & & & & & \\
\hline & & 1325 & 93 & 96 & 104 & $94 / 59$ & $95 / 69$ & $100 / 71$ & 62 & 82 & 88 & 17 & 33 & 34 \\
\hline & & 1375 & 84 & 89 & 92 & $40 / 24$ & $47 / 26$ & $69 / 34$ & 44 & 49 & 61 & 26 & 30 & 32 \\
\hline A8 142-1 & $1.5^{\prime \prime}$ & 1225 & 5 & 6 & 17 & $8 / 3$ & $9 / 9$ & $11 / 11$ & 2 & 3 & 13 & 5 & 6 & 7 \\
\hline$(\mathrm{T} a)$ & & 1275 & 6 & 7 & 24 & $6 / 6$ & $14 / 8$ & $18 / 14$ & 4 & 5 & 8 & 1 & 3 & 5 \\
\hline (L8644 & & $1290(M) B$ & & & & $7 / 8$ & $19 / 12$ & $25 / 17$ & & & & & & \\
\hline & & $1290(M) T$ & & & & $10 / 6$ & $11 / 6$ & $23 / 15$ & & & & & & \\
\hline & & $1320(\mathrm{M}) \mathrm{B}$ & & & & $38 / 33$ & $39 / 34$ & $38 / 39$ & & & & & & \\
\hline & & $1320(M) T$ & & & & $66 / 43$ & $65 / 43$ & $60 / 45$ & & & & & & \\
\hline & & 1325 & 69 & 86 & 94 & $83 / 57$ & $93 / 62$ & $96 / 86$ & 64 & 74 & 88 & 4 & 5 & 13 \\
\hline & & 1375 & 4 & 7 & 11 & $63 / n a$ & $67 / \mathrm{na}$ & $70 /$ na & 7 & 10 & 38 & 3 & 4 & 5 \\
\hline & & $1380(M) B$ & & & & $193 / 123$ & $193 / 131$ & $195 / 131$ & & & & & & \\
\hline & & $1380(\mathrm{M}) \mathrm{T}$ & & & & $149 / 127$ & $167 / 152$ & $184 / 157$ & & & & & & \\
\hline A8141-2 & $3^{\prime \prime}$ & 1225 & 4 & 7 & 9 & $6 / 5$ & $8 / 6$ & $17 / 9$ & 3 & 4 & 4 & 2 & 2 & 3 \\
\hline$(L 7974)$ & & 1275 & 7 & 8 & 13 & $4 / 5$ & $6 / 7$ & $8 / 9$ & 3 & 5 & 5 & 4 & 4 & 5 \\
\hline & & $1290(M) B$ & & & & $6 / 8$ & $18 / 10$ & $25 / 20$ & & & & & & \\
\hline & & $1290(M) T$ & & & & $10 / 6$ & $11 / 10$ & $13 / 13$ & & & & & & \\
\hline & & $1320(M) B$ & & & & $128 / 121$ & $126 / 122$ & $129 / 125$ & & & & & & \\
\hline & & $1320(M) T$ & & & & $110 / 100$ & $113 / 107$ & $121 / 104$ & & & & & & \\
\hline & & 1325 & 81 & 86 & 88 & $63 / 19$ & $69 / 23$ & $75 / 25$ & 26 & 29 & 42 & 6 & 6 & 8 \\
\hline & & 1375 & 97 & 99 & 114 & $109 / \mathrm{na}$ & $115 / \mathrm{na}$ & $118 / \mathrm{na}$ & 43 & 48 & 59 & 20 & 28 & 36 \\
\hline A8142.2 & 3" & 1225 & 9 & 21 & 57 & $5 / 13$ & $16 / 16$ & $19 / 29$ & 3 & 6 & 6 & 4 & 5 & 6 \\
\hline ( $\mathrm{Ta}$ ) & & 1275 & 4 & 11 & 12 & $6 / 7$ & $6 / 9$ & $7 / 9$ & 4 & 6 & 8 & 5 & 5 & 7 \\
\hline (L8644) & & $1290(\mathrm{M}) \mathrm{B}$ & & & & na & na & na & & & & & & \\
\hline & & $1290(M) T$ & & & & na & na & na & & & & & & \\
\hline & & $1320(M) B$ & & & & $69 / 63$ & $65 / 64$ & $61 / 66$ & & & & & & \\
\hline & & $1320(M) T$ & & & & $96 / 85$ & $98 / 88$ & $103 / 84$ & & & & & & \\
\hline & & 1325 & 69 & 76 & 93 & $75 / 35$ & $82 / 35$ & $96 / 40$ & 27 & 33 & 39 & 8 & 11 & 18 \\
\hline & & 1375 & 105 & 120 & 151 & $111 / 71$ & $118 / 98$ & $121 / 102$ & 73 & 67 & 137 & 76 & 86 & 86 \\
\hline
\end{tabular}

The plot in Fig. 14 shows that the Charpy-impact energy at $32^{\circ} \mathrm{F}$ increases with increasing LMP, which reflects an increase in temperature, time, or both. Ultimate tensile levels of 120 and 140 ksi are also shown in this figure. Based on Fig. 14, plates of Grades A and B, tempered for 120ksi tensile strength, will result in Charpy-impact values at $32^{\circ} \mathrm{F}$ of $\sim 40$ to $110 \mathrm{ft}-\mathrm{lb}$. The LMP corresponding to a 120-ksi ultimate tensile strength and acceptable Charpy values gives a target tempering temperature of $\sim 1345^{\circ} \mathrm{F}$. Thus, a temperature of $1345^{\circ} \mathrm{F}\left(730^{\circ} \mathrm{C}\right)$ was chosen as the tempering temperature for both Grades $\mathrm{A}$ and $\mathrm{B}$ for all of the remaining studies in this project.

In a separate study, we investigated the effect of replacing $3 \mathrm{wt} \% \mathrm{~W}$ with $1.5 \mathrm{~W}+0.75$ Mo on Charpy-impact properties of Grade A (Ta-free alloy). Data from this study is shown in Fig. 15. The detailed composition of alloys containing W and W + Mo is also included in this figure. Note that for $1.5 \mathrm{~W}+0.75$ Mo alloys (heat 18608 and 18609 ), the $C$ contents were 0.075 and $0.14 \mathrm{wt} \%$. All of the data was generated for $5 / 8$-in.-thick plates, normalized at $1100^{\circ} \mathrm{C}$ and tempered at $700^{\circ} \mathrm{C}$. It can be seen that the Charpy-impact data for $3 \mathrm{~W}$ (heat 10293) and $1.5 \mathrm{~W}+$ $0.75 \mathrm{Mo}$ (heat 18609 ) are very similar. Furthermore, the lower $\mathrm{C}$ of 0.075 results in expected improvement in Charpy-impact properties. 
3Cr-1.5W-.75Mo (Ta) IMPACT CURVE (1.5")

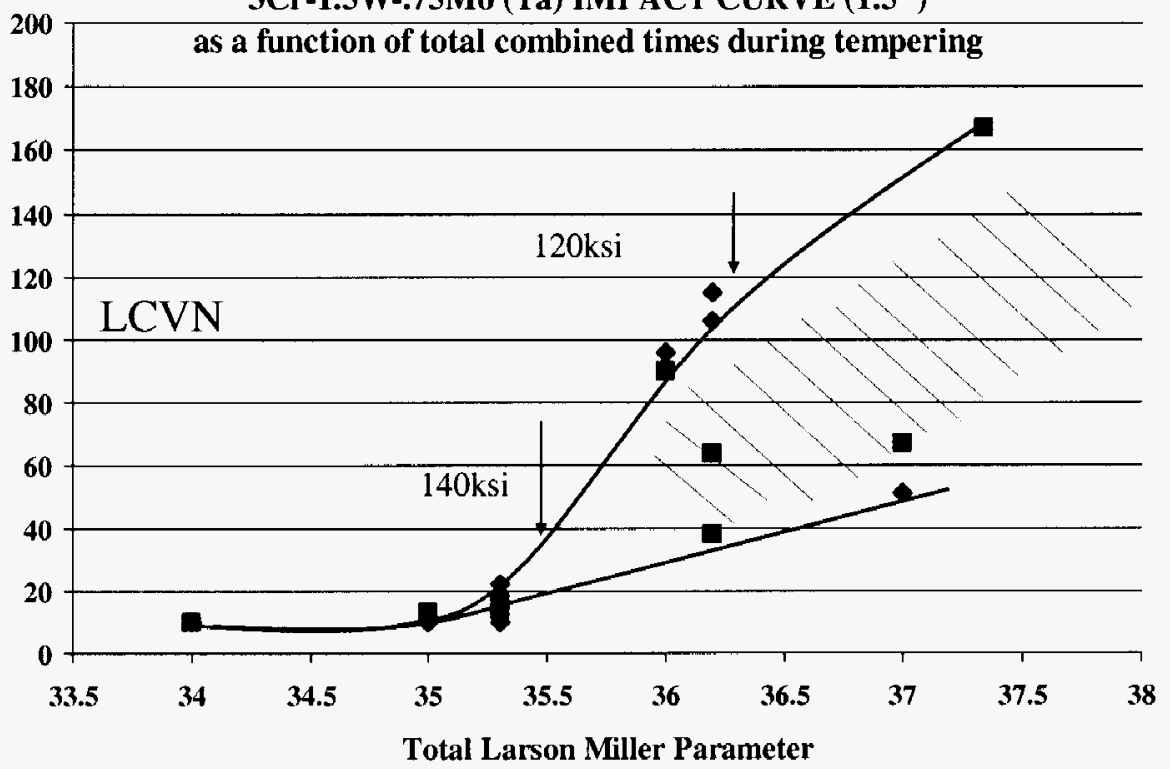

A8141-1.5"

- A8142(Ta)-1.5"

Figure 14. Charpy-impact data at $32^{\circ} \mathrm{F}$ for 1.5 -in.-thick plates of Grades $\mathrm{A}$ and $\mathrm{B}$ as a function of Larson-Miller parameter.

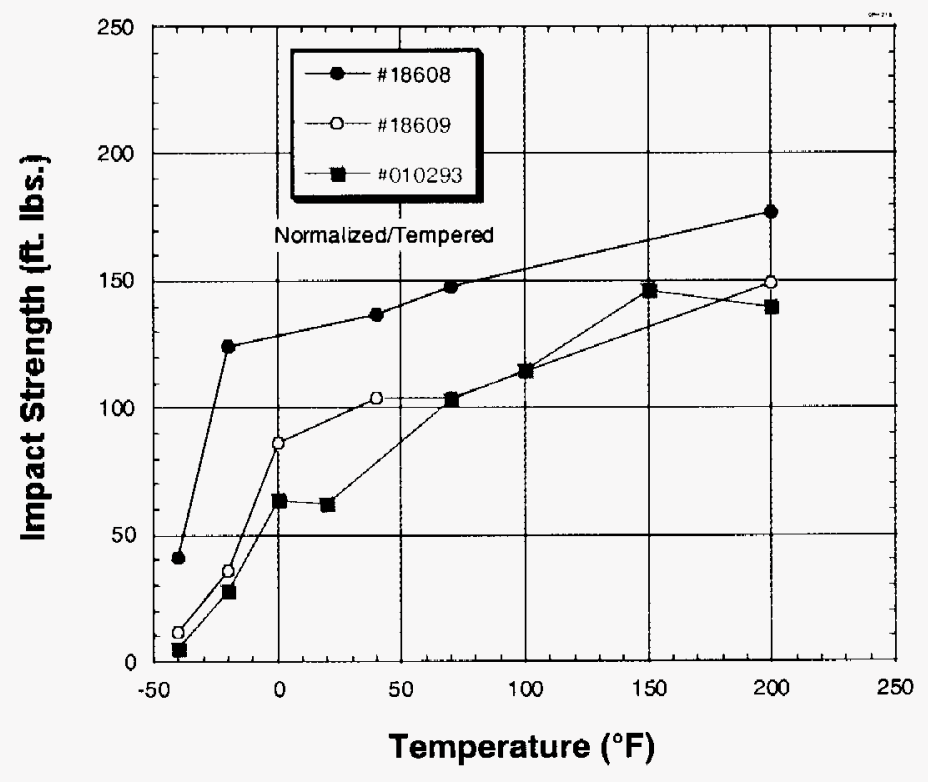

\begin{tabular}{|cccc|}
\hline \multicolumn{4}{|c|}{ Chemicd Composition } \\
\hline Carbon & $\# 18608$ & $\# 18609$ & $\# 010293$ \\
Manganese & 0.075 & 0.14 & 0.10 \\
Phosphorus & 0.006 & 0.480 & 0.39 \\
Sulfur & 0.01 & 0.007 & 0.01 \\
Silicon & 0.21 & 0.21 & 0.004 \\
Nickel & $<0.01$ & $<0.01$ & 0.01 \\
Chromium & 3.01 & 3.02 & 3.04 \\
Molybdenum & 0.75 & 0.76 & 0.01 \\
Vonodum & 0.24 & 0.24 & 0.21 \\
Columbium & 0.001 & 0.002 & 0.003 \\
Titonium & 0.003 & 0.003 & 0.001 \\
Cobat & 0.007 & 0.006 & 0.005 \\
Copper & $<0.01$ & $<0.01$ & 0.01 \\
Alumnium & 0.004 & 0.004 & 0.003 \\
Boron & 0.001 & $<0.001$ & 0.001 \\
T ungsten & 1.54 & 1.52 & 3.05 \\
Arsenic & 0.002 & 0.001 & 0.001 \\
Tin & 0.003 & 0.002 & 0.003 \\
Ziroonium & $<0.001$ & 0.001 & 0.001 \\
Nitrogen & $<0.001$ & $<0.001$ & 0.004 \\
Oxygen & 0.001 & 0.004 & 0.005 \\
Tantalum & $<0.01$ & $<0.01$ & \\
\hline
\end{tabular}

Figure 15. Comparison of Charpy-impact data for Fe-3Cr-3W alloy (heat 010293) with alloys containing $1.5 \mathrm{~W}+0.75 \mathrm{Mo}$ (heats 18608 and 18609 ) as opposed to $3 \mathrm{~W}$. All plates were tested after normalizing at $1100^{\circ} \mathrm{C}$ and tempering at $700^{\circ} \mathrm{C}$. 


\subsubsection{Mechanical Properties}

The commercial heats of both Grades A and B were subjected to mechanical properties tests in support of developing the data base for approvals by ASTM and ASME Code. Although both grades were tested for tensile and impact properties, creep testing of Grade B was limited because of lack of funding to develop the needed data on both grades. The long-term creep testing is continuing on Grade A in order to meet the test time requirement of $10,000 \mathrm{~h}$ by ASME Code. The data plots and observations are presented here.

\subsubsection{Tensile Properties}

The yield, ultimate tensile, total elongation, and reduction of area for three commercial heats of each of the Grades A and B are plotted in Figs. 16 through 23. All tests were on specimens taken from 6- by 6-in. forgings and were normalized and tempered for $1 \mathrm{~h}$ at 1100 and $730^{\circ} \mathrm{C}$, respectively. General observations from these figures are:

1. There is some variation in properties between the three heats of each alloy.

2. Good combination of strength and ductility are noted for both grades across the entire test temperature range. Only one data point at $600^{\circ} \mathrm{F}$ for one of the heats showed unusually low ductility.

3. Grade B showed lower tensile properties than Grade A across the entire test temperature. There is no obvious explanation for this behavior because as seen later, Grade B with 0.1 wt \% Ta did show higher creep strength.

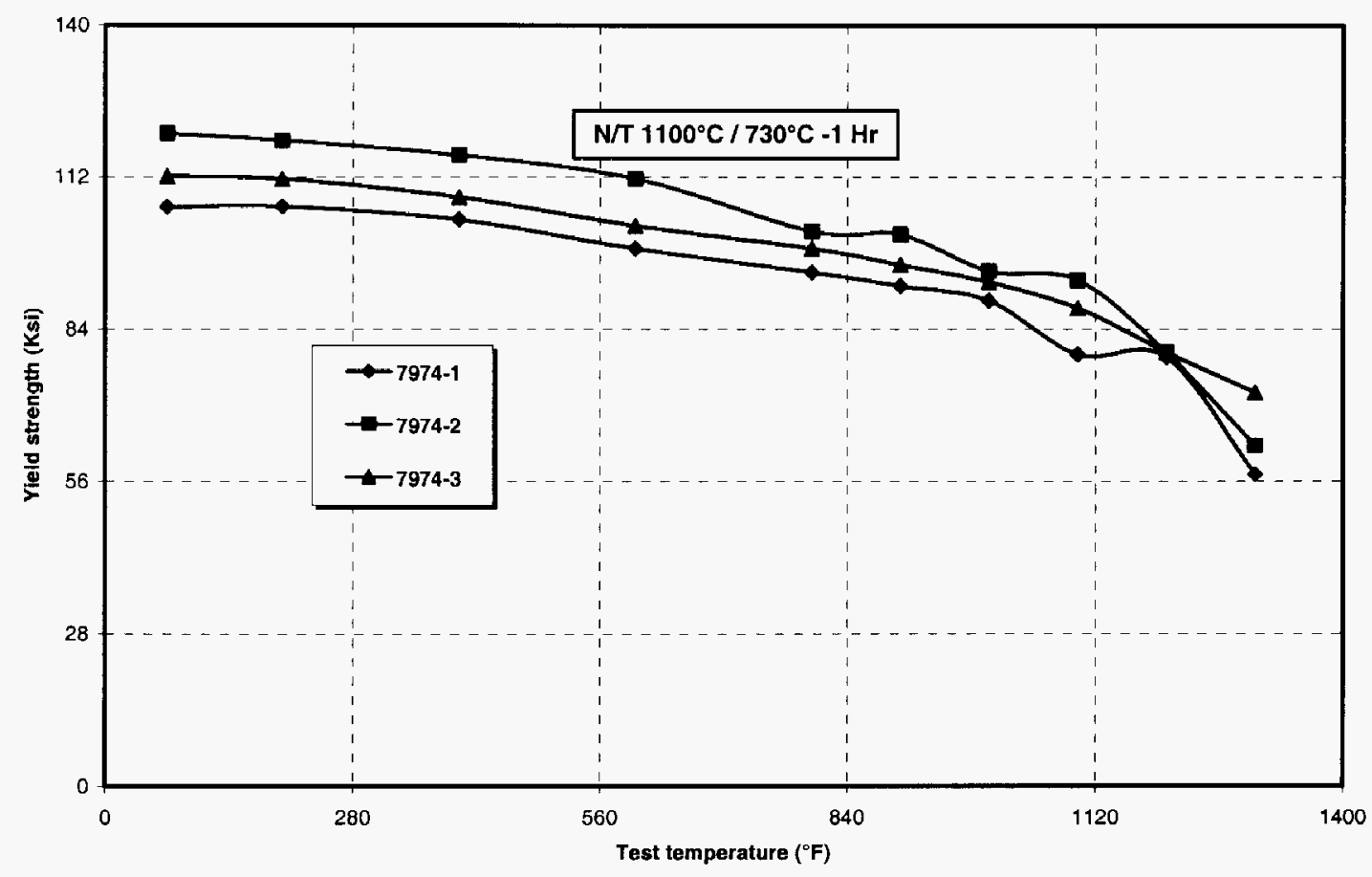

Figure 16. Yield strength as a function of test temperature for three commercial heats of Grade A. 


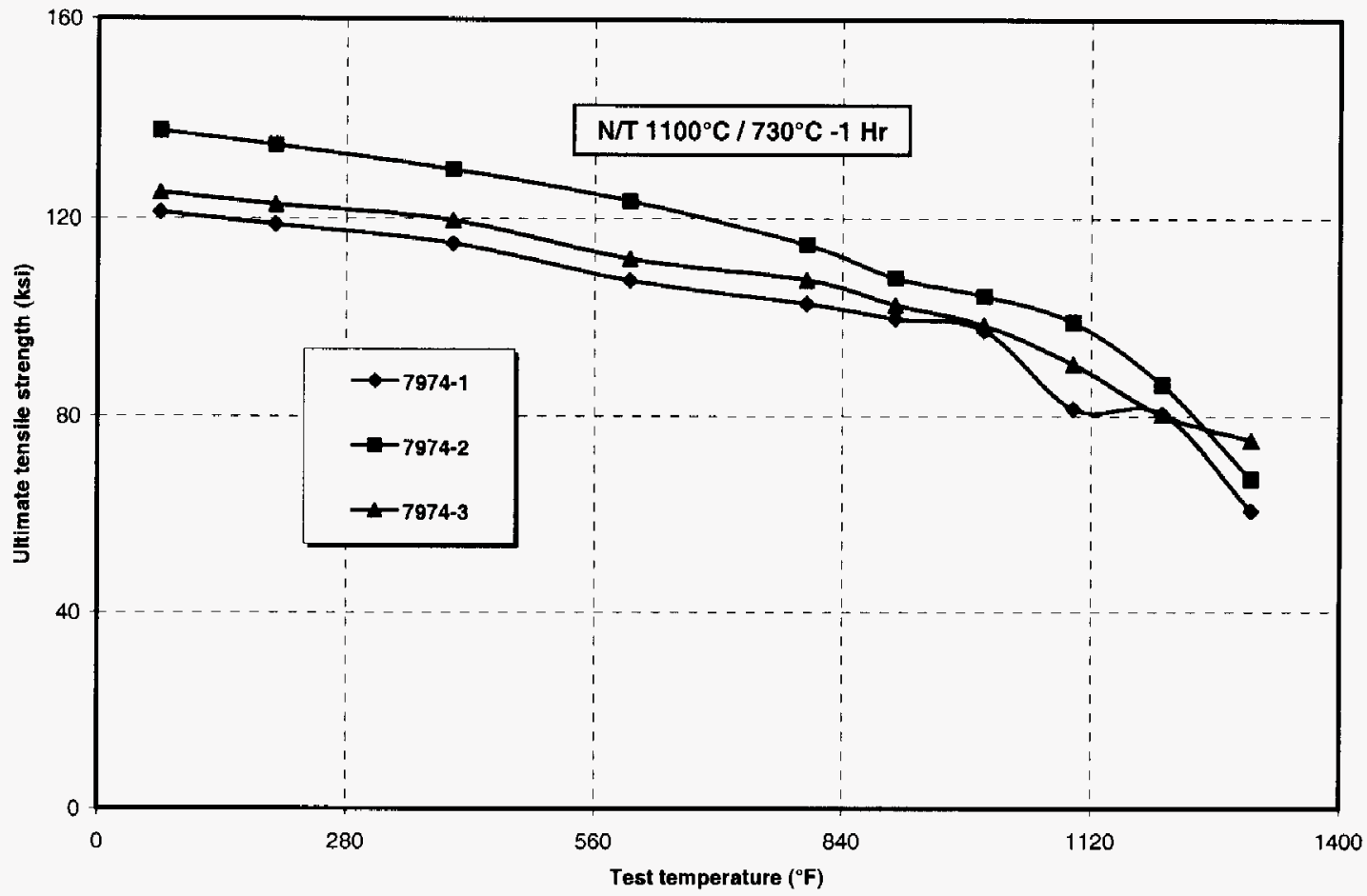

Figure 17. Ultimate tensile strength as a function of test temperature for three commercial heats of Grade A.

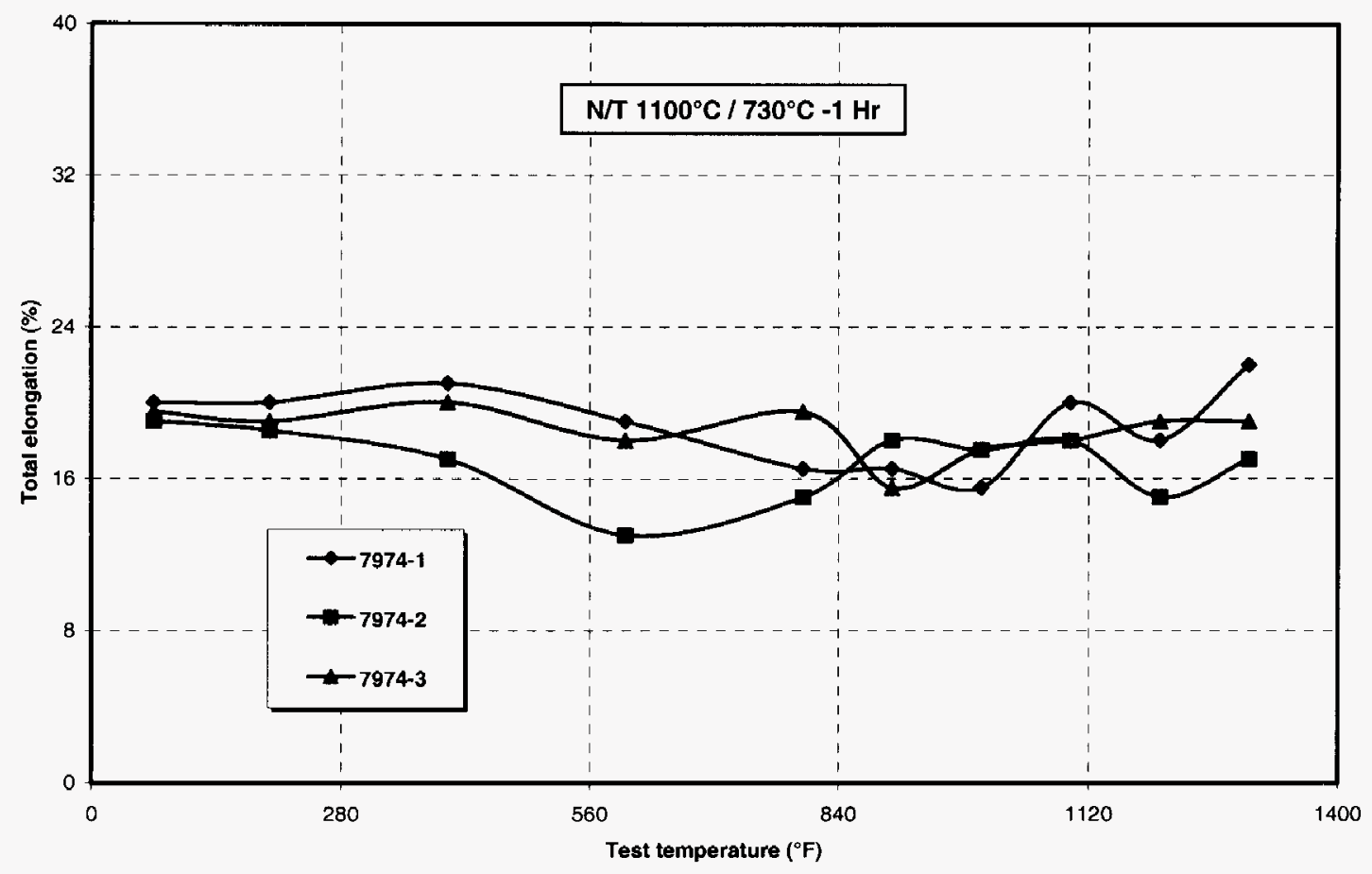

Figure 18. Total elongation as a function of test temperature for three commercial heats of Grade A. 


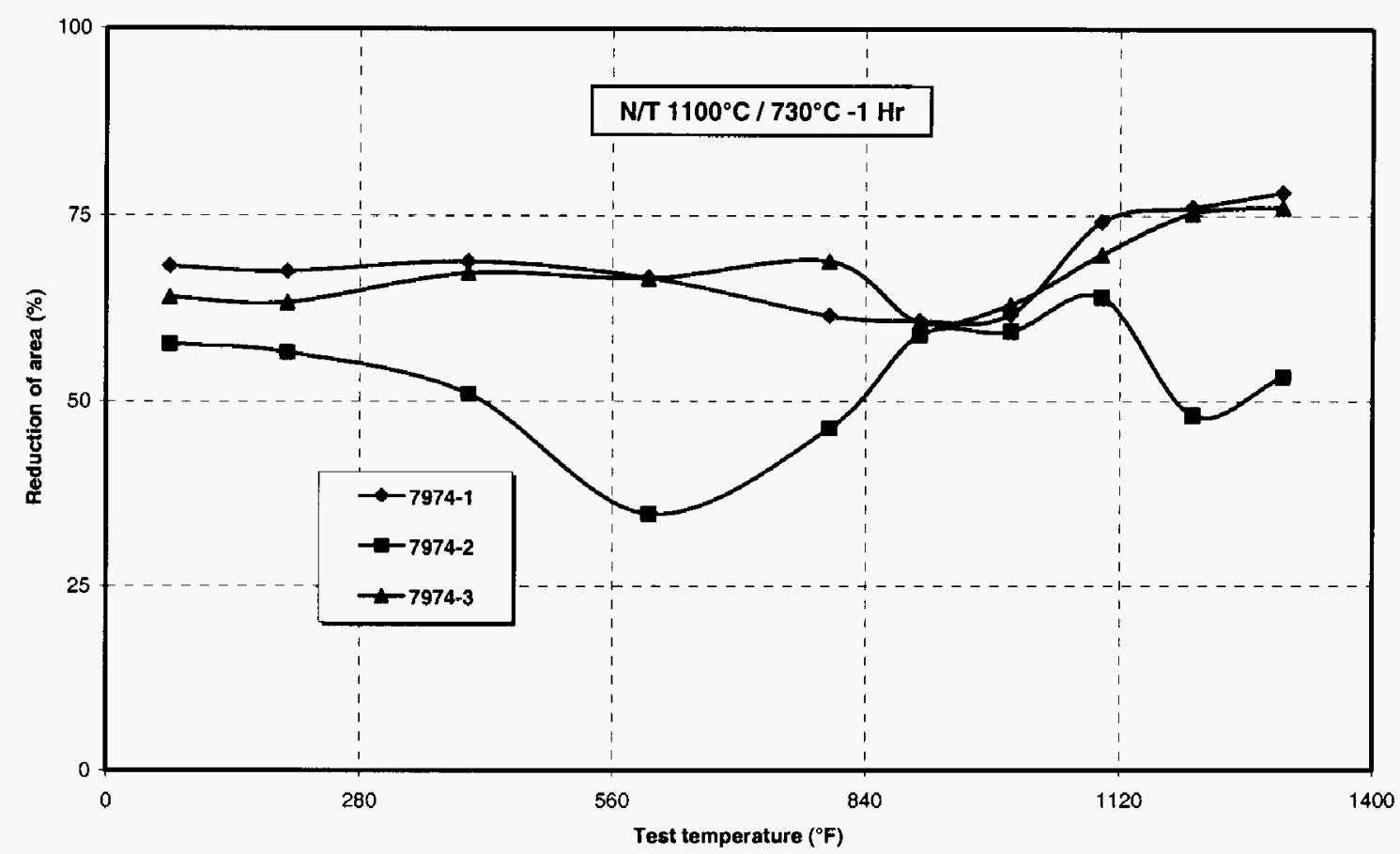

Figure 19. Reduction of area as a function of test temperature for three commercial heats of Grade A.

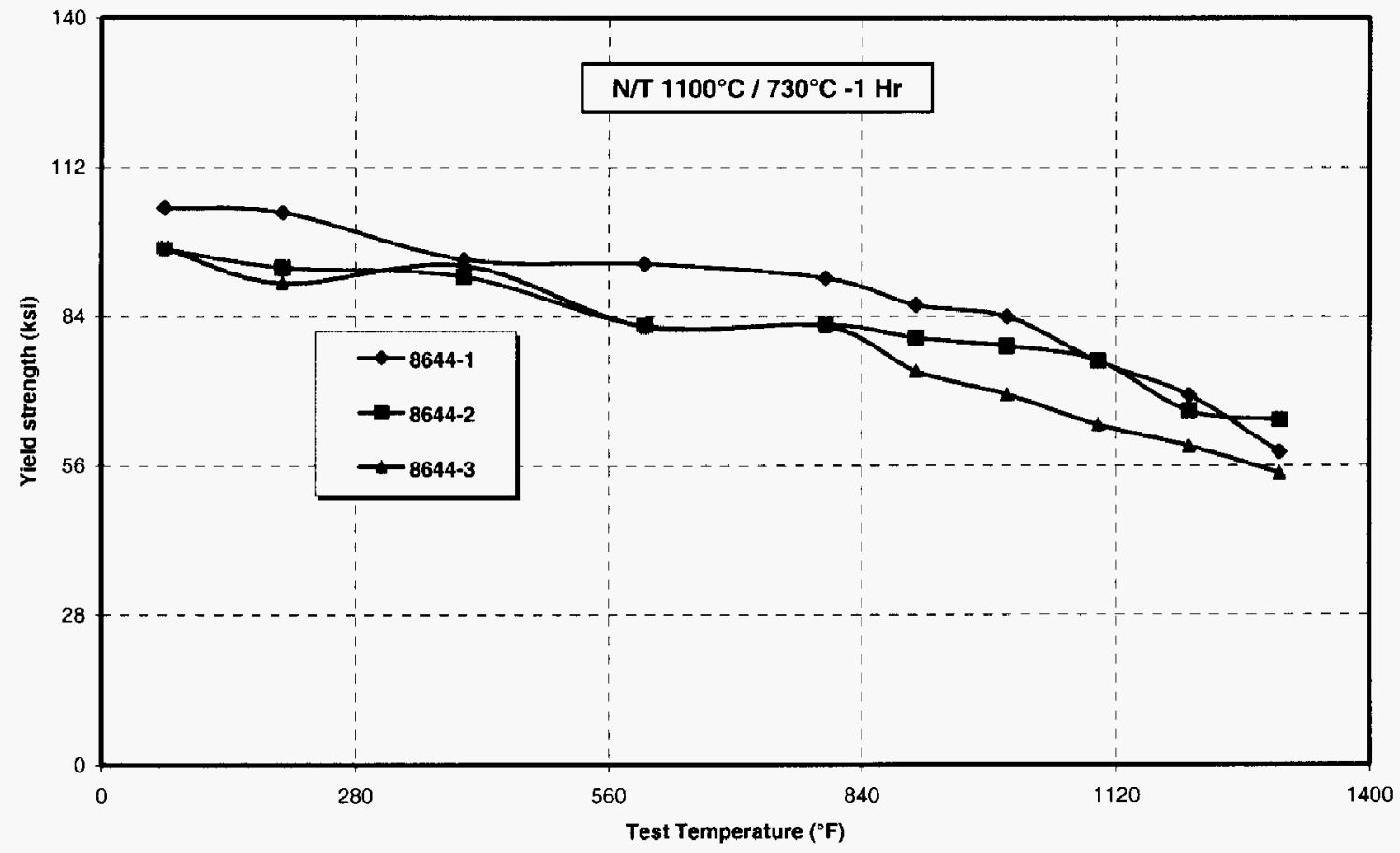

Figure 20. Yield strength as a function of test temperature for three commercial heats of Grade B. 


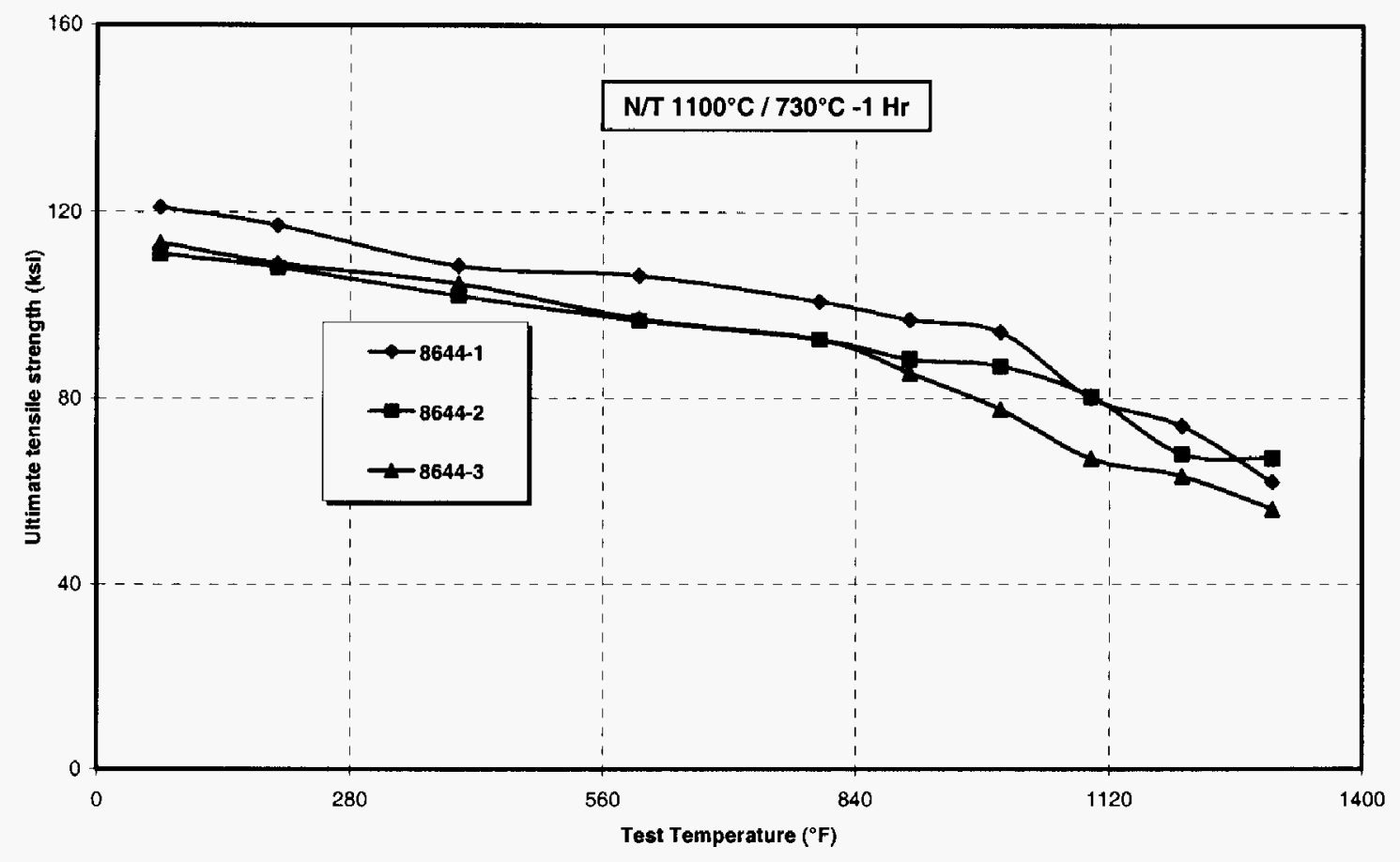

Figure 21. Ultimate tensile strength as a function of test temperature for three commercial heats of Grade B.

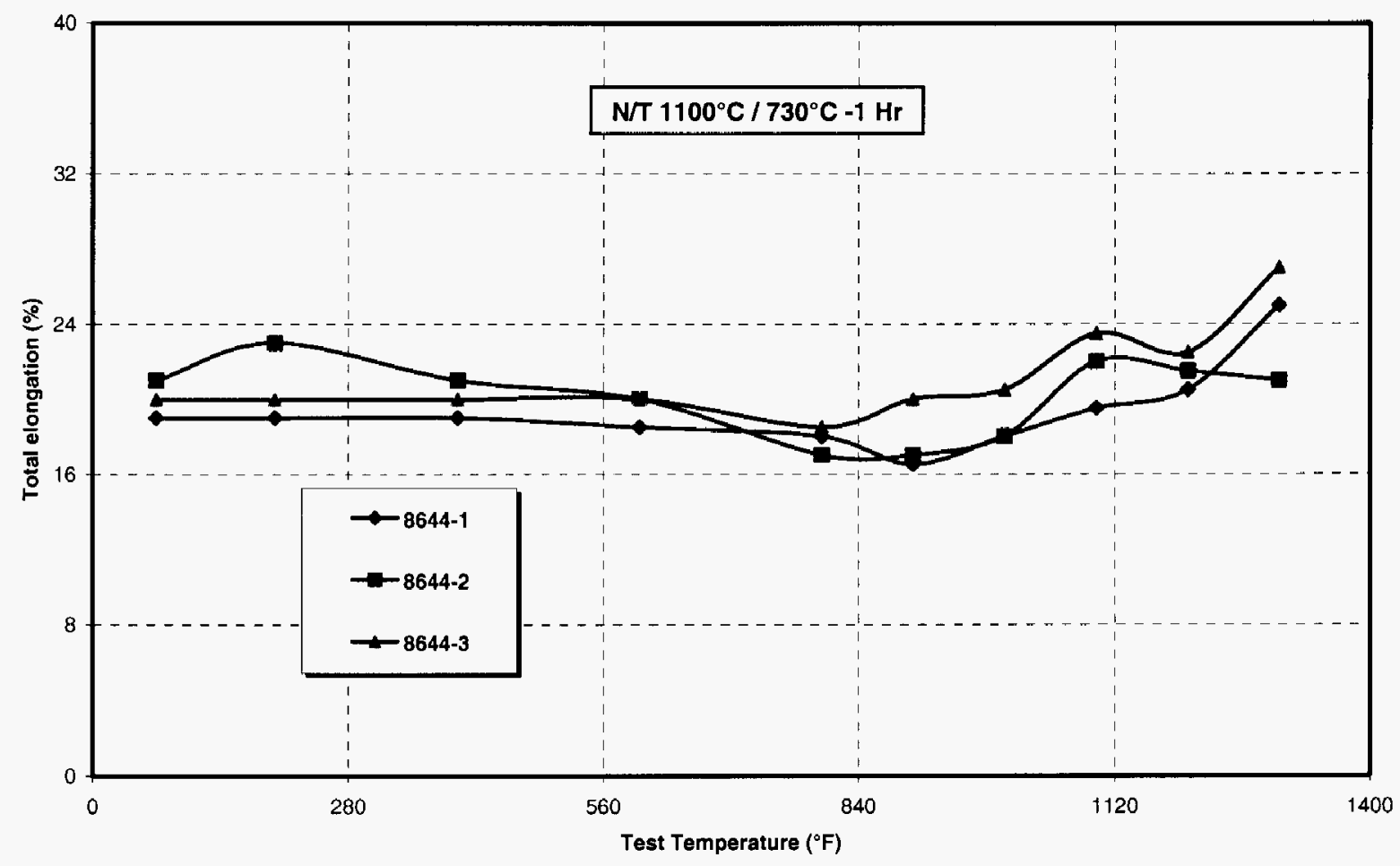

Figure 22. Total elongation as a function of test temperature for three commercial heats of Grade B. 


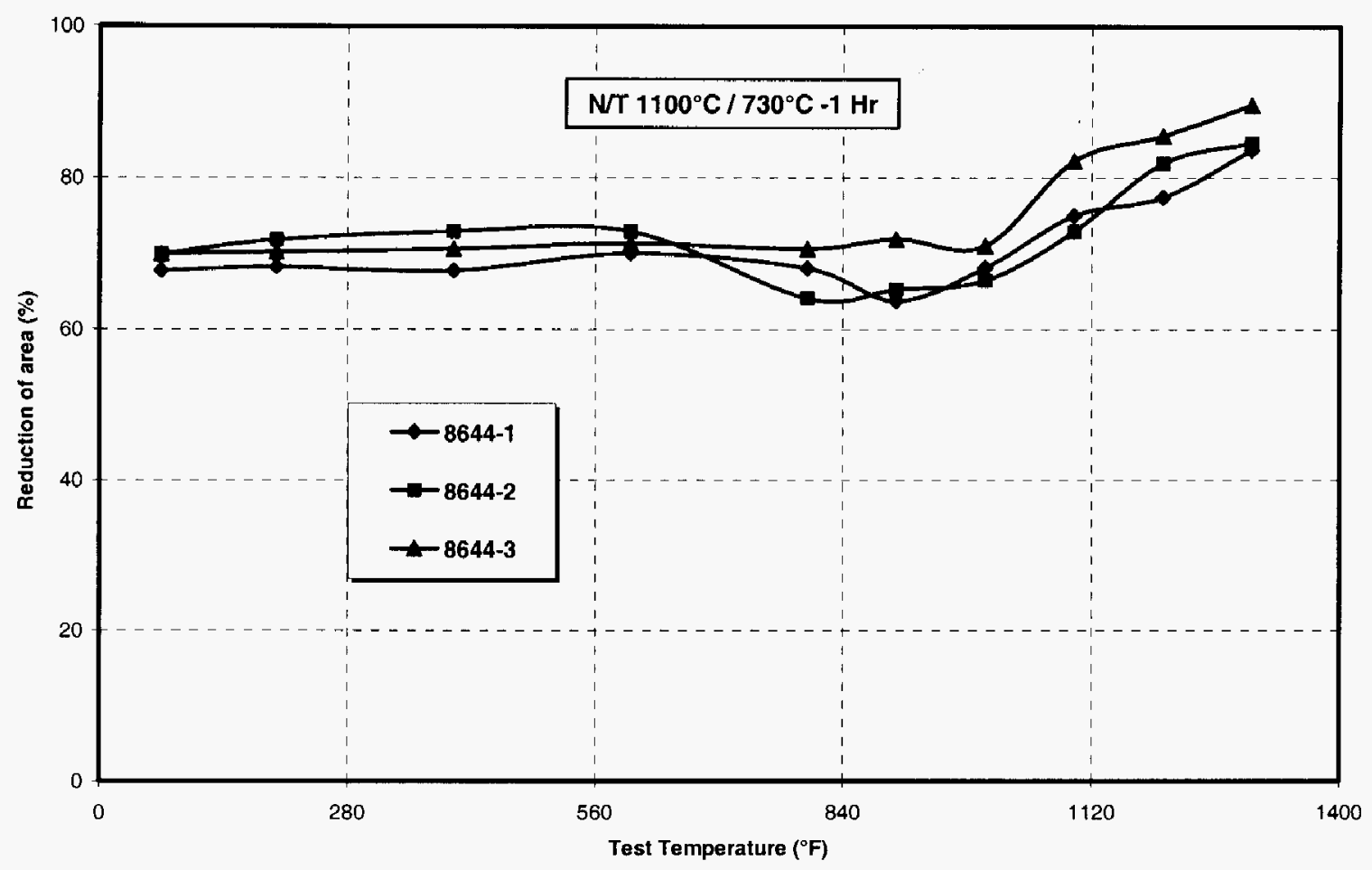

Figure 23. Reduction of area as a function of test temperature for three commercial heats of Grade B.

Tensile properties of commercially melted, electric furnace heats of Grades A and B (heats 79741 and 86441) are compared with the properties of commercial and near-commercial alloys (T22, T23, and T24) in Figs. 24 through 26. These figures show the following:

1. Yield strength values of both Grades A and B are over 20 ksi higher across the entire test temperature range than the highest strength alloy, T23. This is especially significant at $1200^{\circ} \mathrm{F}$, where yield strength values of Grades $\mathrm{A}$ and $\mathrm{B}$ are nearly $75 \%$ higher than those for T23. Both grades have nearly twice the yield strength of the commercial grade of $2.25 \mathrm{Cr}$ 1 Mo steel (T22) for the entire use temperature of T22.

2. Ultimate tensile strength values of Grades $A$ and $B$ are also over 20 ksi higher than T23 across the entire test temperature range. As compared to $2.25 \mathrm{Cr}-1 \mathrm{Mo}$ steel, Grades A and B are nearly 1.5 times stronger for the entire use temperature range of $2.25 \mathrm{Cr}-1 \mathrm{Mo}$ steel (T23).

3. Total elongation values of Grades A and B are little lower than T22 and T24. However, these values are generally acceptable for most of the component forming and equipment fabrication needs.

Data in Figs. 23 through 26 have clearly shown that the new grades have met the tensile strength objectives set for them in this project. 


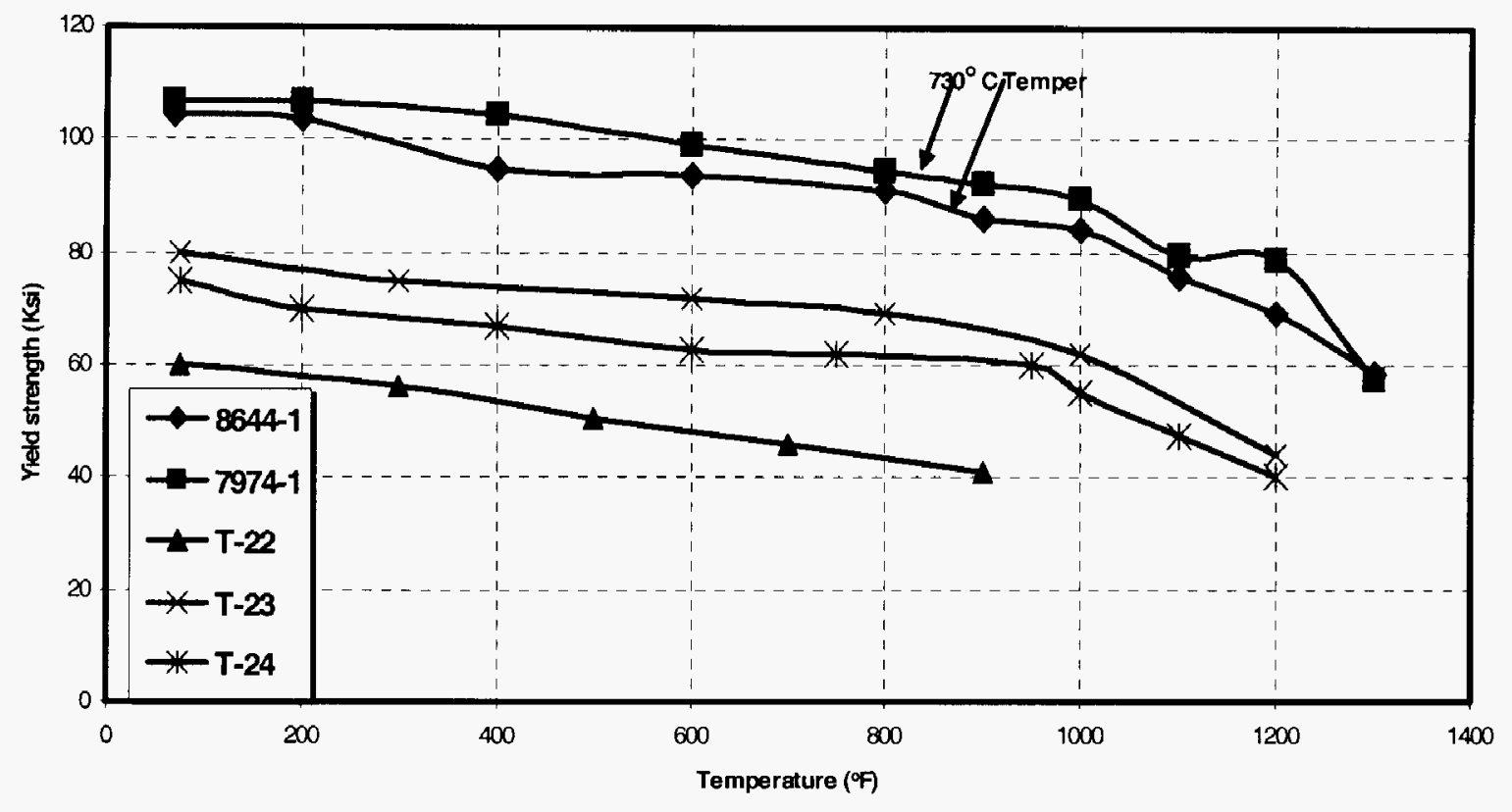

Figure 24. Comparison of yield strength of Grades A and B as compared to commercial and near-commercial grades of steel in a similar chemical analysis range.

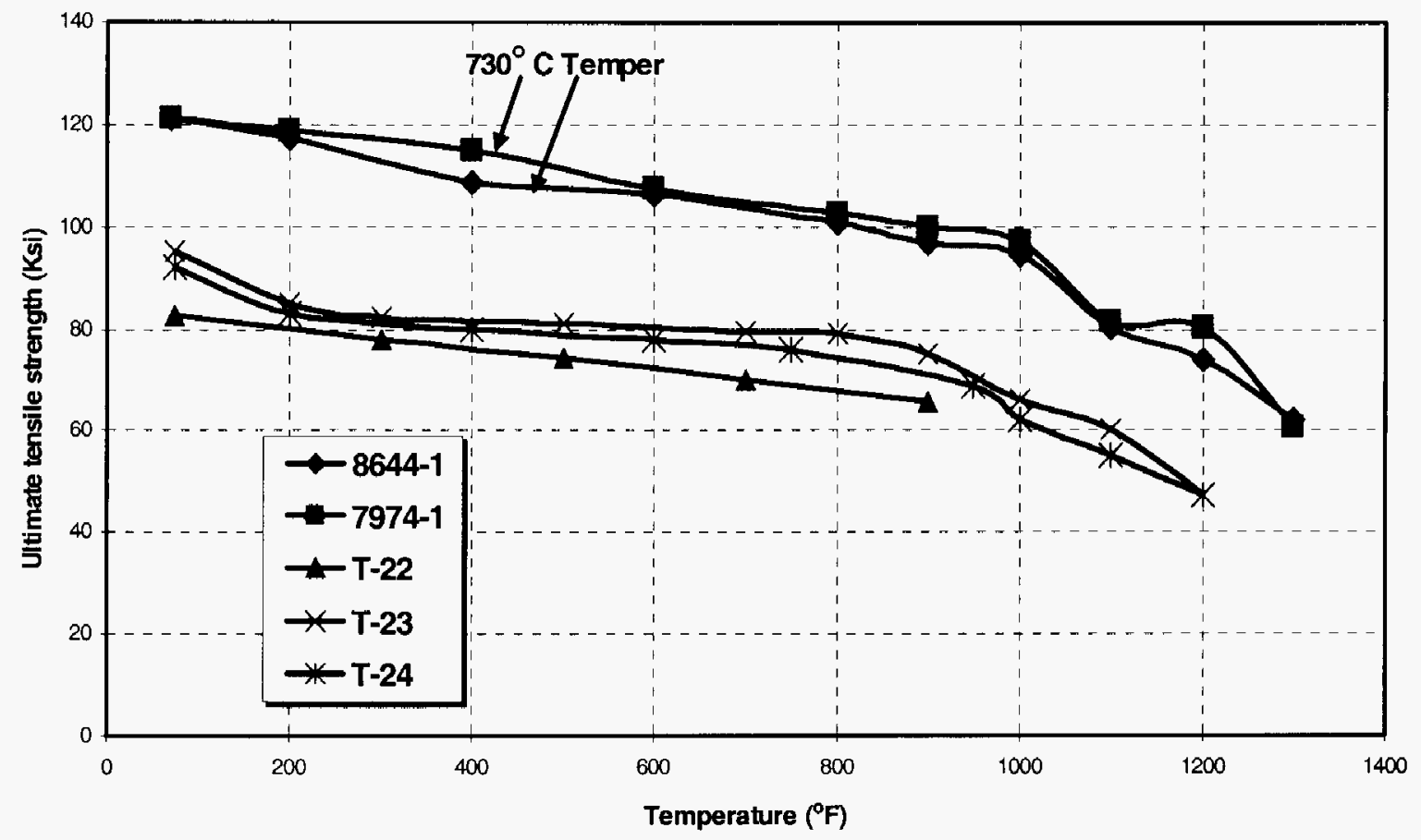

Figure 25. Comparison of ultimate tensile strength of Grades A and B as compared to commercial and near-commercial grades of steel in a similar chemical analysis range. 


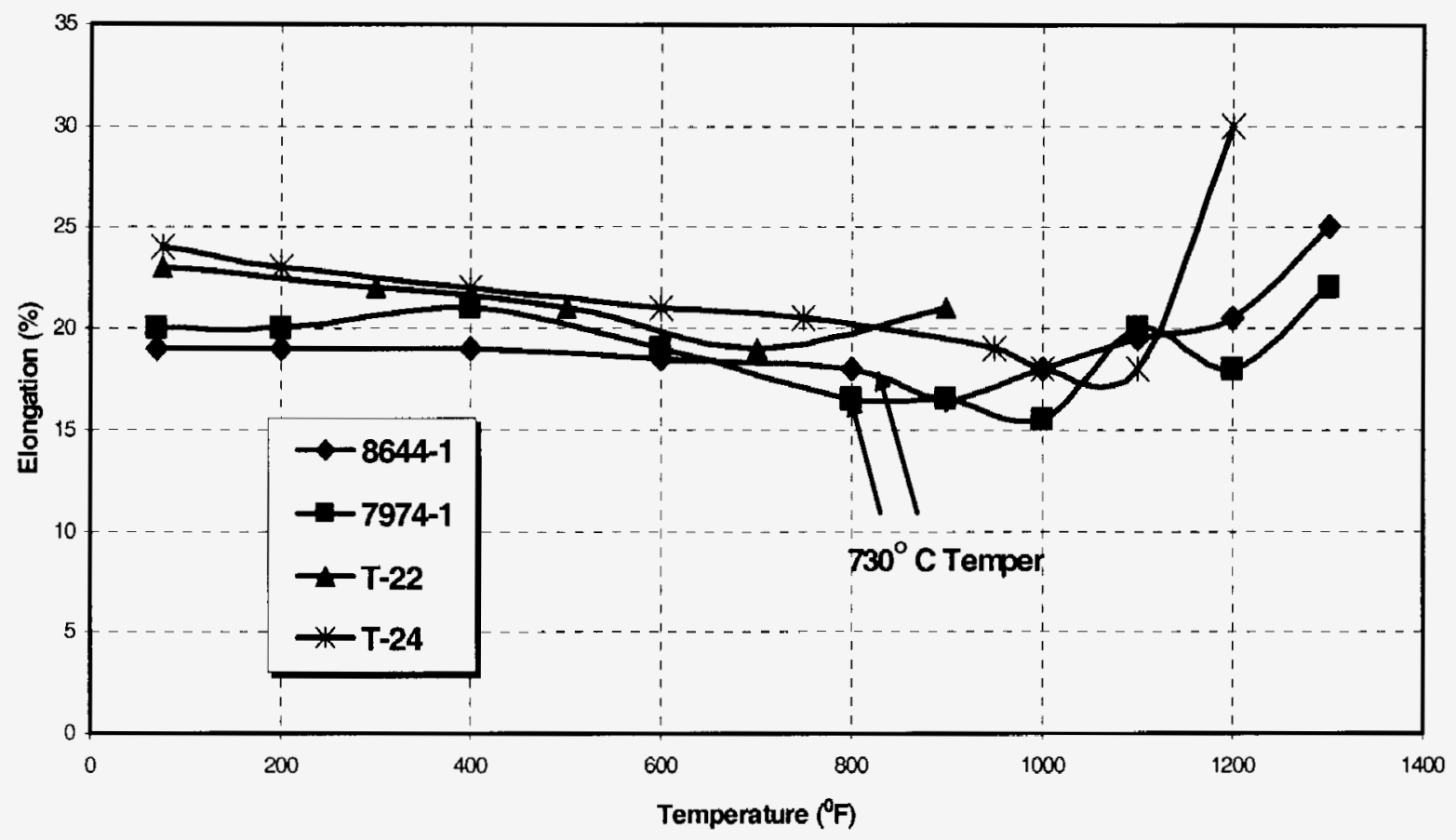

Figure 26. Comparison of total elongation of Grades A and B as compared to commercial and near-commercial grades of steel in a similar chemical analysis range.

\subsubsection{Charpy-Impact Properties}

Charpy-impact properties of electric-furnace-melted commercial heats of Grades A and B are plotted in Fig. 27. These data are for samples taken from the 6- by 6-in. forgings. These plots show the following:

1. Impact properties in the longitudinal orientation are superior to that in the transverse orientation.

2. Impact properties for Ta containing Grade B (heat 86441 ) are slightly poorer than Ta-free Grade A (heat 79741).

3. The impact properties for forgings of both Grades A and B are quite impressive with $15 \mathrm{ft}-\mathrm{lb}$ ductile-brittle-transition temperature (DBTT) of -20 to $-40^{\circ} \mathrm{F}$. The corresponding DBTT for 15 mil lateral expansion is also -20 to $-40^{\circ} \mathrm{F}$.

Charpy-impact energy data for the 1-in.-thick hot-rolled plate of Grade A (heat 79741) is plotted in Fig. 28. The plate data for Grade $\mathrm{A}$ is compared with the data on the 6- by 6-in. forgings of Grades A and B in Fig. 29. These data show some improvement in Charpy-impact properties of the plate as opposed to the forgings.

Data in Figs. 27 through 29 also show that Grades A and B developed in this project have upper shelf Charpy-impact values of $\sim 100 \mathrm{ft}$ and DBTT of -20 to $-40^{\circ} \mathrm{F}$. Both of these values have met or exceeded the objectives of this project of $100 \mathrm{ft}-\mathrm{lb}$ of upper shelf energy and a DBTT of $-10^{\circ} \mathrm{F}$. 

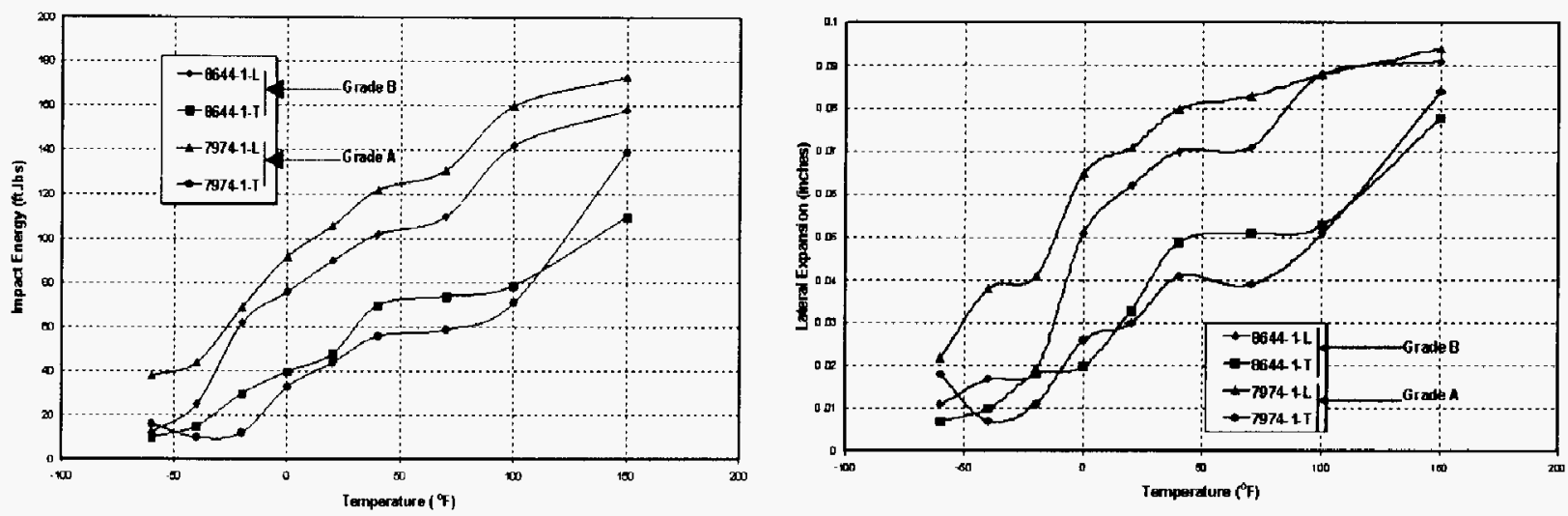

Figure 27. Charpy-impact energy and lateral expansion data for 6- by 6-in. forgings of Grades A and $B$ (heats 79741 and 86441). Both grades were tested in the normalized and tempered conditions $\left(1100\right.$ and $\left.730^{\circ} \mathrm{C}\right)$.

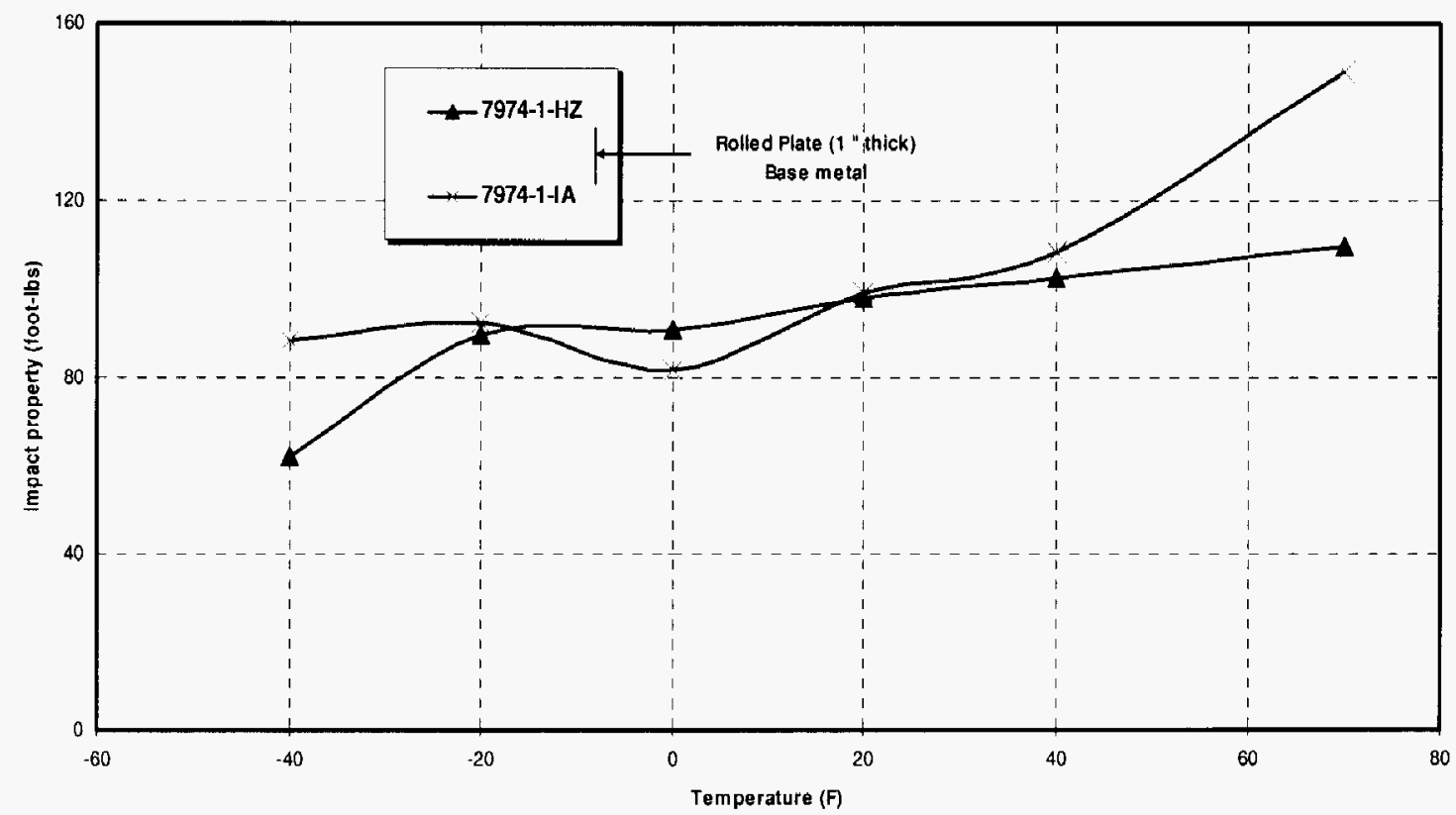

Figure 28. Charpy-impact energy data for 1-in.-thick plate of Grade A (heat 79741). Two different plates designated as $79741-\mathrm{HZ}$ and 79741-IA were tested. All data are for plates in the normalized and tempered conditions $\left(1100\right.$ and $\left.730^{\circ} \mathrm{C}\right)$. 


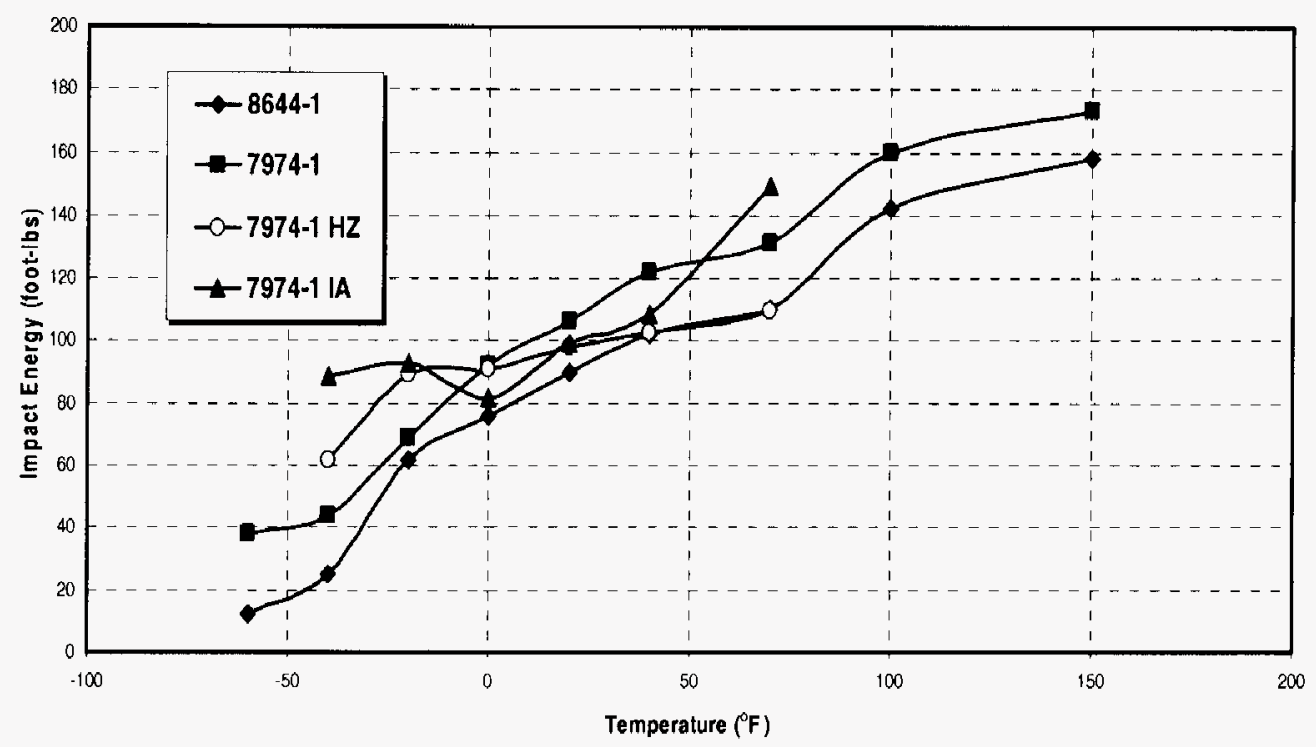

Figure 29. Comparison of Charpy-impact properties of 1-in.-thick plate of Grade A with 6- by 6in. forgings of Grades A and B. Both plate and forgings were tested in the normalized and tempered conditions $\left(1100\right.$ and $\left.730^{\circ} \mathrm{C}\right)$.

\subsubsection{Creep Properties}

Creep tests were conducted on commercial heats of both A and B. As stated earlier, creep testing on Grade A is still continuing, and no tests on Grade B are continuing because of lack of funds. The isothermal plots of creep-rupture data at $900,950,1000,1100,1150$, and $1200^{\circ} \mathrm{F}$ are shown in Figs. 30 through 35. All of the data shown in these figures were developed for a tempering temperature of $730^{\circ} \mathrm{C}$. A limited set of data was also generated for both $\mathrm{A}$ and $\mathrm{B}$ after tempering temperature of $700^{\circ} \mathrm{C}$. These data are plotted in Figs. 36 and 37 for A and B.

The most commonly accepted method for analyzing the creep data for setting the design allowable is LMP. This parameter compresses the data at various test temperatures into a single line or curve. Plots are commonly used to set the $10^{5} \mathrm{~h}$ creep-rupture strength values for ASME Code design stresses. The LMP for creep-rupture data is given as

$$
\mathrm{LMP}=\mathrm{T}\left(20+\log \mathrm{t}_{\mathrm{r}}\right)
$$

where $\mathrm{T}=$ test temperature in $\mathrm{K}$ and $\mathrm{t}_{\mathrm{r}}=$ time to rupture in $\mathrm{h}$.

The LMP plot for all of the creep-rupture data on three commercial heats of Grade A is shown in Fig. 38 which shows a good collapse of data for temperatures in the range of 900 to $1200^{\circ} \mathrm{F}$. However, it appears that data are best described by two lines: one for high stress region and one for low stress region. The transition from high to low stress region appears to occur at approximately $50 \mathrm{ksi}$. The LMP plot for A is compared with the average values reported for the commercially available alloy T23 in Fig. 39. It can be seen from this figure that the creeprupture strength values for Grade A developed in this project exceed the T23 values up to $10^{5} \mathrm{~h}$ at $1100^{\circ} \mathrm{F}$. At higher temperatures or longer times, the A values match that of $\mathrm{T} 23$. 


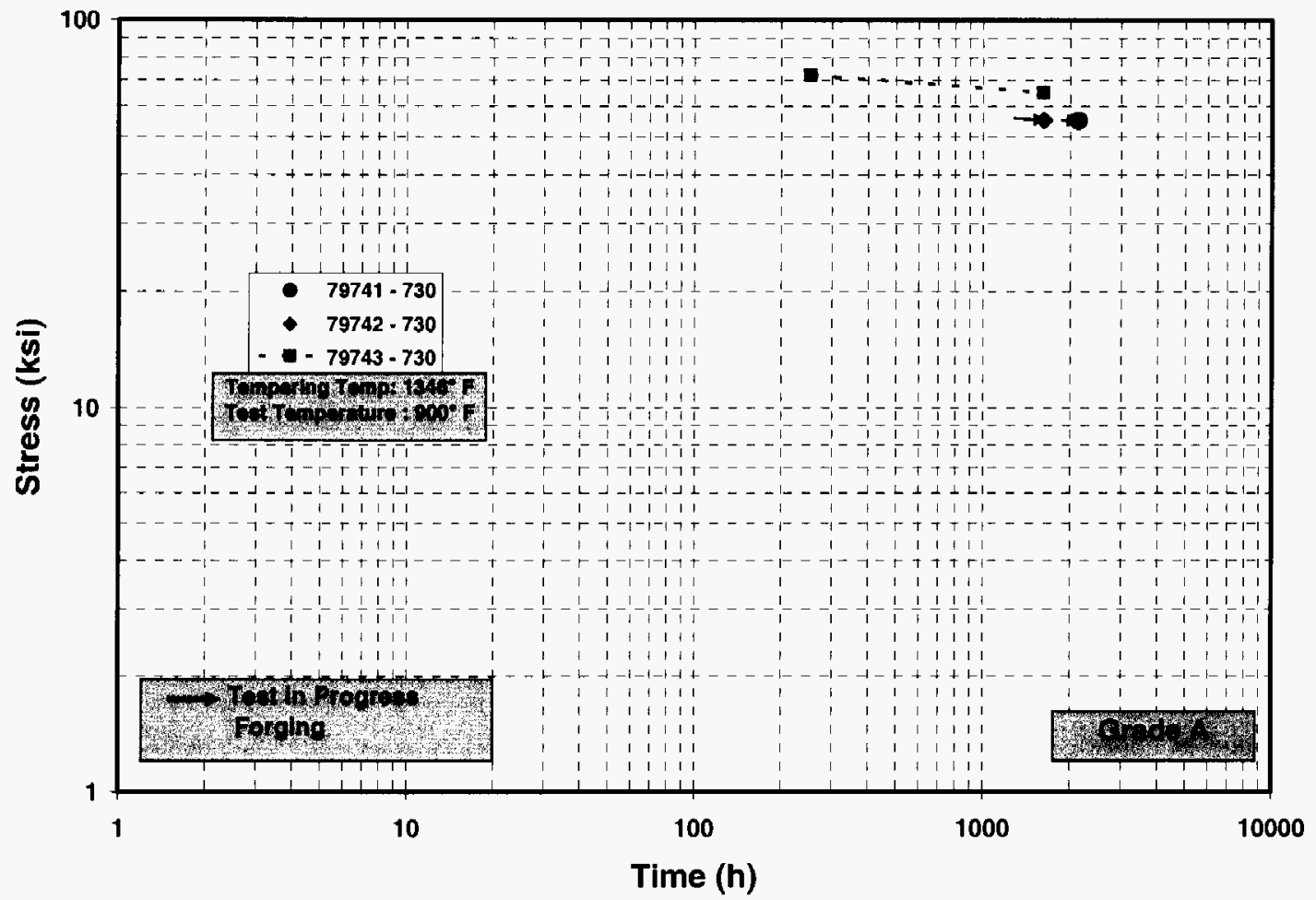

(a)

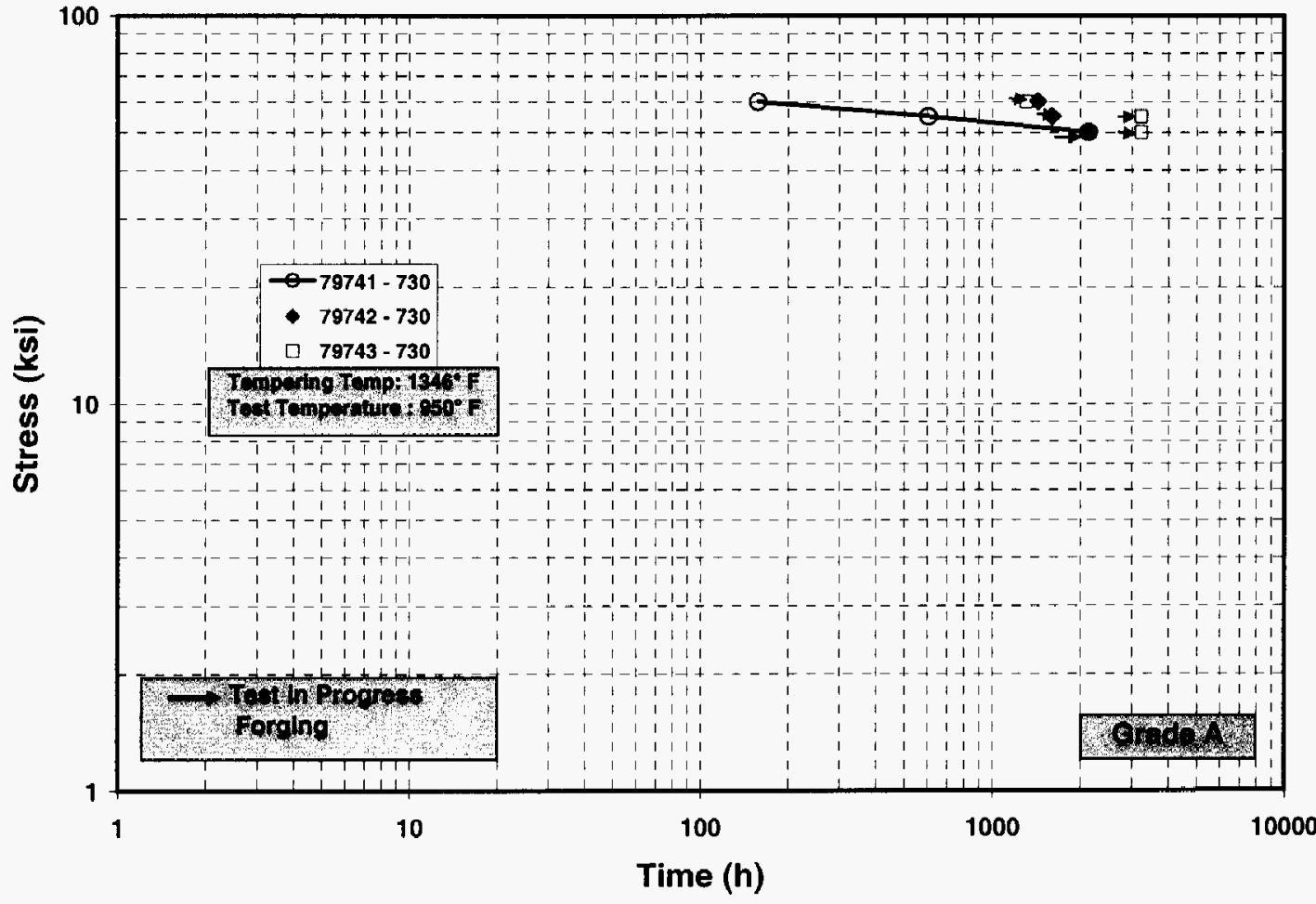

(b)

Figure 30. Isothermal plots of creep-rupture data for three commercial heats of Grade A. All tests are for forgings and plate tested after tempering at $730^{\circ} \mathrm{C}\left(1345^{\circ} \mathrm{F}\right)$ : (a) 900 and (b) $950^{\circ} \mathrm{F}$. 


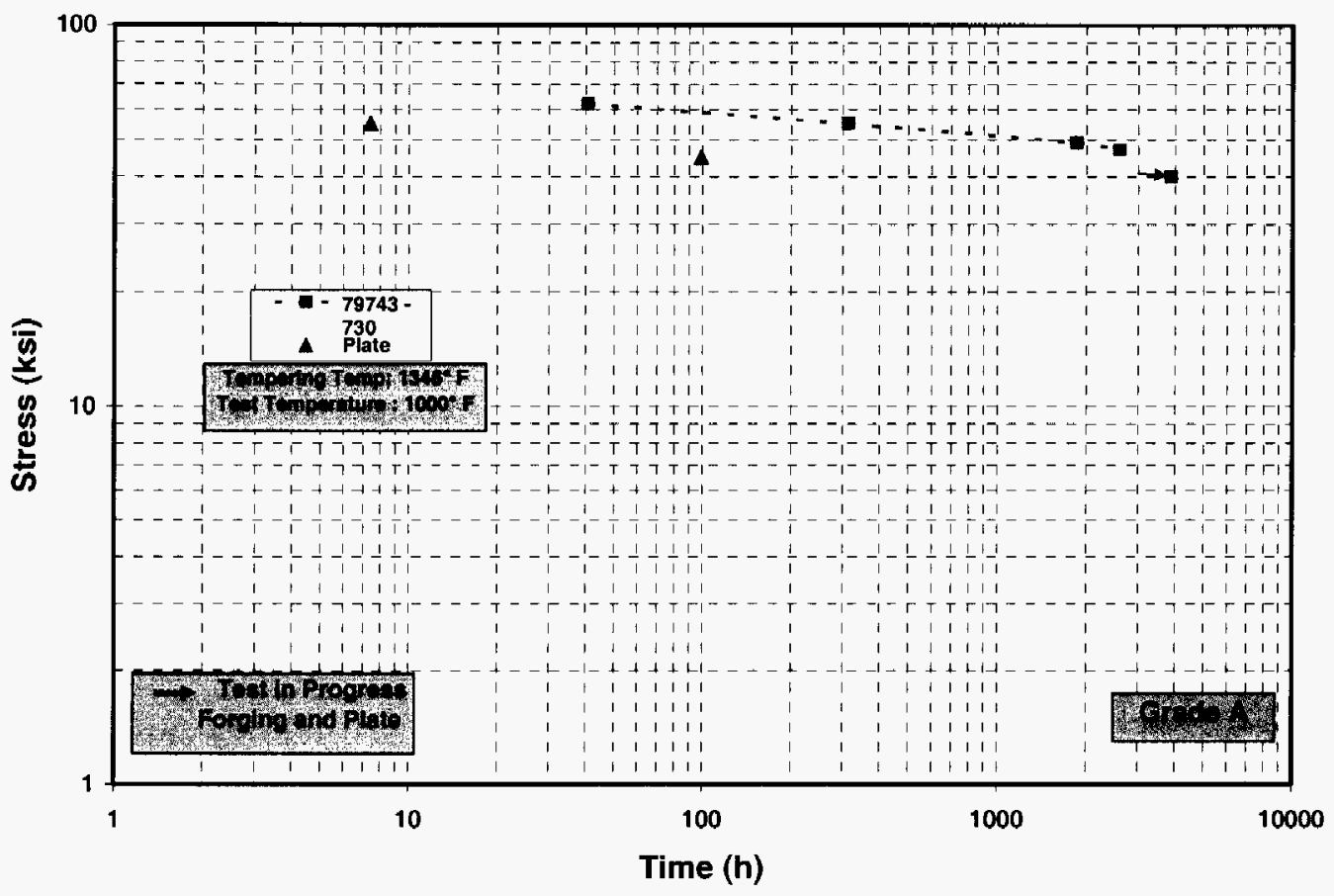

(a)

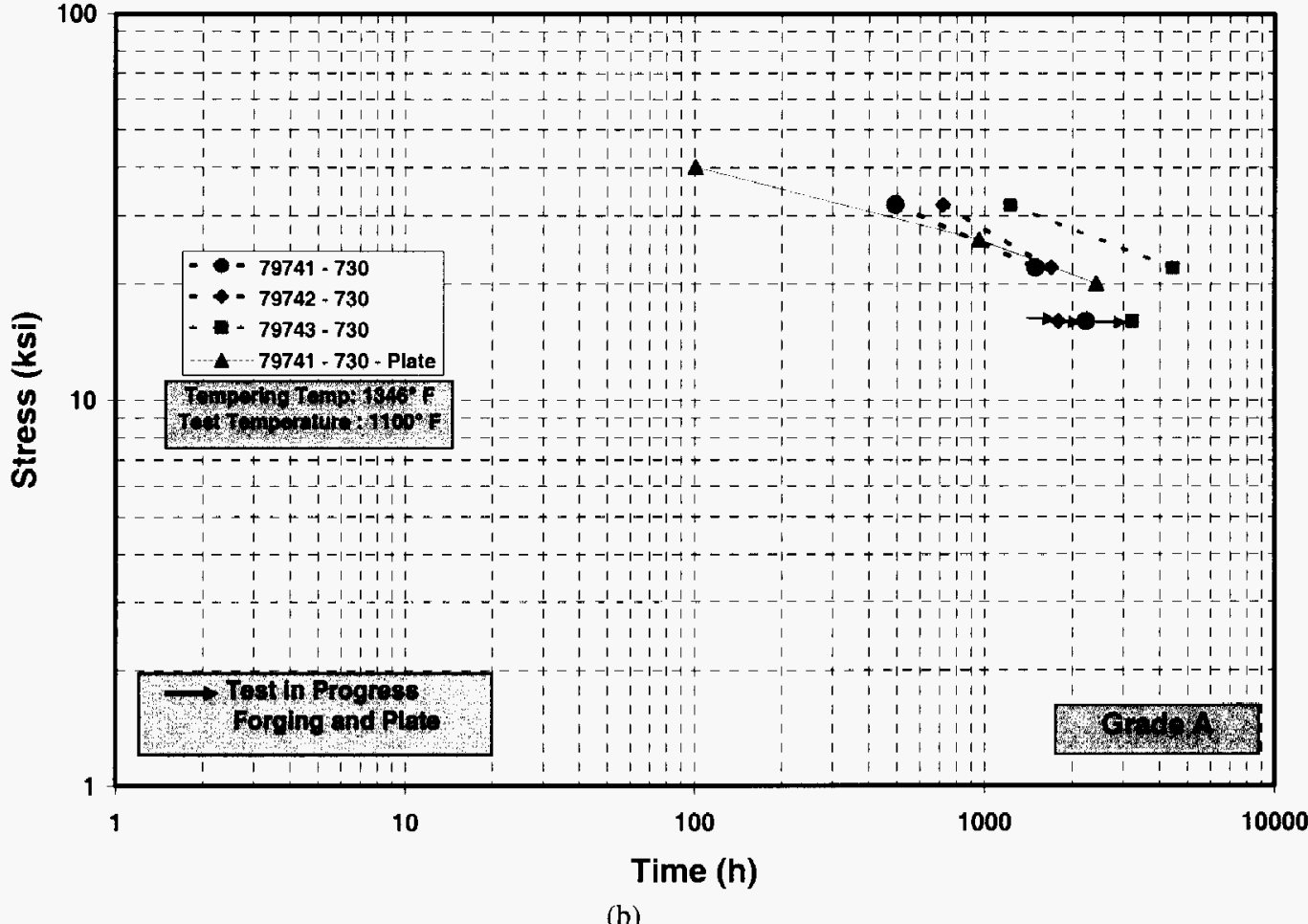

(b)

Figure 31. Isothermal plots of creep-rupture data for three commercial heats of Grade A. All tests are for forgings and plate tested after tempering at $730^{\circ} \mathrm{C}\left(1345^{\circ} \mathrm{F}\right)$ : (a) 1000 and (b) $1100^{\circ} \mathrm{F}$. 


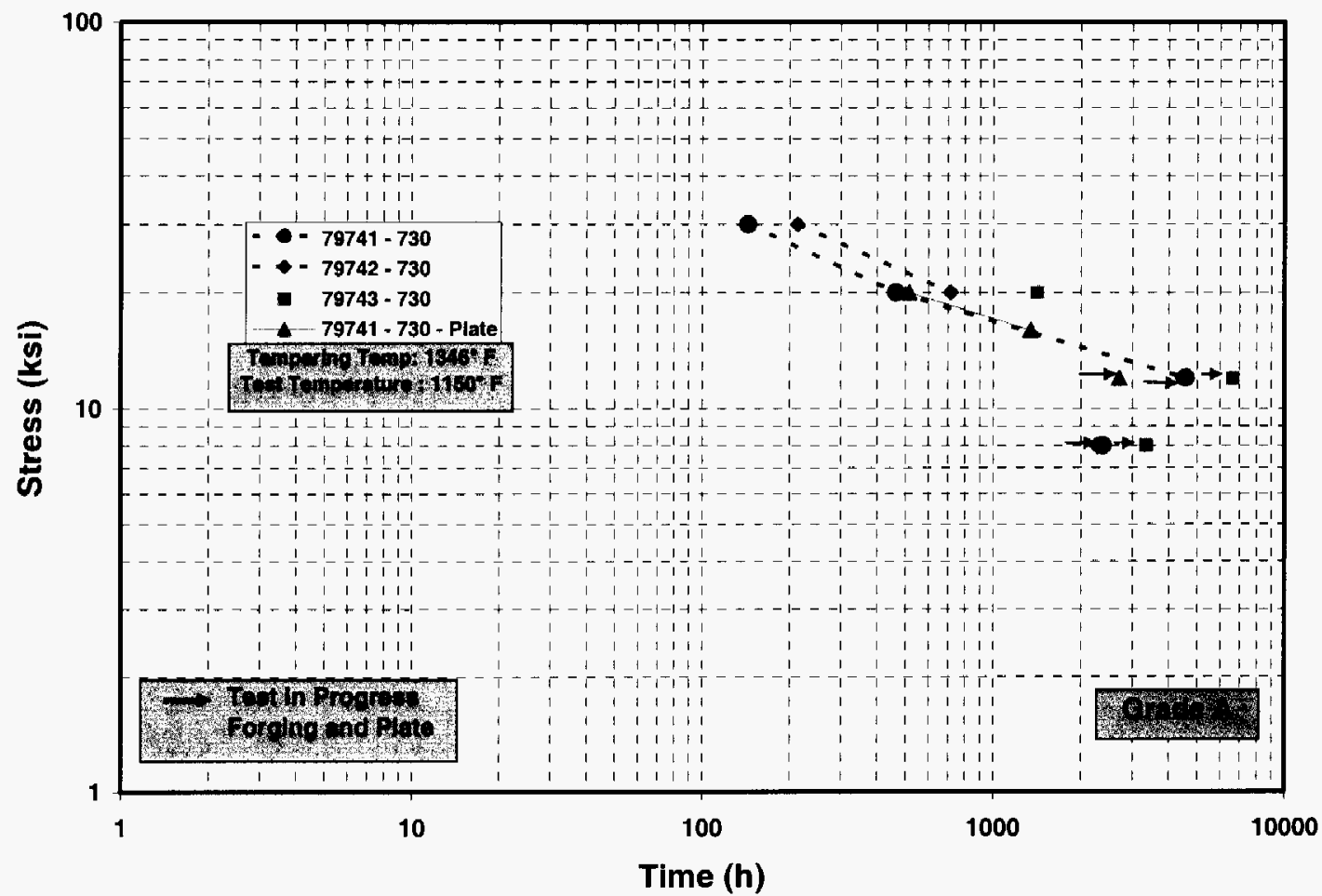

(a)

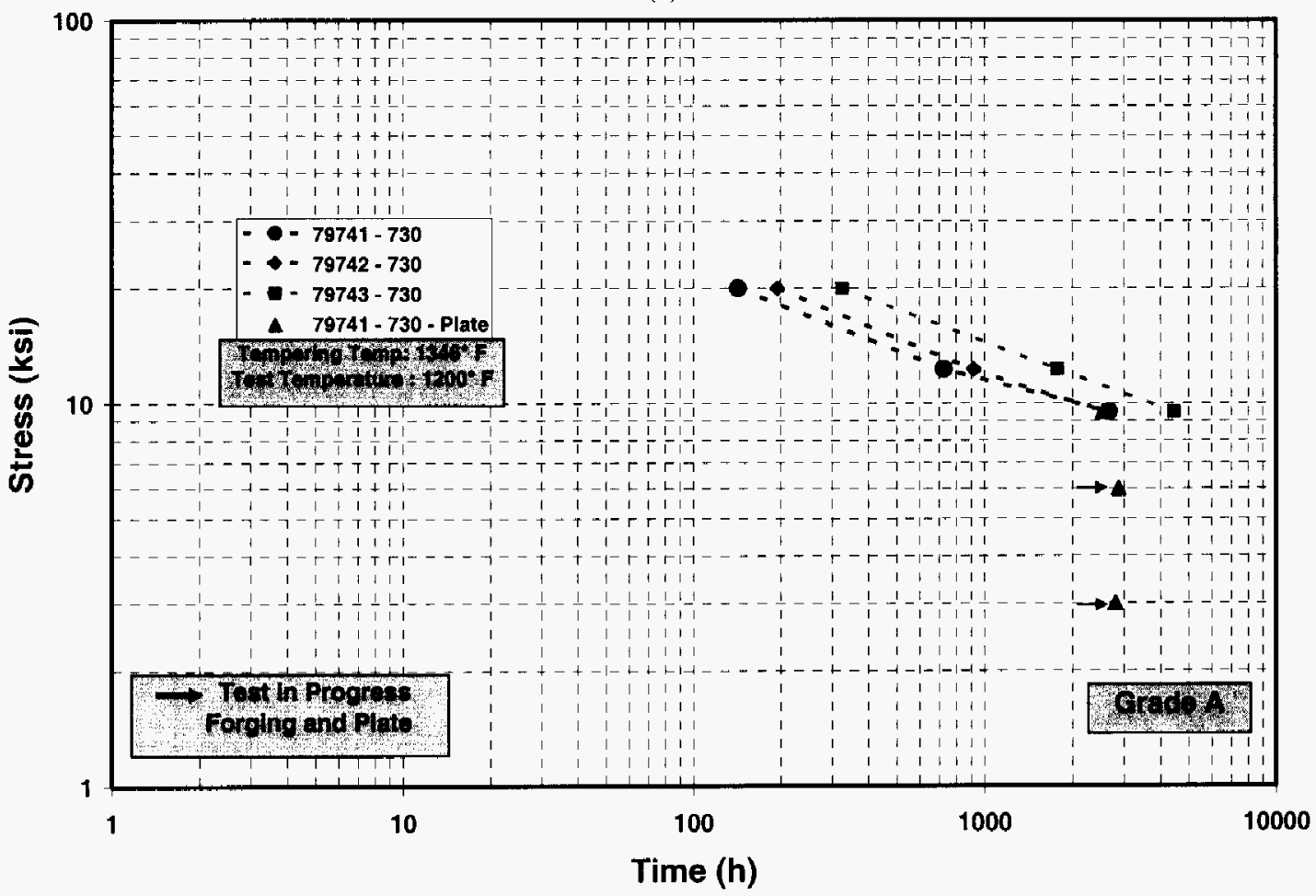

(b)

Figure 32. Isothermal plots of creep-rupture data for three commercial heats of Grade A. All tests are for forgings and plate tested after tempering at $730^{\circ} \mathrm{C}\left(1345^{\circ} \mathrm{F}\right)$ : (a) 1150 and (b) $1200^{\circ} \mathrm{F}$. 


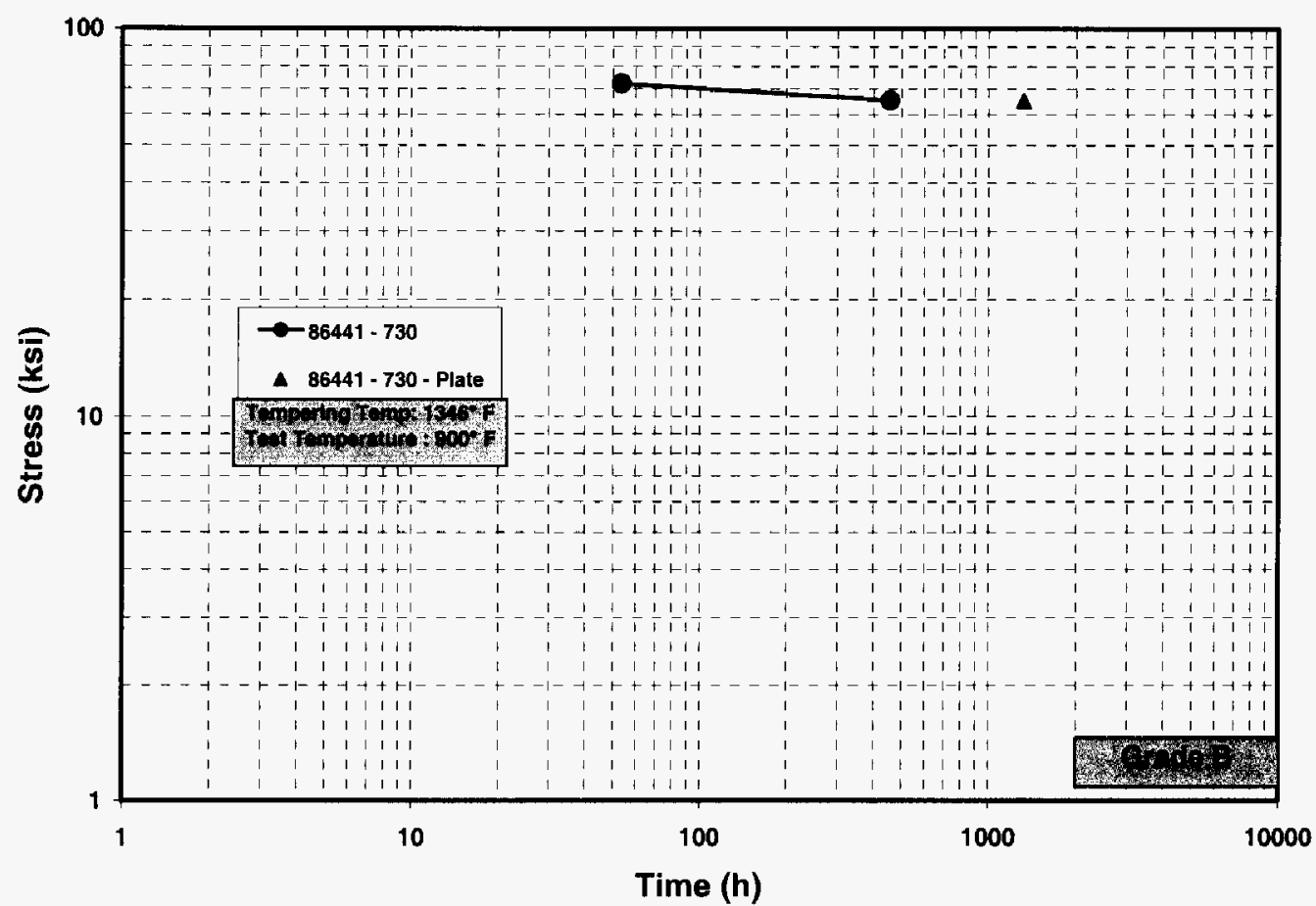

(a)

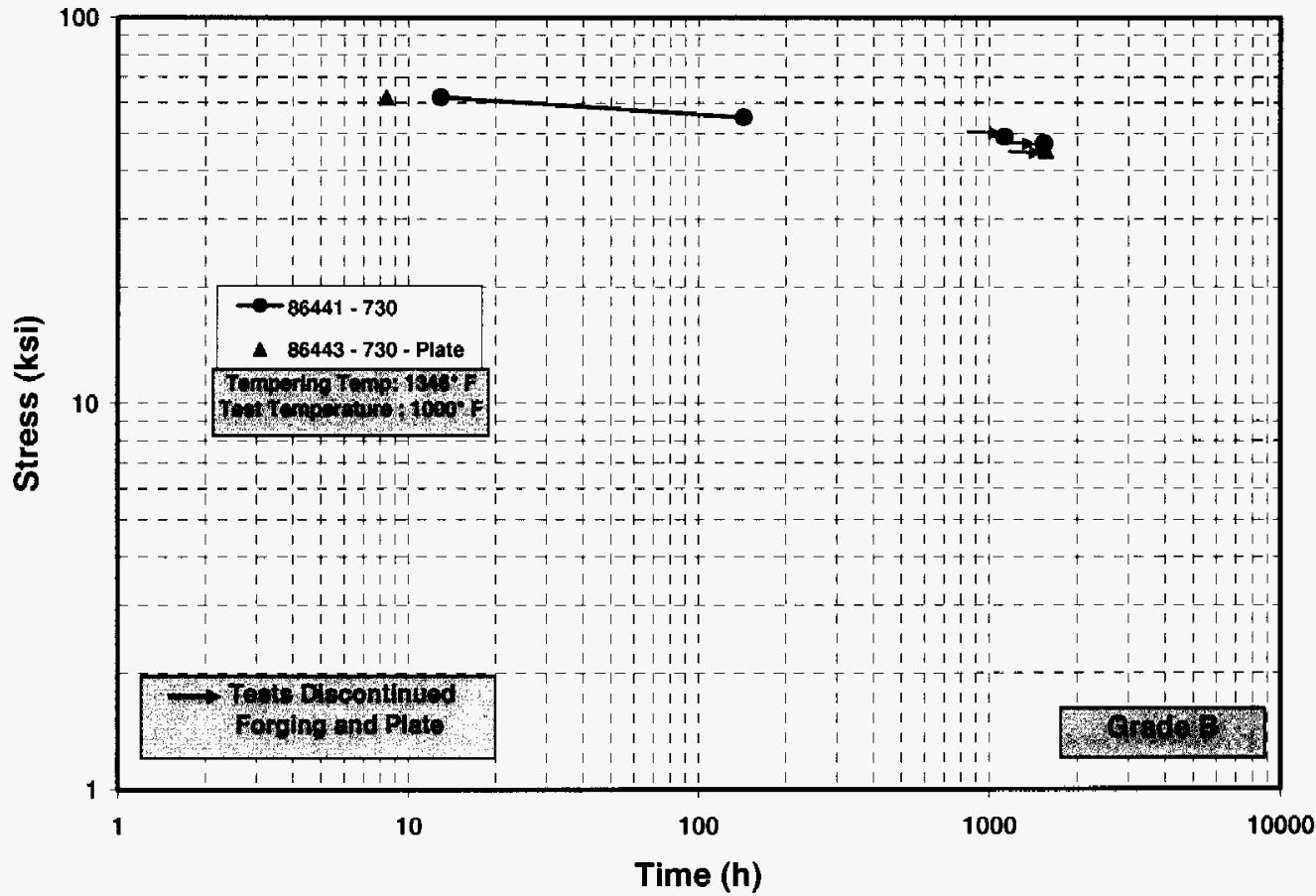

(b)

Figure 33. Isothermal plots of creep-rupture data for three commercial heats of Grade B. All tests are for forgings and plate tested after tempering at $730^{\circ} \mathrm{C}\left(1345^{\circ} \mathrm{F}\right)$ : (a) 900 and (b) $1000^{\circ} \mathrm{F}$. 


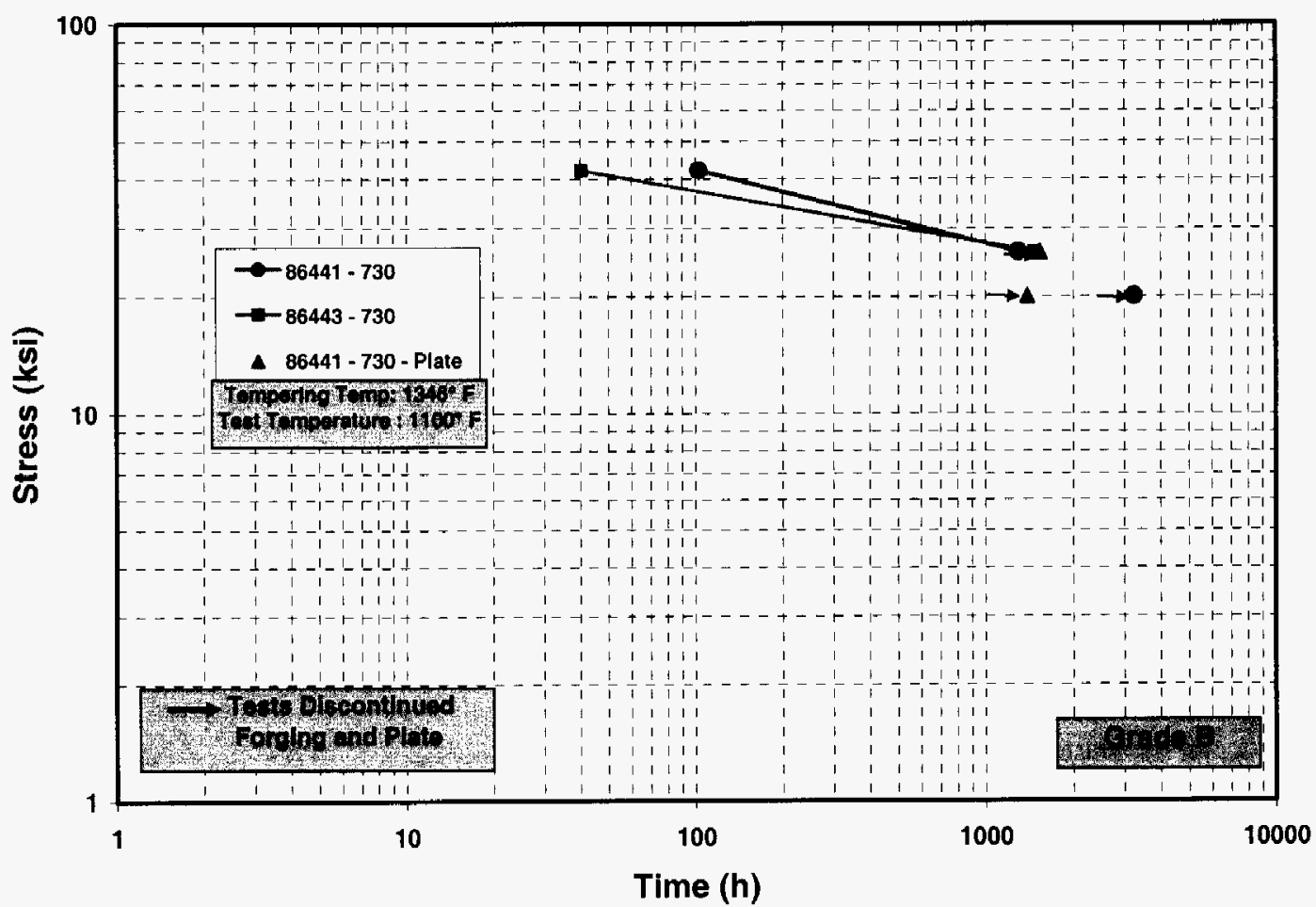

(a)

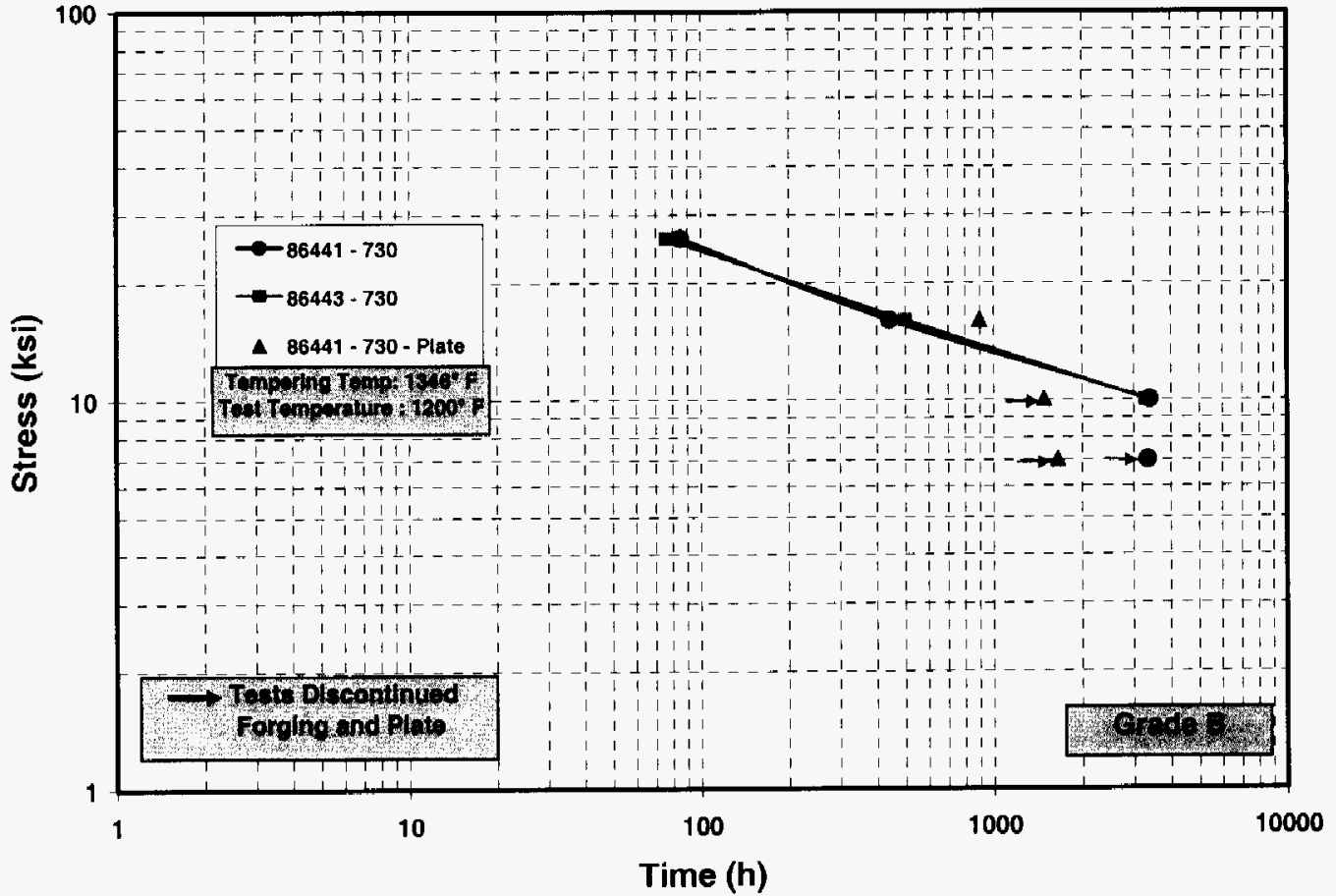

(b)

Figure 34. Isothermal plots of creep-rupture data for three commercial heats of Grade B. All tests are for forgings and plate tested after tempering at $730^{\circ} \mathrm{C}\left(1345^{\circ} \mathrm{F}\right)$ : (a) 1100 and (b) $1200^{\circ} \mathrm{F}$. 


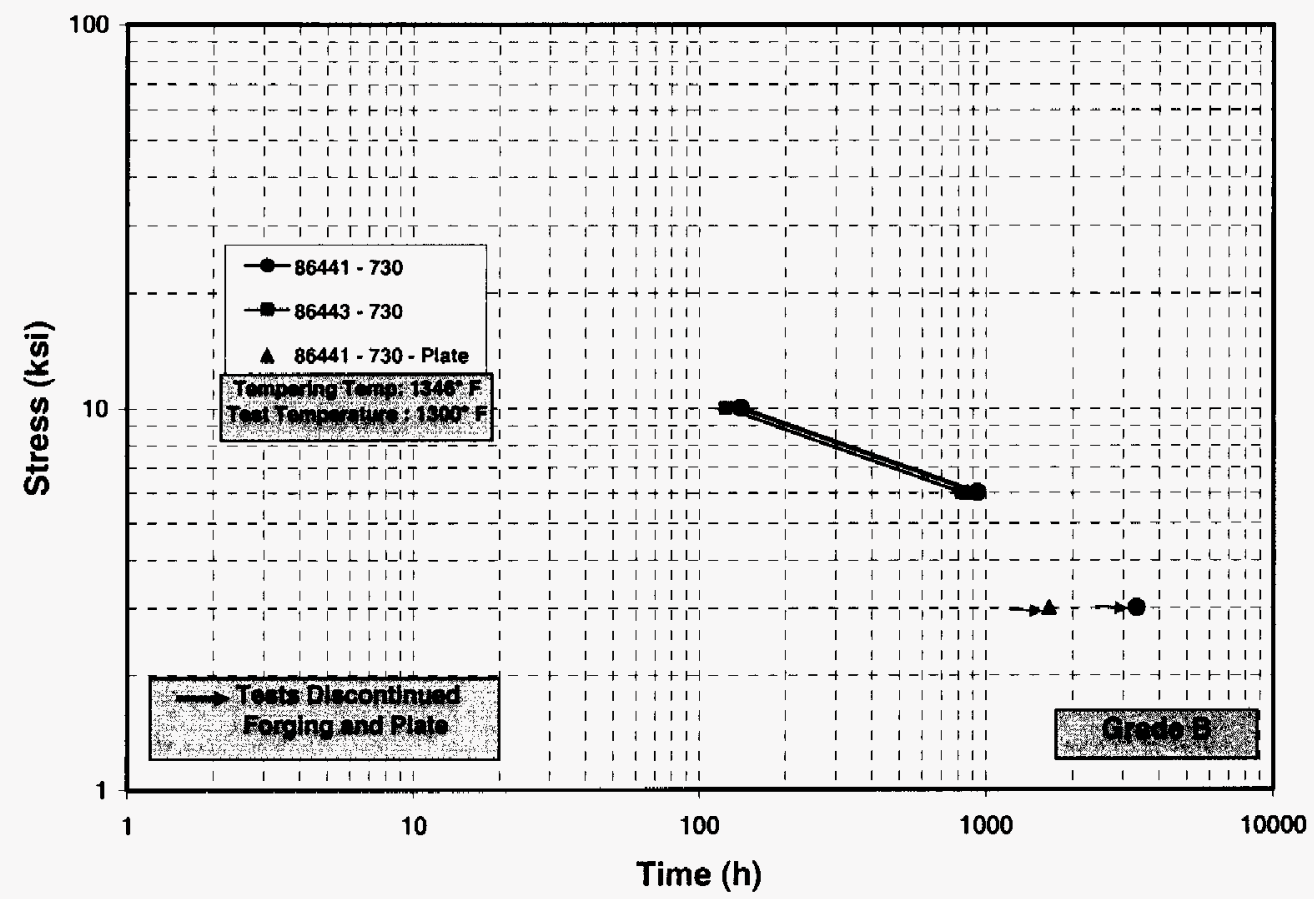

Figure 35. Isothermal plots of creep-rupture data for three commercial heats of Grade B. All tests are for forgings and plate tested after tempering at $730^{\circ} \mathrm{C}\left(1345^{\circ} \mathrm{F}\right)$ : test temperature is $1300^{\circ} \mathrm{F}$.

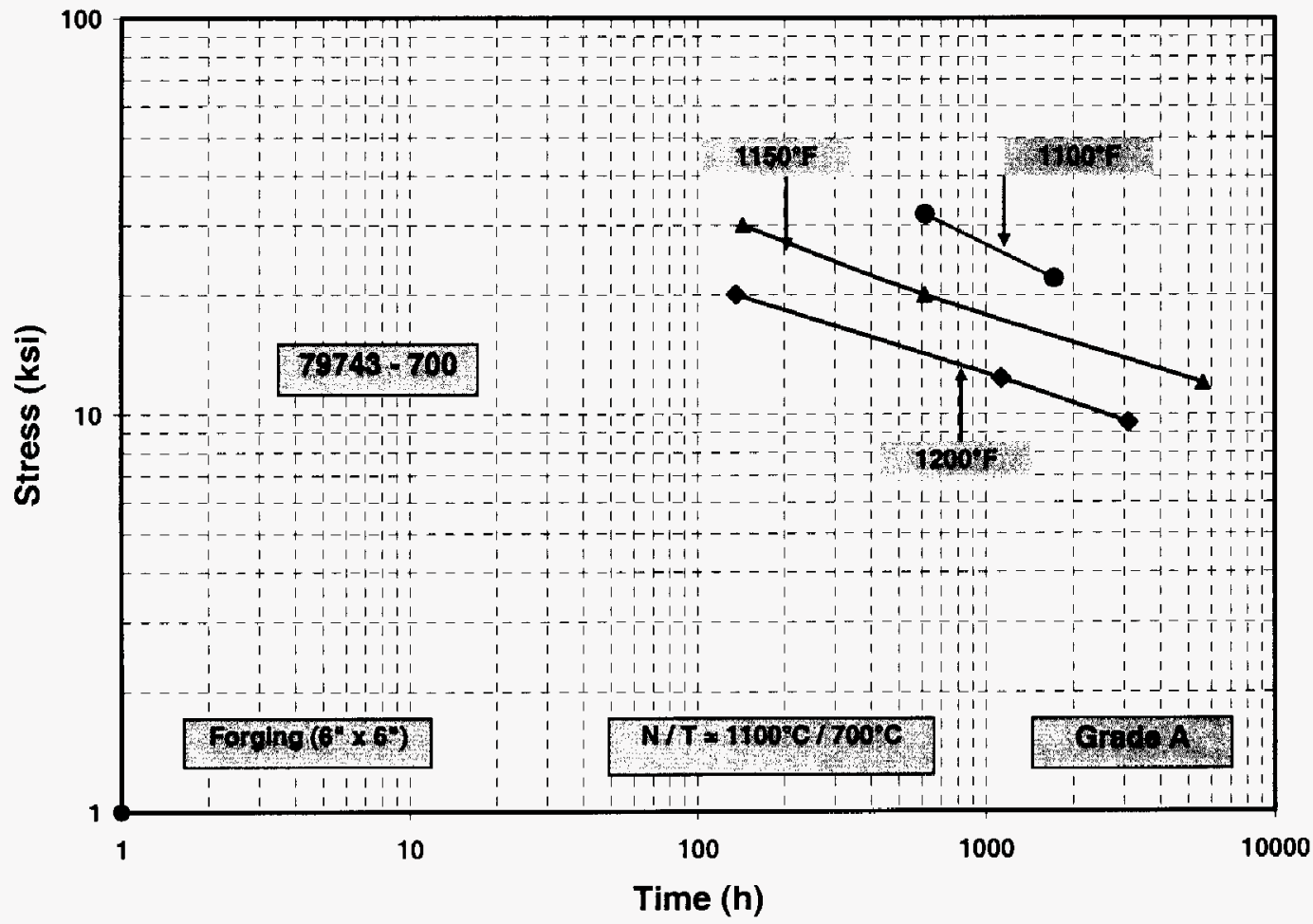

Figure 36. Creep-rupture data for commercial heat 79743 of Grade A tested after tempering at $700^{\circ} \mathrm{C}\left(1292^{\circ} \mathrm{F}\right)$. 


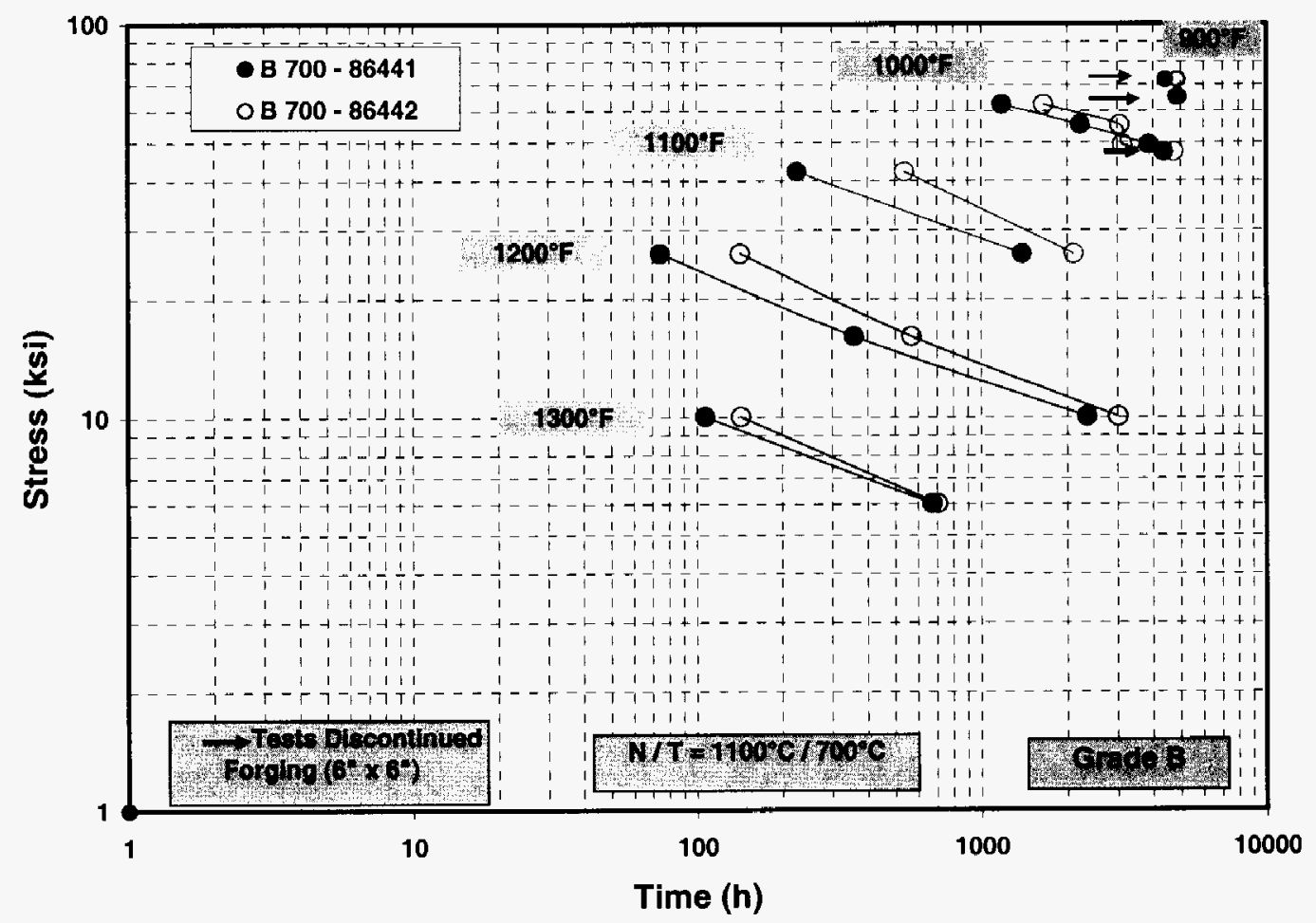

Figure 37. Creep-rupture data for commercial heats 86441 and 86442 of Grade B tested after tempering at $700^{\circ} \mathrm{C}\left(1292^{\circ} \mathrm{F}\right)$.

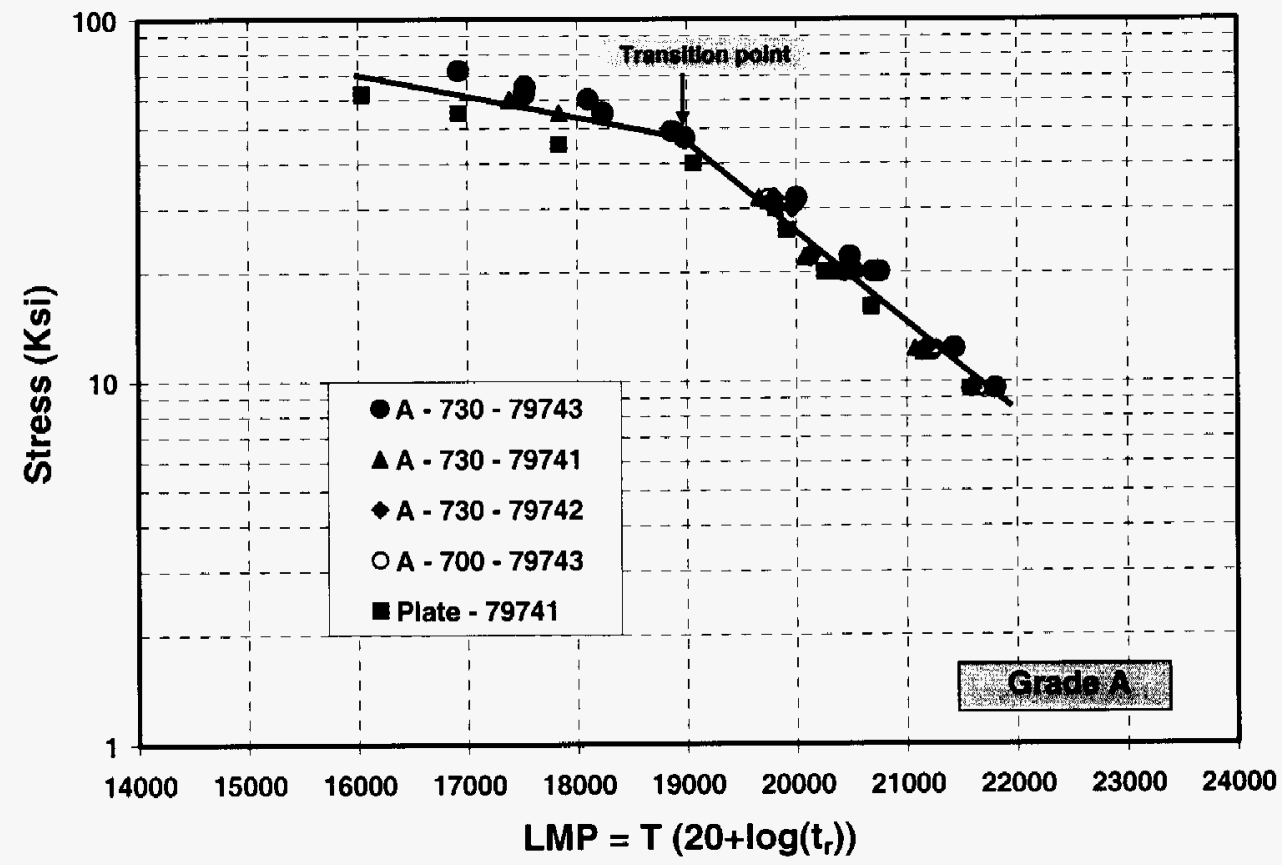

Figure 38. Larson-Miller plot of creep-rupture data for three commercial heats of Grade A. Note the transition point at $50 \mathrm{ksi}$ for change in slope from high stress to low stress region. 


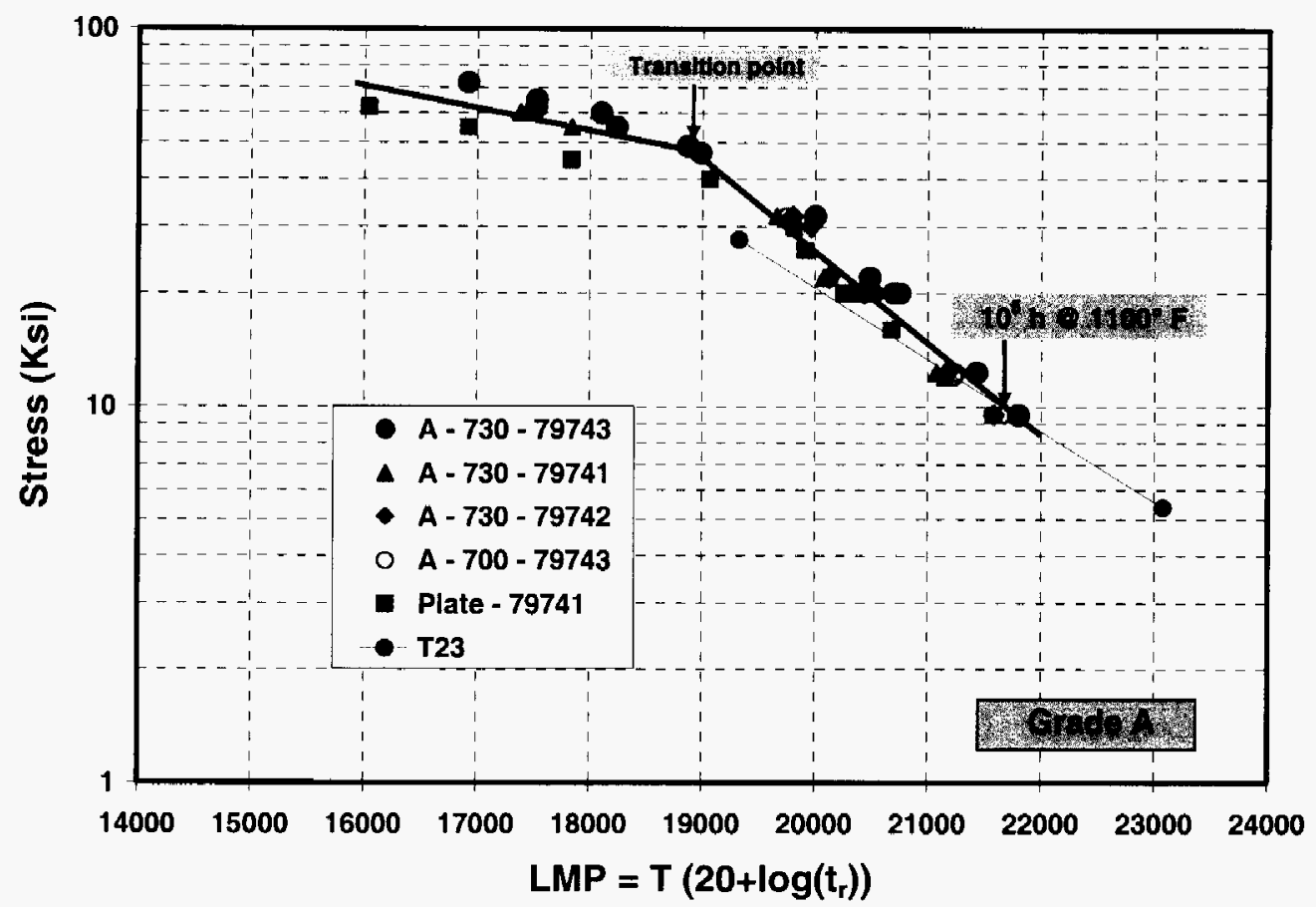

Figure 39. Comparison of Larson-Miller plot for three commercial heats of Grade A with average values reported for the commercial grade T23. Note the crossover point in strength at $10^{5} \mathrm{~h}$ at $1100^{\circ} \mathrm{F}$ between Grade A and T23.

The LMP for all of the creep-rupture data on three commercial heats of Grade B is shown in Fig. 40. Data for Grade B also shows a transition in slope from high to low stress region, similar to that noted for Grade A in Fig. 38. It is to be noted that the transition for Grade B occurs at approximately $55 \mathrm{ksi}$, which is $5 \mathrm{ksi}$ higher than observed for Grade A. The LM plot for Grade $\mathrm{B}$ is compared with the average values for the commercially available alloy $\mathrm{T} 23$ in Fig. 41 . This figure shows that the creep-rupture values of Grade B, developed in this project, are higher than T23 for conditions of $10^{5} \mathrm{~h}$ at $1100^{\circ} \mathrm{F}$. For example, at a LMP value of 20,000 , the creep-rupture strength of Grade B is $30 \mathrm{ksi}$ as opposed to $20 \mathrm{ksi}$ for T23. However, the creep-rupture strength value of Grade B crosses over the T23 at a LMP corresponding to $10^{5} \mathrm{~h}$ rupture at $1100^{\circ} \mathrm{F}$. The Grade B values are somewhat lower beyond the crossover point than T23. These lower values are believed to be caused by several creep tests carried out at $1300^{\circ} \mathrm{F}$ for Grade $\mathrm{B}$, where reduction in creep-rupture strength is expected from the reduction in specimen cross section from excessive oxidation. Thus, more longer term data are needed at test temperatures of $\leq 1200^{\circ} \mathrm{F}$, to further assess the extent of creep-rupture strength enhancement of Grade B as opposed to T23.

The LM plots of average values of creep-rupture strength of Grades A and B are compared in Fig. 42. This figure shows that Grade B has higher creep-rupture strength than Grade A. For LMP values corresponding to $10^{5} \mathrm{~h}$ rupture at $1100^{\circ} \mathrm{F}$. Grade B falls slightly below Grade A. This again is considered as the effect of test temperature on the oxidation and corresponding reduction in creep-rupture strength. All tests on Grade $A$ were at temperatures $\leq 1200^{\circ} \mathrm{F}$. For Grade B, several tests were carried out at $1300^{\circ} \mathrm{F}$. 


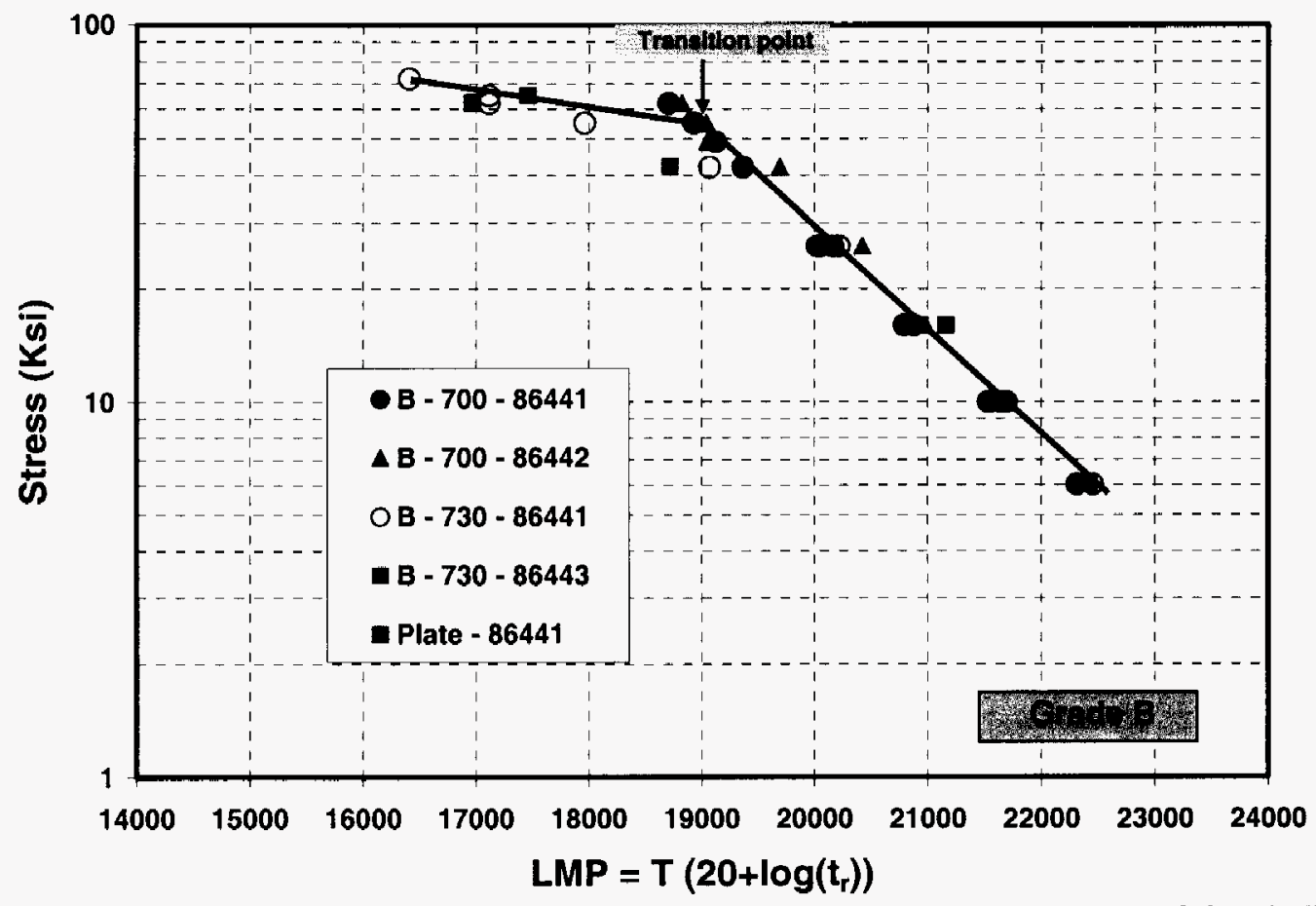

Figure 40. Larson-Miller plot of creep-rupture data for three commercial heats of Grade B. Note the transition point at $50 \mathrm{ksi}$ for change in slope from high stress to low stress region.

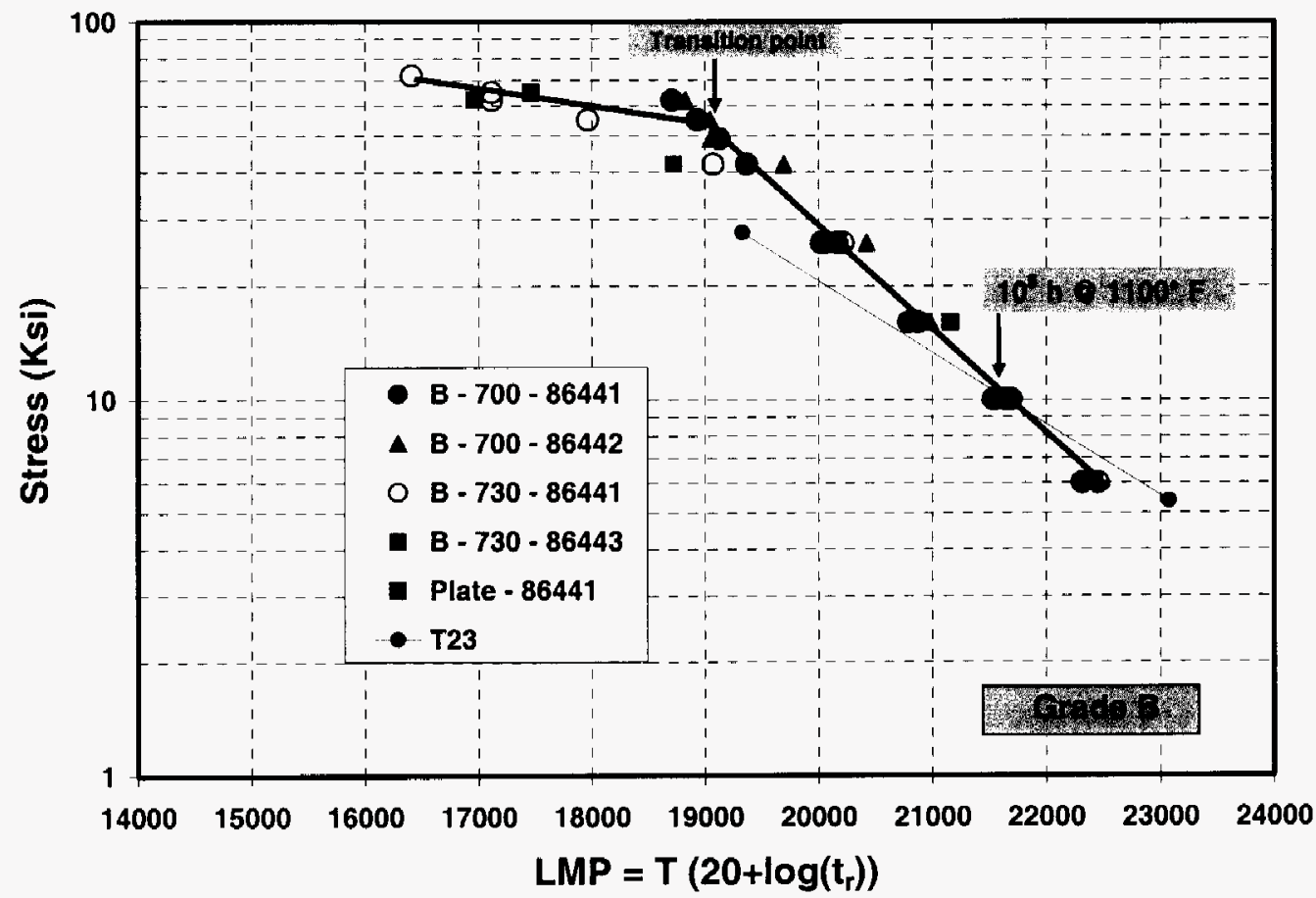

Figure 41. Comparison of Larson-Miller plot for three commercial heats of Grade B with average values reported for the commercial grade $\mathrm{T} 23$. Note the crossover point in strength at $10^{5} \mathrm{~h}$ at $1100^{\circ} \mathrm{F}$ between Grade B and T23. 


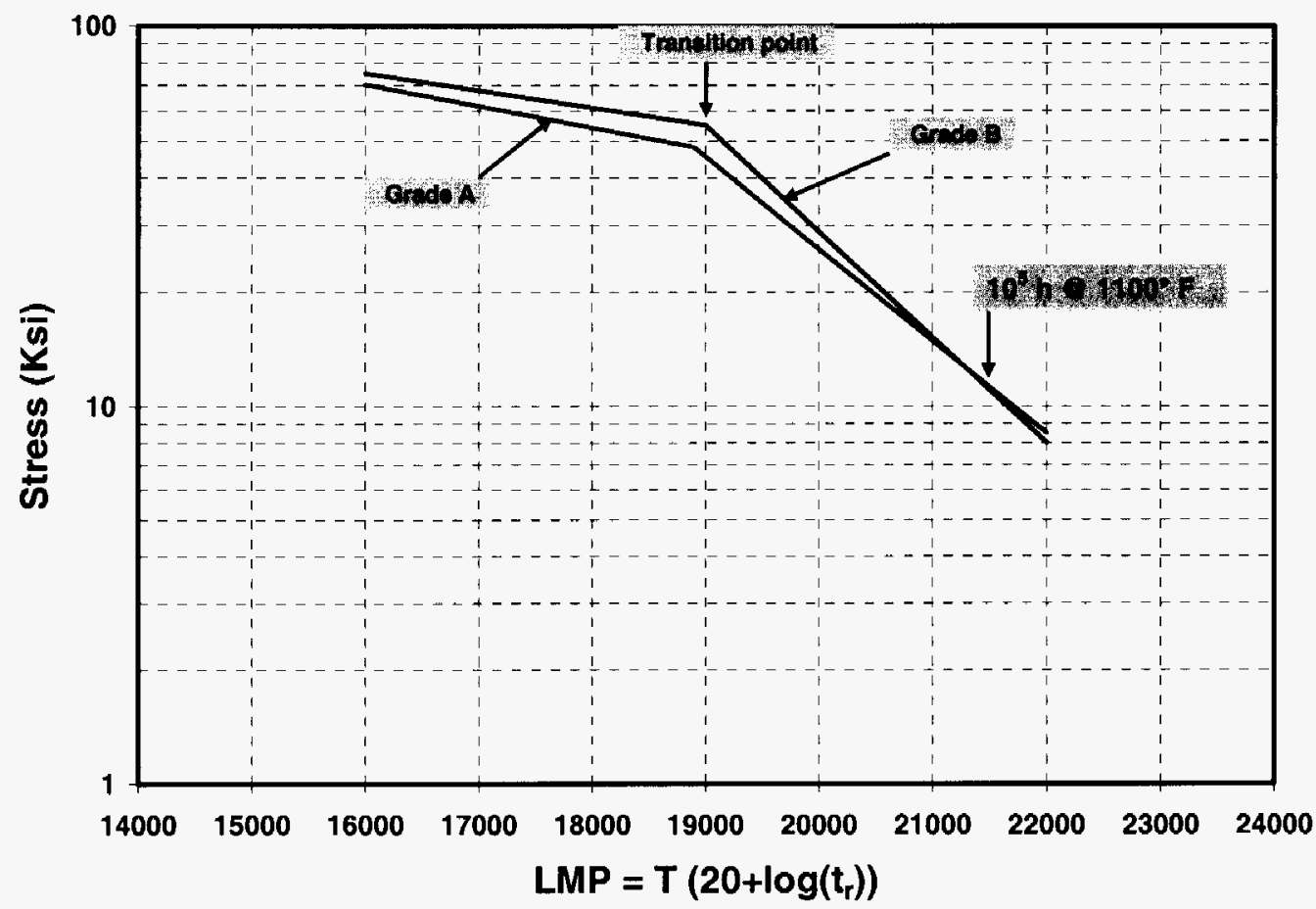

Figure 42. Comparison of average values of creep-rupture strength of Grades A and B.

Creep-rupture elongation and reduction of area for A and B are plotted as a function of LMP in Figs. 43 through 46. These figures show the data for all test temperatures and stresses for which the creep rupture has already occurred. The following observations are made from these figures:

The creep-rupture elongation for most tests is over $10 \%$ for all test conditions. Two data points have fallen below $10 \%$, and no detailed analysis is carried out to find the cause for observed values of 6 and $7 \%$. Similar to total elongation, reduction of area values for most tests are over $40 \%$, with the exception of three tests that are between 15 and $25 \%$.

The total elongation values (Fig. 45) for Grade B were mostly over 10\%. However, four very high-stress tests at 1000 and $1100^{\circ} \mathrm{F}$ showed low values of 1.5 to $\sim 5 \%$. The low values are only for tests on material tempered at $700^{\circ} \mathrm{C}\left(1292^{\circ} \mathrm{F}\right)$. No values for $730^{\circ} \mathrm{C}\left(1345^{\circ} \mathrm{F}\right)$ temper fell below $10 \%$. The reduction of area values for Grade B (Fig. 46) are typically over $40 \%$. There were only five tests that showed values between 4 to $\sim 18 \%$. All of these tests were for tempering temperature of $700^{\circ} \mathrm{C}\left(1292^{\circ} \mathrm{F}\right)$. Reduction of area values for all tests after tempering temperature of $730^{\circ} \mathrm{C}\left(1345^{\circ} \mathrm{F}\right)$ are over $40 \%$.

In general, the observed elongation and reduction of area values for Grades A and B are considered acceptable. 


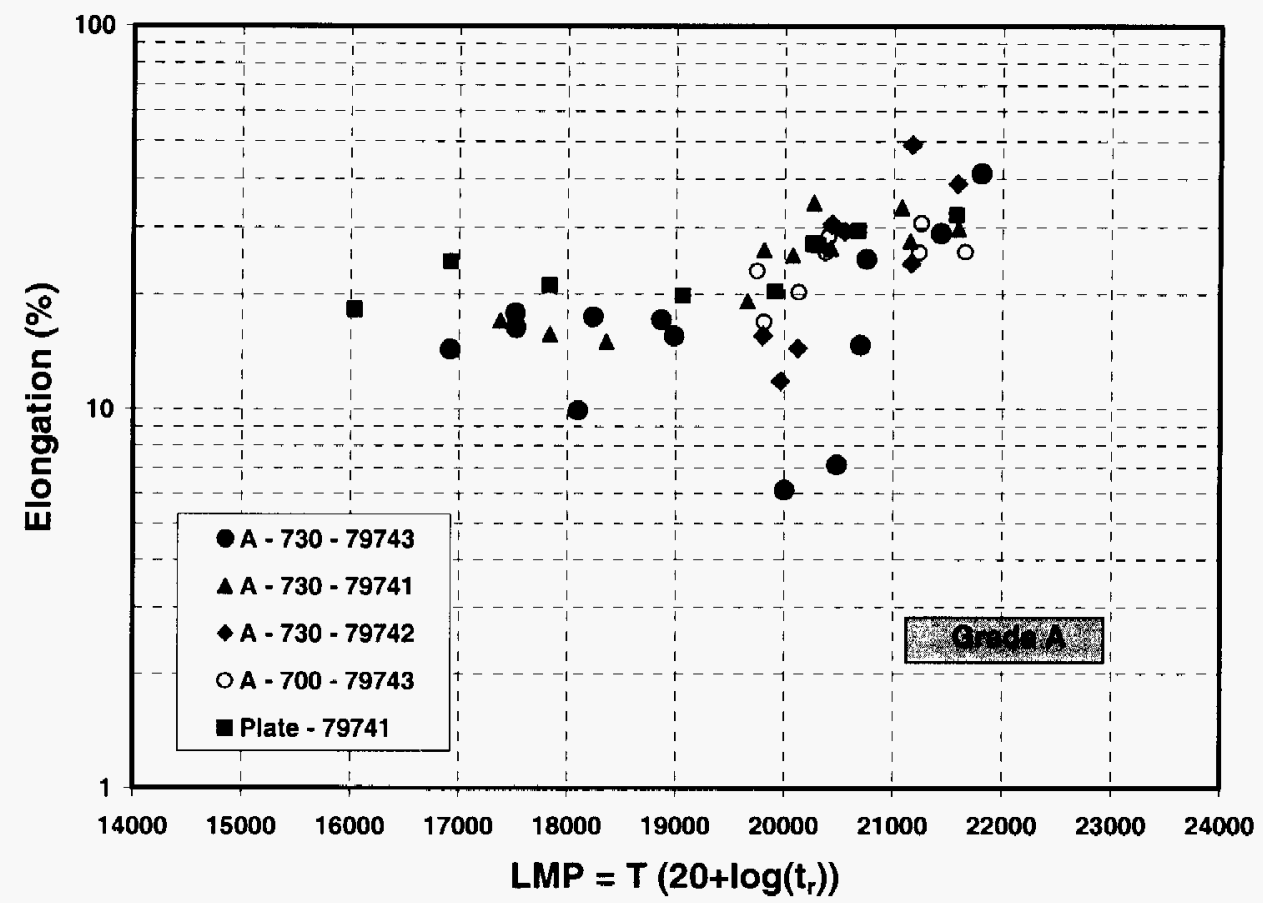

Figure 43. Creep-rupture elongation for creep tests carried out on three commercial heats of Grade A. Data are included for specimens tested after tempering temperatures of 700 and $730^{\circ} \mathrm{C}$ $\left(1292\right.$ and $\left.1345^{\circ} \mathrm{F}\right)$.

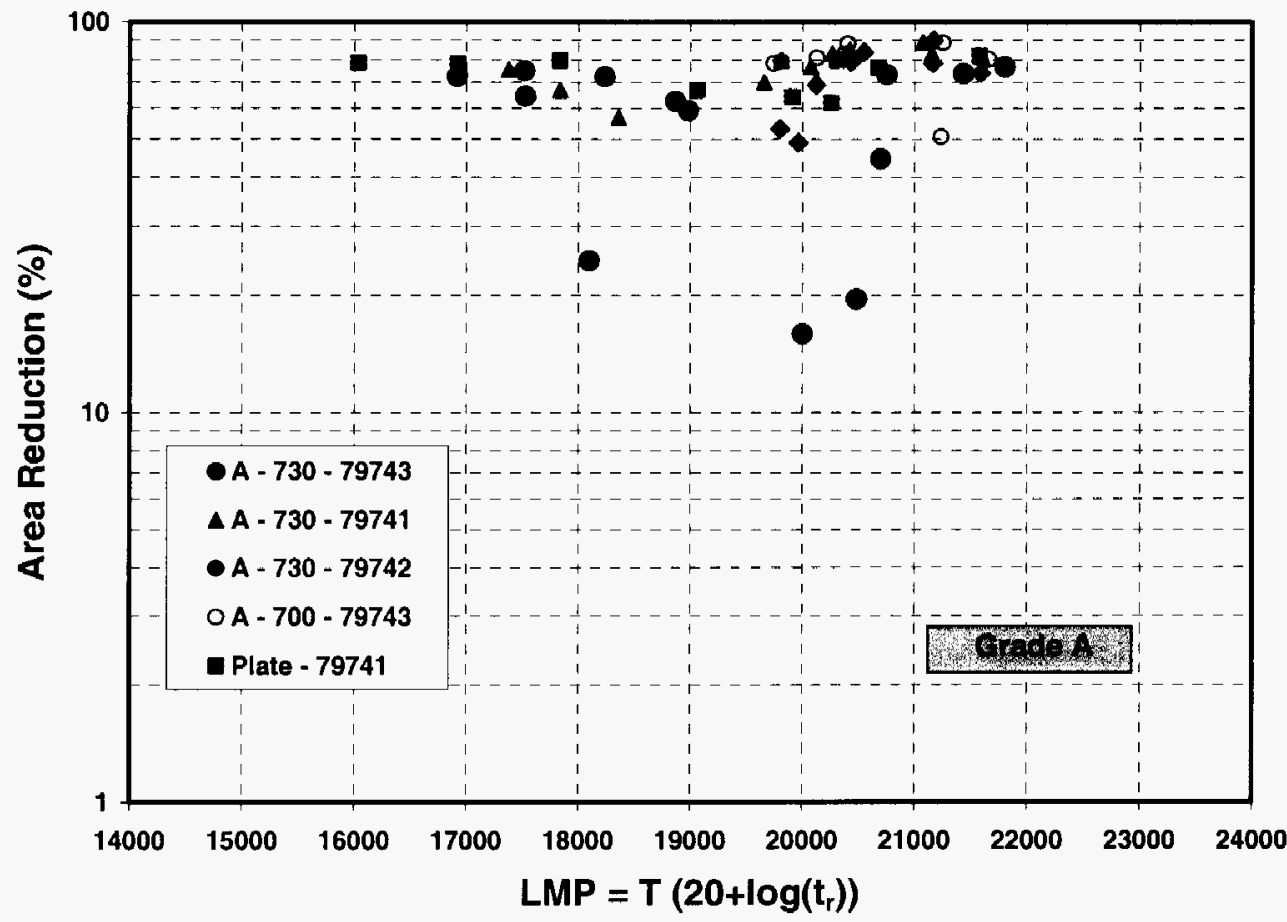

Figure 44. Reduction of area for creep tests carried out on three commercial heats of Grade A. Data are included for specimens tested after tempering temperatures of 700 and $730^{\circ} \mathrm{C}(1292$ and $\left.1345^{\circ} \mathrm{F}\right)$. 


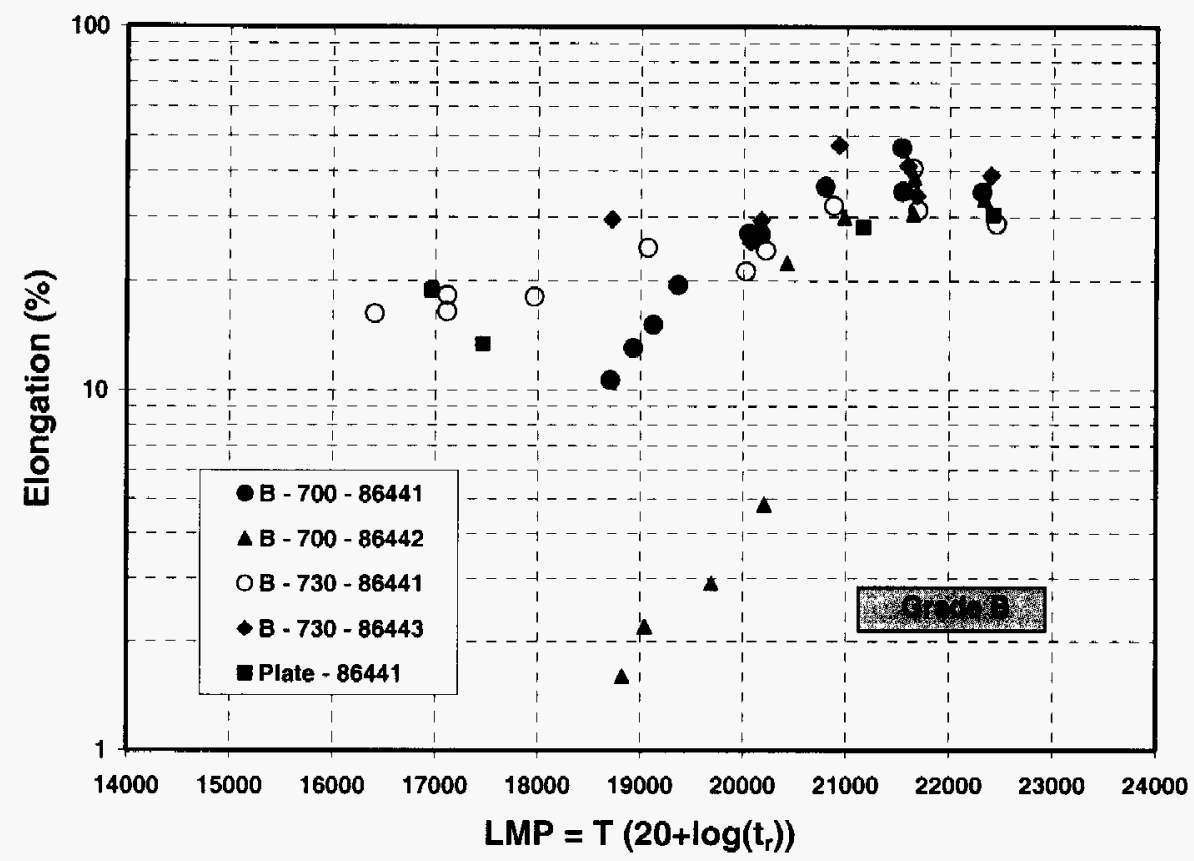

Figure 45. Creep-rupture elongation for creep tests carried out on three commercial heats of Grade B. Data are included for specimens tested after tempering temperatures of 700 and $730^{\circ} \mathrm{C}$ $\left(1292\right.$ and $\left.1345^{\circ} \mathrm{F}\right)$.

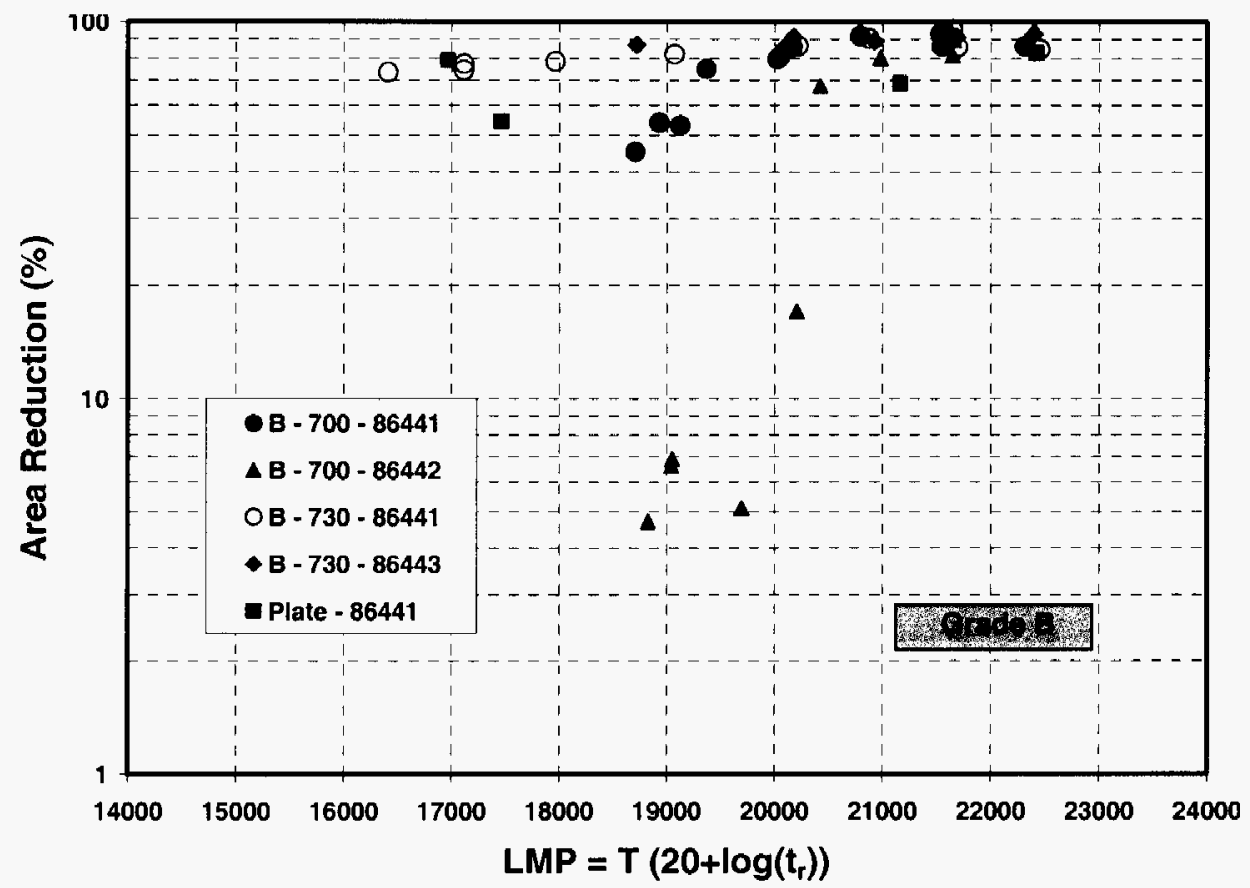

Figure 46. Reduction of area for creep tests carried out on three commercial heats of Grade B. Data are included for specimens tested after tempering temperatures of 700 and $730^{\circ} \mathrm{C}(1292$ and $\left.1345^{\circ} \mathrm{F}\right)$. 


\subsubsection{Weld and Weldment Properties}

The most common welding processes used in equipment manufacturing are SA, GTA, and shielded-metal arc (SMA). Out of these three processes, SA is the highest deposition rate process and, thus, is used most in the fabrication of thick-section components. A comparison of the production rate for the SA and GTA processes is shown in Fig. 47. Note that for the plate of the same thickness, the SA weld only used four passes while the GTA weld used 14 passes. Other characteristic that differentiates the three types of welds include the following:

1. SA uses a flux during welding. This process is used for high-production rates.

2. GTA uses argon or other inert gas as cover gas. This process is used for specialty welds.

3. SMA uses filler wire coated with a flux similar to SAW process. This process is used for manual welding where automated processes of SAW and GTA cannot be used.
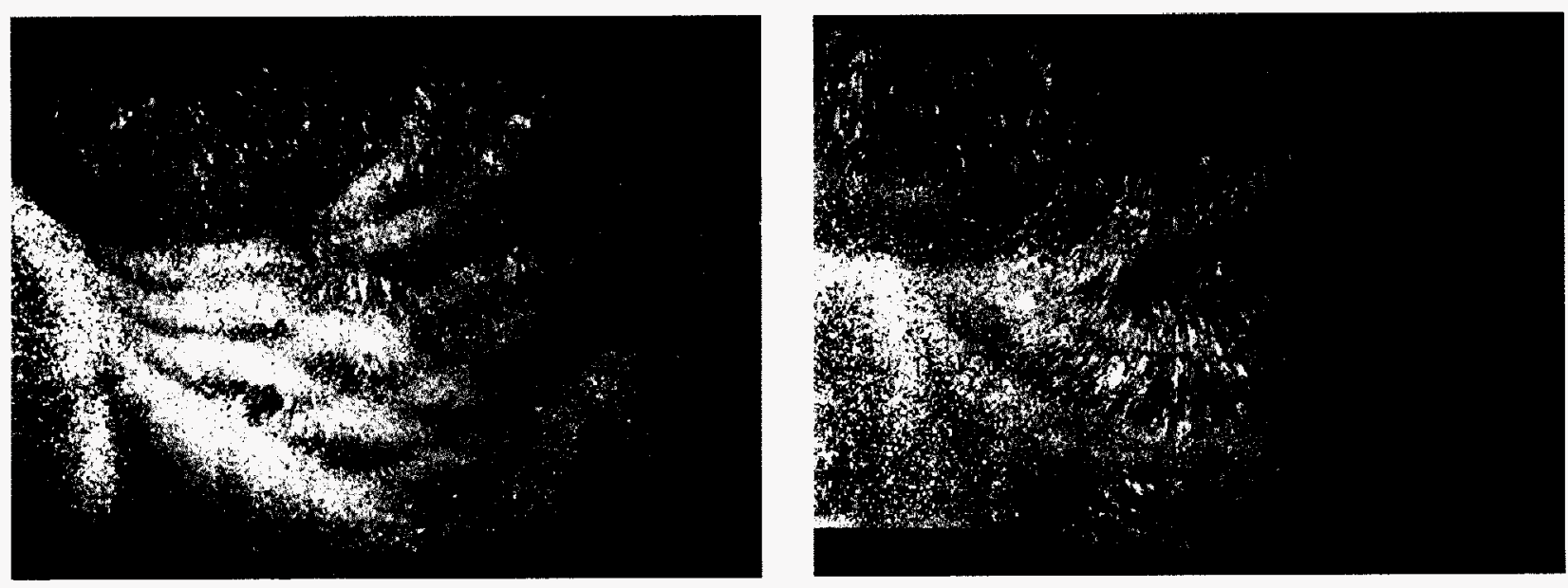

02-3667-01 GTA

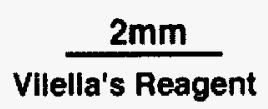

02-3652-01 SA

Figure 47. Macrostructure of gas-tungsten-arc (GTA) and submerged-arc (SA) welds. Note that the SA weld only used one-third the number of passes as compared to the GTA weld.

One focus of this project was to determine the filler wire composition that would yield acceptable Charpy-impact properties without requiring a PWHT. This study was carried out for GTA and SA welds. Data and progress made in each case are discussed below.

\subsubsection{GTA Welds}

Table 9 lists the impact properties of GTA welds made in different base metals and with different filler wire compositions. The Charpy-impact data are at room temperature and $-40^{\circ} \mathrm{F}$. The values for weld and base metal are compared in Table 9 and Fig. 48. This figure shows that there are two ways to get exceptional impact properties in GTA welds. 
Table 9. Comparison of base metal and gas-tungsten-arc weld impact properties

\begin{tabular}{|c|c|c|c|c|c|}
\hline \multirow{3}{*}{$\begin{array}{c}\text { Weld } \\
\text { ID }\end{array}$} & \multirow{3}{*}{$\begin{array}{l}\text { Weld } \\
\text { Type }\end{array}$} & \multicolumn{4}{|c|}{ Impact Values (ft-lb) } \\
\hline & & \multicolumn{2}{|c|}{ Room Temperature } & \multicolumn{2}{|c|}{$-40^{9} \mathrm{~F}$} \\
\hline & & $\mathbf{N}$ & $\mathrm{N} / \mathrm{T}$ & $\mathbf{N}$ & $\mathbf{N} / \mathbf{T}$ \\
\hline 18687 & Base Metal & 84 & 124 & 36 & 32 \\
\hline 18687 & GTA $^{a}$ & 196 & & 172 & \\
\hline 18707R2 & GTA & 118 & & 19 & \\
\hline 18692 & Base Metal & 35 & 105 & 16 & 39 \\
\hline 18692 & GTA $^{\tilde{a}}$ & 73 & & 16 & \\
\hline 18695 & Base Metal & 45 & 167 & 36 & 35 \\
\hline 18695 & $\mathrm{GTA}^{a}$ & 115 & & 32 & \\
\hline 10293 & Base Metal & $39^{b}$ & 103 & $27^{b}$ & 5 \\
\hline 10293 & GTA $^{a}$ & 29 & & 15 & \\
\hline 10293 & GTA $^{c}$ & & 184 & & 124 \\
\hline
\end{tabular}

As-welded data.

${ }^{b}$ Quenched data. All other is normalized.

${ }^{\circ}$ Postweld heat treated at $700^{\circ} \mathrm{C} / 1 \mathrm{~h}$.

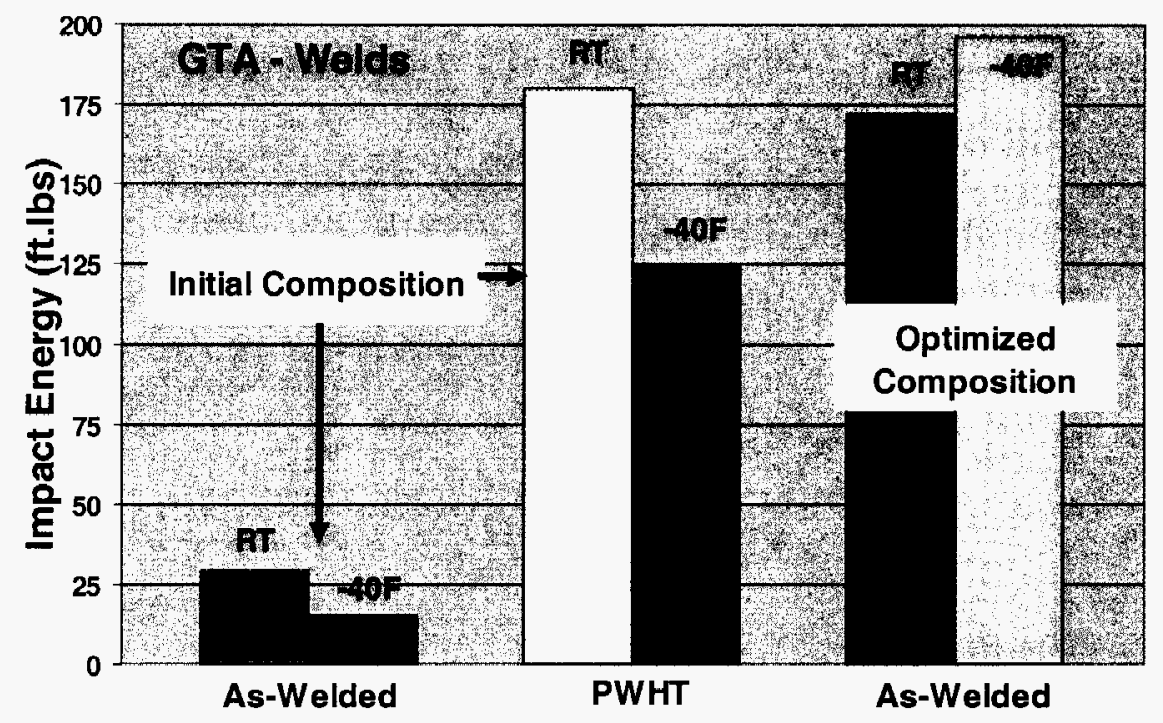

Figure 48. Charpy-impact properties of gas-tungsten-arc welds made with filler wire that requires no postweld heat treatment

In the first case, one can use a PWHT of $700^{\circ} \mathrm{C}\left(1292^{\circ} \mathrm{F}\right)$ and result in significant improvement in impact values at room temperature and $-40 \mathrm{~F}$. In the second case, the filler wire composition can be modified. This was done by using a solid filler wire of heat 18687 , which resulted in Charpyimpact properties similar to those obtained in welds that were given a PWHT. The chemical analysis of the base and filler wires used for GTA welding is presented in Table 10. 
Table 10. Chemical analysis of base metal and filler wire compositions used for gas-tungsten-arc welding

\begin{tabular}{|l|c|c|c|c|c|c|c|c|c|}
\hline \multirow{2}{*}{ Element } & \multicolumn{9}{|c|}{ Weight percent } \\
\cline { 2 - 10 } & $\mathbf{1 8 6 8 7}$ & $\mathbf{1 8 6 9 2}$ & $\mathbf{1 8 6 5 9 5}$ & $\mathbf{1 0 2 9 3}$ & $\begin{array}{c}\text { GTA } \\
\text { Weld } \\
\mathbf{1 8 6 8 7}\end{array}$ & $\begin{array}{c}\text { Weld } \\
\text { Wire } \\
\mathbf{1 8 7 0 7 - R 2}\end{array}$ & $\begin{array}{c}\text { GTA } \\
\text { Weld } \\
\mathbf{1 8 6 9 2}\end{array}$ & $\begin{array}{c}\text { GTA } \\
\text { Weld } \\
\mathbf{1 8 6 9 5}\end{array}$ & $\begin{array}{c}\text { GTA } \\
\text { Deposit } \\
10293\end{array}$ \\
\hline $\mathrm{C}$ & 0.07 & 0.11 & 0.095 & 0.1 & 0.052 & 0.1 & 0.082 & 0.081 & 0.058 \\
\hline $\mathrm{Mn}$ & 0.2 & 0.29 & 0.33 & $\mathbf{0 . 3 9}$ & 0.2 & 0.47 & 0.28 & 0.34 & 0.37 \\
\hline $\mathrm{P}$ & 0.008 & 0.006 & 0.008 & 0.01 & 0.006 & 0.006 & 0.005 & 0.007 & 0.004 \\
\hline $\mathrm{S}$ & 0.005 & 0.007 & 0.006 & 0.004 & 0.005 & 0.006 & 0.006 & 0.005 & 0.004 \\
\hline $\mathrm{Si}$ & 0.21 & 0.23 & 0.2 & 0.16 & 0.24 & 0.21 & 0.26 & 0.22 & 0.15 \\
\hline $\mathrm{Ni}$ & 1 & 1.13 & 0.5 & 0.01 & 1 & 2.11 & 1.12 & 0.5 & 0.01 \\
\hline $\mathrm{Cr}$ & 3.03 & 3.36 & 3.03 & 3.04 & 3.07 & 3.01 & 3.33 & 3.01 & 2.92 \\
\hline $\mathrm{Mo}$ & 0.78 & 0.84 & 0.74 & 0.01 & 0.77 & 0.74 & 0.84 & 0.75 & 0.08 \\
\hline $\mathrm{V}$ & 0.25 & 0.26 & 0.23 & 0.21 & 0.25 & 0.23 & 0.26 & 0.24 & 0.23 \\
\hline $\mathrm{Cb}$ & 0.002 & 0.005 & 0.002 & 0.003 & 0.003 & 0.002 & 0.006 & 0.003 & $<0.01$ \\
\hline $\mathrm{Ti}$ & 0.003 & 0.003 & 0.003 & 0.001 & 0.003 & 0.003 & 0.003 & 0.003 & 0.003 \\
\hline $\mathrm{Co}$ & 0.008 & 0.008 & 0.006 & 0.005 & 0.007 & 0.009 & 0.008 & 0.006 & 0.008 \\
\hline $\mathrm{Cu}$ & 0.01 & 0.01 & 0.01 & 0.01 & 0.01 & 0.01 & 0.02 & 0.02 & 0.01 \\
\hline $\mathrm{Al}$ & 0.004 & 0.002 & 0.002 & 0.003 & 0.004 & 0.003 & 0.005 & 0.002 & 0.004 \\
\hline $\mathrm{B}$ & 0.001 & $<0.001$ & $<0.001$ & 0.001 & 0.001 & 0.001 & $<0.001$ & $<0.001$ & 0.001 \\
\hline $\mathrm{W}$ & 1.56 & 1.74 & 1.54 & 3.05 & 1.54 & 1.52 & 1.73 & 1.53 & 2.84 \\
\hline $\mathrm{As}$ & 0.001 & 0.001 & 0.002 & 0.001 & 0.002 & 0.002 & 0.003 & 0.001 & $<0.001$ \\
\hline $\mathrm{Sn}$ & 0.002 & 0.003 & 0.002 & 0.003 & 0.002 & 0.002 & 0.003 & 0.003 & 0.003 \\
\hline $\mathrm{Zr}$ & $<0.001$ & $<0.001$ & 0.001 & 0.001 & $<0.001$ & $<0.001$ & 0.001 & 0.001 & $<0.001$ \\
\hline $\mathrm{N}$ & 0.001 & $<0.001$ & $<0.001$ & 0.004 & $<0.001$ & $<0.001$ & 0.001 & $<0.001$ & 0.012 \\
\hline $\mathrm{O}$ & 0.003 & 0.003 & 0.001 & 0.005 & 0.002 & 0.001 & 0.005 & 0.001 & 0.007 \\
\hline
\end{tabular}

\subsubsection{SA Welds}

The optimization of filler wire compositions that would allow acceptable Charpy-impact properties of $15 \mathrm{ft}-\mathrm{lb}$ of energy and 15 mils lateral expansion at room temperature for SA welds without PWHT was challenging because this welding procedure results in high oxygen contents in the weld of nearly ten times than that observed for the base metal or GTA welds. A significant effort was devoted in this area and progress made in improving the Charpy properties of SA welds without requiring PWHT is shown in Figs. 49 and 50. Results in Fig. 49 are for Charpy-impact properties at room temperature. These data show the following: initial filler composition, which is the same as base metal, results in low-impact properties without PWHT, which significantly improve with a PWHT of $700^{\circ} \mathrm{C}$. The initial filler wire composition led to further optimization so that Charpy-impact properties of energy and mils lateral expansions could be met without PWHT.

Data in Fig. 49 show progress made in meeting the Charpy-impact property requirements through three incrementally improving filler wire compositions. It can be noted from Fig. 49 that filler wire composition-III resulted in impact properties that were nearly three times that of the initial composition and met both the energy and mils lateral expansion requirements of SA welds without requiring PWHT. 


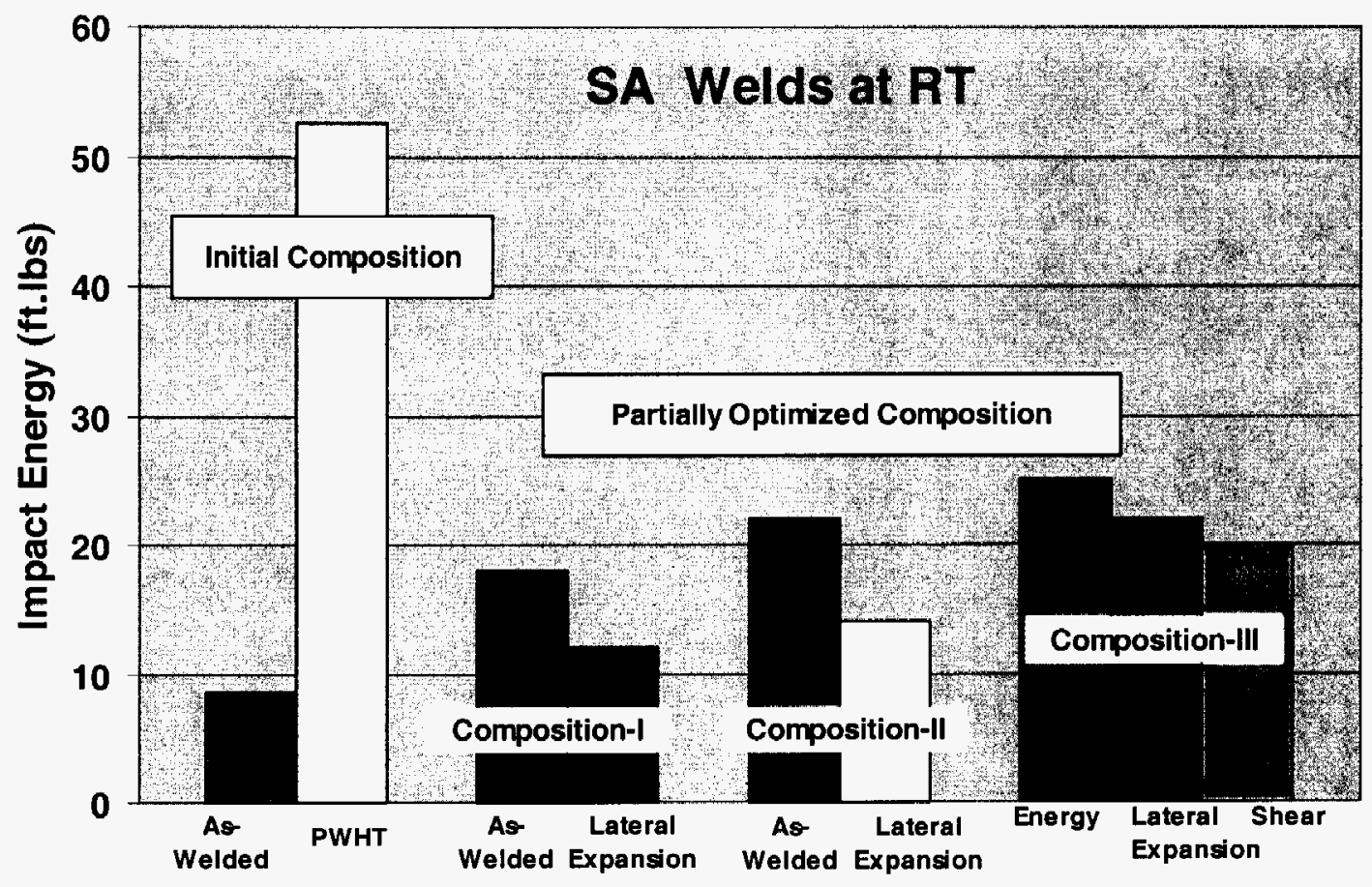

Figure 49. Charpy-impact properties at room temperature for submerged-arc welds made with various filler wires. Filler wires were used to obtain $15 \mathrm{ft}-\mathrm{lb}$ of energy and 15 mil of lateral expansion at room temperature without any postweld heat treatment.

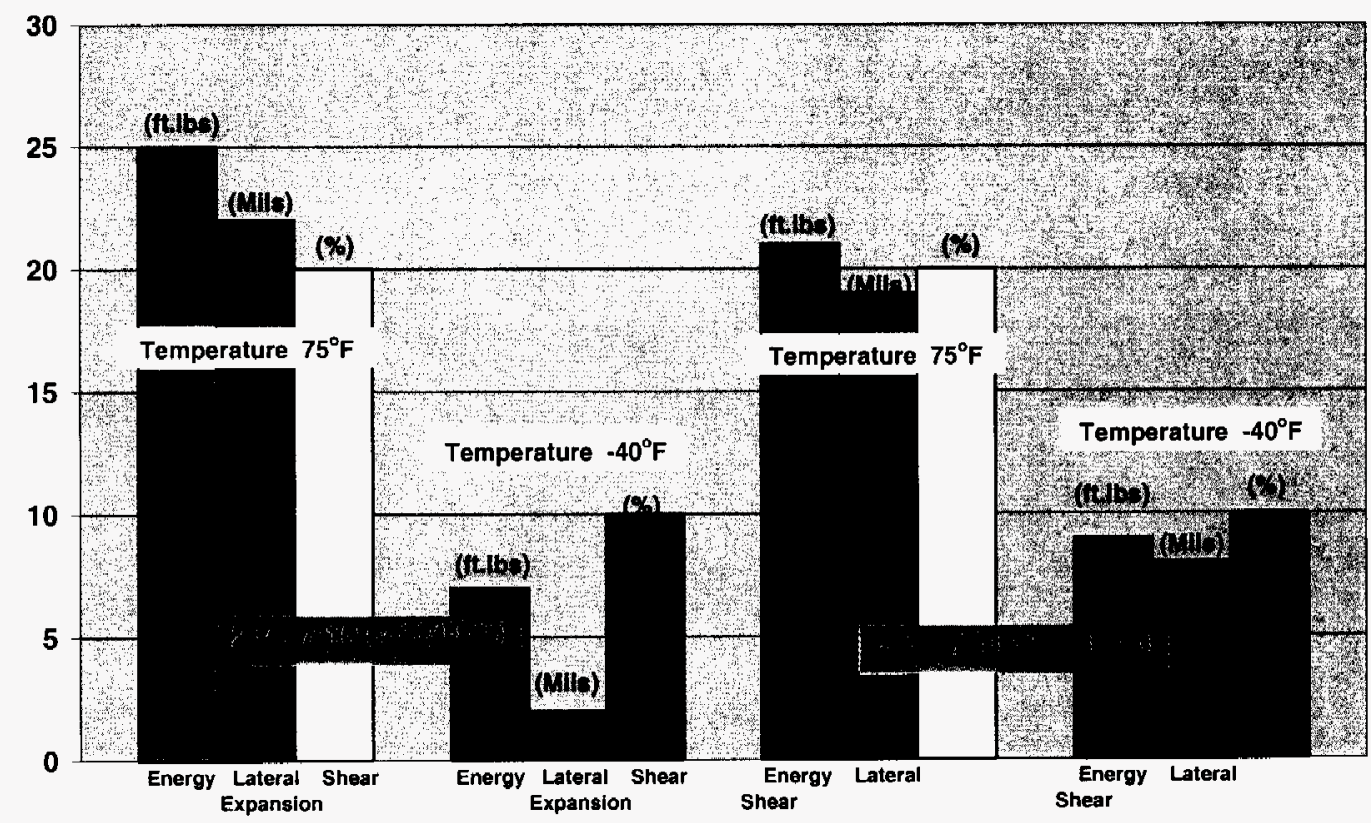

Figure 50. Charpy-impact properties at room temperature and $-40 \mathrm{~F}$ for submerged-arc welds made with two filler wires that exceed the criteria of $15 \mathrm{ft}-\mathrm{lb}$ of energy and 15 mil of lateral expansion without requiring postweld heat treatment. 
Two of the filler wire compositions that met the Charpy-impact property requirements at room temperature were further used to determine the properties at $-40^{\circ} \mathrm{F}$. Data in Fig. 50 at room temperature and $-40^{\circ} \mathrm{F}$ show that while we could obtain good impact values at room temperature, values at $-40^{\circ} \mathrm{F}$ were less than $10 \mathrm{ft}-\mathrm{lb}$. Tensile properties at room temperature for the weldments made with the filler wires used in Fig. 50 are shown in Fig. 51. This figure shows one of the filler wire 25A67-10 resulted in failure in the base metal, indicating that the weld made with this wire is stronger than the base metal in the as-welded condition. However, the filler wire 25A6711 resulted in failure in the weld metal, indicating that it is weaker than the base metal. However, in both cases, the weldment properties are very impressive.

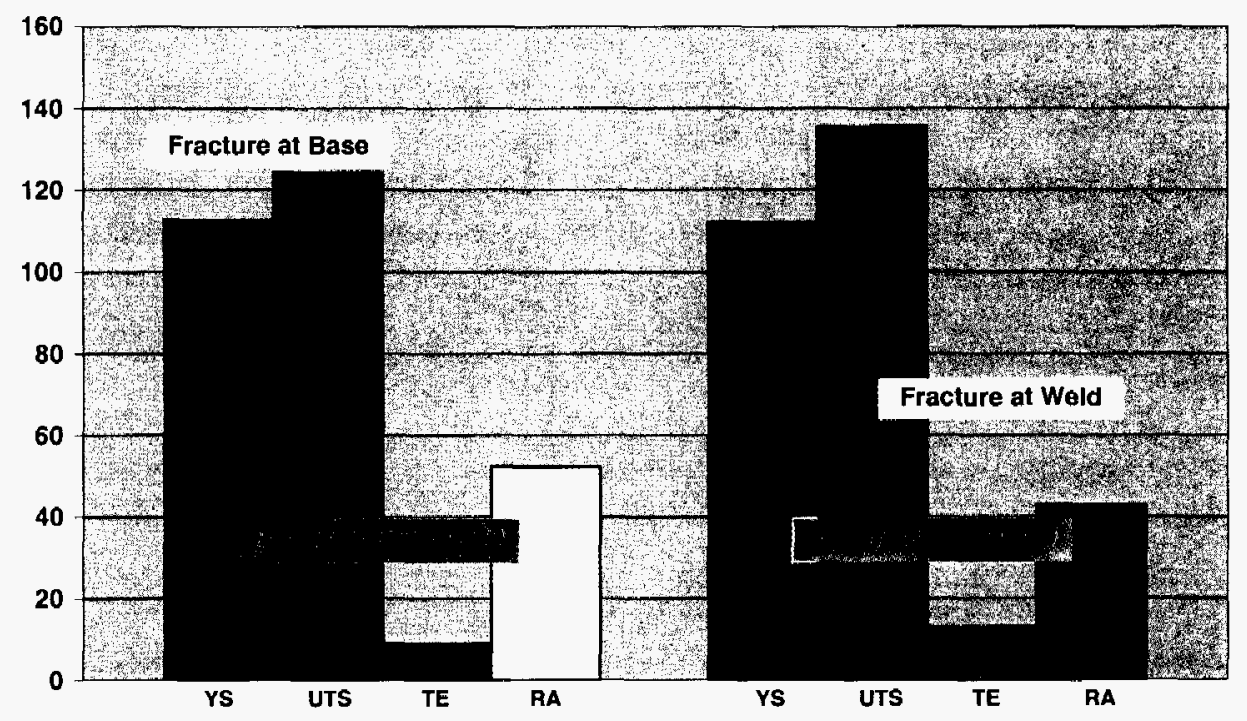

Figure 51. Comparison of tensile properties and fracture locations for the submerged-arc welds that met the Charpy-impact requirements without postweld heat treatment.

Tensile properties at room temperature of selected GTA and SA welds without PWHT are compared in Table 11. Filler wires that resulted in failures in the weld, indicating the weld to be weaker than base metal, generally resulted in acceptable Charpy-impact properties without PWHT. Chemical compositions of filler wires that resulted in acceptable Charpy-impact properties of $15 \mathrm{ft}-1 \mathrm{~b}$ energy and 15 mils of lateral expansion at room temperature are shown in Table 12.

\subsubsection{GTA, SA, and SMA Welds and Properties}

Although it was demonstrated that acceptable Charpy-impact properties could be obtained for SA welds without PWHT, the project team decided that for consistently acceptable properties, SA welds should be given a PWHT. It was recognized that the GTA welds results in exceptional properties without PWHT and, thus, could be used without PWHT. The SMA welds produce weld compositions of high oxygen similar to the SA welds. Although no significant discussion took place, it is expected that the SMA welds should be treated similar to the SA welds and, thus, should be give a PWHT. 
Table 11. Comparison of base metal and weldment tensile properties at room temperature for gas-tungsten-arc and submerged-arc welds without postweld heat treatment

\begin{tabular}{|c|c|c|c|c|c|c|}
\hline \multirow[b]{2}{*}{$\begin{array}{l}\text { Weld } \\
\text { ID }\end{array}$} & \multirow[b]{2}{*}{$\begin{array}{l}\text { Weld } \\
\text { Type }\end{array}$} & \multicolumn{2}{|c|}{ Strength (ksi) } & \multicolumn{2}{|c|}{ Percent } & \multirow[b]{2}{*}{$\begin{array}{c}\text { Failure } \\
\text { Location }\end{array}$} \\
\hline & & Yield & $\begin{array}{c}\text { Ultimate } \\
\text { Tensile }\end{array}$ & Elongation & Reduction & \\
\hline 18718 & Base Metal & 129.9 & 144.6 & 16.7 & 74.4 & $\mathrm{BM}^{\prime \prime}$ \\
\hline $\begin{array}{l}18718 / \\
18707 R 2\end{array}$ & GTA $^{a}$ & 119.8 & 134.1 & 13.3 & 70.8 & $\mathbf{W} \mathbf{M}^{c}$ \\
\hline 10293 & Base Metal & 120.0 & 156.0 & 16.0 & & $\mathbf{B M}^{t^{\prime}}$ \\
\hline $\begin{array}{l}10293 / \\
10293 / \\
\text { 420TTR }\end{array}$ & $\mathbf{S A}^{a}$ & 138.0 & 145.0 & 14.5 & 47.6 & $\mathbf{B M}^{\prime \prime}$ \\
\hline 18718 & Base Metal & 129.9 & 144.6 & 16.7 & 74.4 & $\mathrm{BM}^{b}$ \\
\hline $\begin{array}{l}18687 / \\
18660 / 880\end{array}$ & $\mathbf{S} \boldsymbol{A}^{a}$ & 120.3 & 132.6 & 12.9 & 16.0 & $\mathbf{W M}^{c}$ \\
\hline
\end{tabular}

${ }^{a}$ As-welded condition.

${ }^{b} \mathrm{BM}=$ base metal.

${ }^{c} \mathrm{WM}=$ weld metal.

Table 12. Chemical analysis of two base metal plates and the submerged-arc weld deposits made with matching fill 10293 and filler wires $25 \mathrm{~A} 67-10$ and 25A67-11

\begin{tabular}{|c|c|c|c|c|c|}
\hline \multirow[b]{2}{*}{ Element } & \multicolumn{2}{|c|}{ Base Metal } & \multicolumn{3}{|c|}{ SAW Deposit } \\
\hline & 54624 & 10293 & $\begin{array}{c}54624 / \\
25 A 67-10 / \\
880\end{array}$ & $\begin{array}{c}54624 / \\
25 A 67-11 / \\
880 \\
\end{array}$ & $\begin{array}{c}10293 / \\
\text { 10293/ } \\
\text { 420TTR }\end{array}$ \\
\hline $\mathrm{C}$ & 0.093 & 0.1 & 0.025 & 0.027 & 0.091 \\
\hline $\mathrm{Mn}$ & 0.24 & 0.39 & 0.63 & 0.62 & 0.57 \\
\hline$P$ & 0.012 & 0.01 & 0.009 & 0.008 & 0.004 \\
\hline $\mathrm{S}$ & 0.01 & 0.004 & 0.009 & 0.009 & 0.003 \\
\hline $\mathrm{Si}$ & 0.21 & 0.16 & 0.33 & 0.33 & 0.2 \\
\hline $\mathrm{Ni}$ & 1.02 & 0.01 & 0.99 & 0.99 & 0.01 \\
\hline $\mathrm{Cr}$ & 3.33 & 3.04 & 2.63 & 2.56 & 2.85 \\
\hline Mo & 0.75 & 0.01 & 0.69 & 0.46 & 0.01 \\
\hline $\mathrm{V}$ & 0.24 & 0.21 & 0.027 & 0.029 & 0.22 \\
\hline $\mathrm{Cb}$ & 0.007 & 0.003 & $\cdots$ & $\cdots$ & $<0.01$ \\
\hline $\mathrm{Ti}$ & 0.027 & 0.001 & - & $--\cdot$ & 0.005 \\
\hline Co & 0.009 & 0.005 & --- & $-\cdots$ & 0.008 \\
\hline $\mathrm{Cu}$ & 0.020 & 0.01 & $-\cdots$ & -- & 0.01 \\
\hline $\mathrm{Al}$ & 0.001 & 0.003 & --- & $\cdots$ & 0.016 \\
\hline B & $<0.001$ & 0.001 & -- & $\overline{-\cdots}$ & 0.001 \\
\hline W & 1.61 & 3.05 & 1.32 & 1.37 & 2.98 \\
\hline As & 0.001 & 0.001 & $\cdots$ & $\cdots$ & $<0.001$ \\
\hline $\mathrm{Sn}$ & 0.002 & 0.003 & --- & $-\cdots$ & 0.003 \\
\hline $\mathrm{Zr}$ & $<0.001$ & 0.001 & $\cdots$ & --- & $<0.001$ \\
\hline $\mathrm{N}$ & 0.002 & 0.004 & 0.009 & 0.1 & 0.002 \\
\hline 0 & 0.003 & 0.005 & 0.08 & 0.08 & 0.029 \\
\hline $\mathrm{Ta}$ & $<0.01$ & $=-$ & $\cdots$ & $--\cdot$ & $<0.01$ \\
\hline
\end{tabular}


During this project, we also used a neural network-based model for identifying effects of composition and PWHT on properties of welds. This is an extremely useful tool.

A detailed report on welding and property status of GTA, SA, and SMA welds was recently prepared and is included as Appendix $E$ in this report. This report also makes recommendations for the final filler wire composition that can result in optimum combination of impact, tensile, and creep properties. The optimum filler compositions have been prepared by Stoody Company and are currently being tested.

\subsection{Accomplishments}

This project has met the technical, technology transfer, and commercialization goals. Each of the accomplishments is described below.

\subsubsection{Technical Goals}

A new class of Fe-3Cr-W(V) steels (designated as Grades A and B) were developed during this project. Grade A, which was studied in greater detail, exceeded the goals of the project for its strength, toughness, and PWHT requirements during welding. Both Grades A and B were scaled up to commercial size heats of 50 ton each and processed commercially into forgings, plate, and tubing. Both alloys were characterized for their mechanical properties including tensile, Charpyimpact, and creep. However, between the two grades, A has more creep data that B.

Both grades were tested for their response to common welding methods (GTA, SA, and SMA). However, Grade A was investigated in great detail for properties of welds and weldments.

All of the technical goals were met through team effort that consisted of ExxonMobil Chemical Co., BP Amoco, DuPont, ISG Plate, Ellwood Materials Technologies, Ellwood National Forge, Plymouth Tube Company, Stoody Company, and Nooter Eriksen.

\subsubsection{Technology Transfer}

The technology of new Fe-3Cr-W(V) steels developed in this project was transferred to industry. Two mechanisms were used:

1. The project team consisted of steel producers, producer of products such as forgings, plate, and tubing, welding wire producer, component and pressure vessel fabricators, and users. The team partners actively participated in all aspects of this project and, thus, acquired significant knowledge of the newly developed steels in this project.

2. The technology transfer beyond the team partners was accomplished through:

(a) presentations at annual project review meetings, (b) three presentations at national and international technical review meetings, and (c) publication of two technical papers in conference proceeding. Further technology transfer was also accomplished through presentations by industrial partners at certain committee meetings such as ASTM and presentations of data on the new steels to their customers. 


\subsubsection{Publications and Patents}

Publications from this project are listed below and their full version is included in Appendix B of this report. Key presentations from this project are included in Appendix $\mathrm{C}$ of this report.

1. V. K. Sikka, R. L. Klueh, P. J. Maziasz, S. Babu, M. L. Santella, M. H. Jawad, J. R. Paules, and K. E. Orie, "Mechanical Properties of New Grades of Fe-3Cr-W Alloys," pp. 97-106 in Experience with Creep-Strength Enhanced Ferritic Steels and New and Emerging Computational Methods, PVP-Vol. 476, ASME, New York, 2004.

2. V. K. Sikka, "High-strength Fe-3Cr-W(Mo) Steel for Petrochemical Applications," Proceedings of 2004 NPRA Maintenance Conference, (Published as conference proceedings CD) May 25-28, 2004, San Antonio, TX.

3. Kenneth Orie, "Mechanical Property Evaluation of New Fe-3Cr-Mo-W(Ta) Steel," ISG Plate, Coatesville, PA, March 26, 2004.

4. Standard Specification for Pressure Vessel Plates, Alloy Steel, Chromium-TungstenMolybdenum-Vanadium and Chromium-Tungsten-Molybdenum-Vanadium-Tantalum, submitted by Ken Orie at ISG Plate to ASTM for approval, May 2004.

In addition to publications and presentations, two patent disclosures were made from this project. These patent disclosures are listed below.

1. A new invention disclosure (ID 1156, S-99,347) entitled "Improved Cr-W-V Bainitic/Ferritic Steel Composition" was filed on September 19, 2002.

2. The invention (ID1156C), retitled "CR-W-V Bainitic/Ferritic Steel Compositions," has been filed in the U.S. Patent Office and foreign (PCT), December 16, 2003.

\subsubsection{Commercialization}

Significant progress towards commercialization of the new steels developed in this project was made through the following steps:

1. Approval of specifications in ASTM was obtained for both Grades A and B.

2. Got closer to obtaining ASME Pressure Vessel and Boiler Code approved design allowable stresses for Grade A by submitting its comprehensive mechanical properties data package to the code committees.

3. Retaining Dr. Maan Jawad as a consultant to the project for participating at the ASME Code Committee Review meetings to answer any questions that might arise during deliberations.

Further commercialization will occur through visits by Dr. Maan Jawad to various companies and making their system design engineers familiar with the advantages of using the new steels 


\subsection{Summary and Conclusions}

\subsubsection{Summary}

This project developed a new class of $\mathrm{Fe}-3 \mathrm{Cr}-\mathrm{W}(\mathrm{V})$ ferritic steels for chemical processing equipment such as hydrocrackers, hydrotreaters, and heat recovery systems. The key property targets for the new steels were: (1) $50 \%$ higher tensile strength properties up to 500 to $600^{\circ} \mathrm{C}$ as opposed to the currently available materials in its class, (2) potential for not requiring PWHT for certain welding processes, (3) reducing the equipment weight by $25 \%$, and (4) result impact properties of approximately $100 \mathrm{ft}-\mathrm{lb}$ of upper shelf energy and a DBTT of $-10^{\circ} \mathrm{F}$. The commercially available competing alloys in this class included widely used $2.25 \mathrm{Cr}-1 \mathrm{Mo}$ steel (also known as Grade 22) and recently available Grades T23 and T24.

The proposed research and development was conducted by a team consisting of chemical and petrochemical industries (ExxonMobil Chemical Company, BP Amoco, and DuPont), materials producers (ISG Plate, Ellwood Materials Technologies Company, Plymouth Tube Company, and Ellwood National Forge), component fabricator and welding process developer (Nooter Fabrication Services Inc.), weld wire producer and process developer (Stoody Company), heat recovery unit construction company (Nooter-Eriksen), and a national laboratory, ORNL]. Industry participated by: (1) identifying reactor vessels and other components that can take advantage of the new steel,

(2) component testing, (3) assisting in producing production-size heats of the new steel, (4) assisting in component fabrication and process development, and (5) welding process development. Welding wire suppliers produced small batches for trials by Nooter Fabrication Services Inc. and ORNL. Industry representatives also provided guidance and direction to the project through active participation in identifying and monitoring project deliverables and technical progress reports.

The project identified two compositions with $\mathrm{Fe}-3 \mathrm{Cr}-\mathrm{W}(\mathrm{V})$ as the base. These compositions were designated as Grades A and B or sometimes referred to as Grades 315 and 315T. Grades A and $B$ are only different in that the latter contains $0.10 \mathrm{wt} \% \mathrm{Ta}$. Both grades were scaled up to commercial heats of 50 tons each. Ingots from both heats were processed (using commercial practice) into forgings, plate, and tubing.

Detailed mechanical property characterization was carried out on both Grades A and B. The most expensive of the mechanical tests was creep. Because of the budget constraints, only the long-term creep tests are continuing on Grade A and have been discontinued on Grade B.

A significant effort was devoted to the development of the welding process and weldment properties for the new steel.

Steel compositions and mechanical properties data base were used to prepare data packages for obtaining ASTM Specifications and ASME Code approvals for the new steels. 


\subsubsection{Commercialization Aspects (Plans, Status, Barriers)}

A plan that identified steps needed for commercialization of the new steels was developed. Identified steps included: (1) getting specifications of the new steels approved in ASTM, (2) getting ASME Pressure Vessel and Boiler Code approved allowable design stresses for the new steels, (3) getting designer of systems to become familiar with the properties of the new steels so that they can be specified as material of choice, and (4) providing test material and welding filler for fabricators to become familiar in the use of new steels.

The progress made towards the commercialization included:

1. Both Grades A and B were approved for inclusion in American Standards for Testing Materials (ASTM) specifications: This has already been accomplished. The new alloys are listed in Specification A1041-04.

2. Design allowable stresses for the alloy have to be set by American Society of Mechanical Engineers (ASME) Boiler and Pressure Vessel Code committees. Setting of the design allowables by ASME requires the submission of detailed mechanical property data package for review and analysis by the Code committees. The data package for the advanced alloy developed in this study was submitted in August 2004 (see Appendix A). It typically takes 12 to 24 months for Code bodies to review all of the information and perform analysis to set the design allowable stresses. In order to expedite the ASME Code approval process, we have subcontracted Dr. Maan Jawad of Global Engineering (previously with Nooter Corporation) to actively pursue the process by participating in ASME Code Committee meetings on a regular basis and respond to any questions that may be asked.

3. New alloys need to be specified by equipment designers. In addition to approvals by ASTM and ASME Code, a parallel activity is needed to educate the equipment designers about the benefits of the new alloy. This activity was partially accomplished by: (a) presenting papers at technical conferences, and (b) sharing information on this alloy by the industrial partners of this project within their companies (for the users) and with their customer (for the alloy producers). Although both of these activities are making the users aware of the new alloy, we are relying on our consultant, Dr. Maan Jawad, to further this cause by making visits to individual companies and making presentations about this alloy. Because of his design background gained at Nooter Corporation and familiarity with both chemical and heat recovery systems, it is anticipated that his involvement will further reduce the time for commercial use of the new alloy.

4. Commercial Suppliers of alloy, welding consumables, and component fabrication experience. In addition to approvals by ASTM and ASME and designer specifying the new alloy as material of choice, it has to be commercially available at a competitive price in various product forms (forgings, plate, tubing, and piping). Furthermore, the welding consumables such as filler wire, flux, and electrodes need to be available commercially. The team members of this project are capable of meeting both of these requirements as they arise. The component fabricators have been contacting ORNL to receive the plate samples from the newly developed alloy so that they can develop their own procedures for bending, forming, and welding. The plate samples are currently being offered at no cost to U.S.-based companies for their use. Based on these trials, these companies will be ready to build equipment when the need arises. 
In summary, all elements essential for commercialization of the new alloy are in place and further technology transfer is necessary.

\subsection{Recommendations}

This project has accomplished nearly all proposed aspects. However, the following is the list of recommendations that can further take advantage of this project:

1. Provide support to continue long-term creep testing of Grade A: these data are essential for obtaining ASME Code approval and gaining confidence from users for long-term stability of the new steels.

2. Provide support to initiate the creep tests on Grade B.

3. Support for installing components from the new steel in commercial production conditions: Successful installation and operation under production conditions develops user confidence in trying new steels. One example of this installation could include tubing in heat recovery boilers.

4. Although progress on welding process and filler wire development was made during this project, there is a need to develop a significant amount of mechanical property data of weldment. This effort is needed initially for welds in 2- to 4-in.-thick plates of Grade A and subsequently for welds in Grade B.

5. The welding process also needs to be demonstrated for actual components such as tube-totube or tube-to-tube sheet. Again, this is required initially for Grade A followed by Grade B.

6. In order to be competitive in the global market, the U.S. needs to stay active in further development of high-strength steels. The new tools of thermodynamic and kinetic modeling and the experience in developing steels in this project will make future developments somewhat easier.

\section{Subject Inventions}

A new invention disclosure (ID1156, S-99,347) entitled "Improved Cr-W-V Bainitic/Ferritic Steel Composition" was filed on September 19, 2002.

The invention (ID1156C), retitled "CR-W-V Bainitic/Ferritic Steel Compositions," was filed in the U.S. Patent Office and foreign (PCT) on December 16, 2003.

\section{Commercialization Possibilities}

This CRADA resulted in two new Fe-3Cr-W(Mo) steel compositions (Grades A and B). Grade $A$ is a lower strength lower cost version of the steel. Grade B is a higher strength high cost versionof steel because it contains $0.1 \mathrm{wt} \% \mathrm{Ta}$. Even such small amount of Ta in the steel can add significant cost to the steel because Ta cost can vary from $\$ 100$ to $\$ 300$ per pound.

Both Grades A and B are the highest strength versions of steels in this class [Fe-2.25-3Cr$\mathrm{W}(\mathrm{Mo})$ ] developed in the United States. These steels compete with the commonly used commercial alloy Fe-2.25Cr-1Mo. In principal, the steels developed during this CRADA would 
replace the currently used $\mathrm{Fe}-2.25 \mathrm{Cr}-1 \mathrm{Mo}$ steel and would have a significant commercial potential. However, prior to commercial applications, the following items need to be addressed:

- New alloys need ASTM specifications

The ASTM specifications for the new alloys have been accepted and published for the plate product. Similar specifications are still needed for the forgings, tubing, and piping products.

- Design allowable stresses need to be established for the new alloys by ASME Boiler and Pressure Vessel Code bodies

Extensive data packages of tensile and creep properties are needed for the ASME Code committees to carry out the analysis and set the design allowable stresses.

Because of the extensive cost of creep testing, the current project budget could not permit generating the creep data for both Grades A and B. Thus, testing of Grade B was discontinued and all effort was focused on completing the data base for Grade A. Several long-term creep tests on Grade A are still continuing in order to obtain the required creep test times of $10,600 \mathrm{~h}$.

All of the tensile and creep data on Grade A was assembled and submitted as a package for analysis by ASME Code committees. The approval process is still in progress and could take another 9 to 12 months for full acceptance. Thus, commercialization process is somewhat limited until ASME Code sets the design allowable stresses.

\section{Plan for Future Collaboration}

There are no plans for additional work.

\section{Conclusions}

The following are the important conclusions from this project:

1. Through this project, industry-ORNL team has developed two U.S. versions of high-strength steels based on Fe-3Cr-W(V) composition (Grades A and B). Grade B has higher creep strength than Grade $\mathrm{A}$, but it comes through the addition of $0.1 \mathrm{wt} \% \mathrm{Ta}$ which adds to the cost of the alloy.

2. The Grade A of newly developed steel, which was invested in more detail than Grade B, showed the following attributes as compared to the commonly used $2.25 \mathrm{Cr}-1 \mathrm{Mo}$ steel and a recent high-strength version known as T23:

a. 60 and $25 \%$, respectively, higher yield at room temperature as compared to well established alloy $2.25 \mathrm{Cr}-1 \mathrm{Mo}$ (Grade 22) and a recent high-strength version known as T23 from Japan.

b. $110 \%$ higher yield strength at $482^{\circ} \mathrm{C}\left(900^{\circ} \mathrm{F}\right)$ as compared to $2.25 \mathrm{Cr}-1 \mathrm{Mo}$ and $45 \%$ higher at $600^{\circ} \mathrm{C}\left(1110^{\circ} \mathrm{F}\right)$ as compared to $\mathrm{T} 23$.

c. 50 and $33 \%$, respectively, higher ultimate tensile strength at room temperature as compared to $2.25 \mathrm{Cr}-1 \mathrm{Mo}$ and $\mathrm{T} 23$.

d. $50 \%$ higher ultimate tensile strength at $482^{\circ} \mathrm{C}\left(900^{\circ} \mathrm{F}\right)$ as compared to $2.25 \mathrm{Cr}-1 \mathrm{Mo}$ and $33 \%$ higher at $600^{\circ} \mathrm{C}\left(1110^{\circ} \mathrm{F}\right)$ as compared to $\mathrm{T} 23$. 
e. Charpy-impact upper shelf energy of approximately $100 \mathrm{f}$-lb and $50 \mathrm{ft}$-lb ductile-to-brittle transition temperature of -20 to $-40^{\circ} \mathrm{F}$.

f. Creep-rupture strength values higher than the high-strength T23 grade temperatures of $\leq$ $593^{\circ} \mathrm{C}\left(1100^{\circ} \mathrm{F}\right)$. For $10^{5} \mathrm{~h}$ rupture time at $593^{\circ} \mathrm{C}\left(1100^{\circ} \mathrm{F}\right)$ and above, rupture strength of the new alloy matches $\mathrm{T} 23$.

g. New steels can be welded by all common welding processes [gas tungsten arc (GTA), submerged arc (SA), and shielded-metal arc (SMA)]. For the GTA process, welds can be used in the as-welded condition. For SA and SMA, a postweld heat treatment of $700^{\circ} \mathrm{C}$ $\left(1295^{\circ} \mathrm{F}\right)$ is recommended.

3. Grades A and B have been shown to be scaleable to 50-ton heats by standard electric furnace melting techniques. Furthermore, both grades were processable by commercial methods to forgings, plate, and tubing.

4. The new steels are used in normalized and tempered (N/T) conditions. The N/T treatment consists of austenitizing at $1100^{\circ} \mathrm{C}\left(2012^{\circ} \mathrm{F}\right)$ followed by air cooling to room temperature and tempering at $730^{\circ} \mathrm{C}\left(1345^{\circ} \mathrm{F}\right)$.

5. A significant number of creep tests at temperatures ranging from 482 to $704^{\circ} \mathrm{C}(900$ to $1300^{\circ} \mathrm{F}$ ) were conducted on both grades. Grade A has several creep tests that exceed $5000 \mathrm{~h}$ of test time. Long-term creep testing of Grade B was discontinued because of lack of funds.

6. Alloy composition, heat treatment, and tensile property data on Grades A and B were used to obtain their ASTM Specifications. Both grades are included in ASTM Specification A104104. This is the first step in newly developed steel grades to be recommended by equipment designers for the construction of chemical processing equipment.

7. A detailed mechanical property database on Grade A was compiled and submitted to ASME Pressure Vessel and Piping Code committees. This package will be used to establish the design allowable stresses for the new steel. This is the second step in the newly developed steel to be recommended by the equipment designers for the construction of chemical processing equipment.

8. Commercial use of the new steels requires introducing them to potential users. This was accomplished through presentations about the new steels at national technical meetings sponsored by ASME, ASM International, and others. Part of the commercialization will also occur because steel producers, welding wire producers, component and system fabricators, and steel users were part of this project. 